\title{
Pobreza multidimensional en España. Una aplicación de la metodología de Alkire y Foster. 2008 - 2015
}

\author{
Corbelle Cacabelos, Fernando \\ Universidad de Santiago de Compostela \\ Correo electrónico: nandocorbelle@hotmail.com \\ TROITIÑo COBAS, ÁNGELA \\ Universidad de Santiago de Compostela \\ Correo electrónico: angela.troitino@usc.es
}

\begin{abstract}
RESUMEN
Considerando la pobreza como un fenómeno que limita la capacidad de desarrollo de las personas en todas sus dimensiones, se aborda su estudio multidimensional tomando como referencia la metodología de Alkire y Foster (2011). Su aplicación al ámbito español, usando la Encuesta de Condiciones de Vida (ECV2008ECV2015), genera nueva evidencia sobre la medición de la pobreza multidimensional y su sensibilidad a los criterios de identificación, contribuyendo al debate sobre la pertinencia de esta metodología como referencia.

Los resultados permiten concluir el incremento de la pobreza multidimensional en el período estudiado, tanto en incidencia como en intensidad, con independencia del umbral seleccionado. Se observa la existencia de cambios en los perfiles de pobreza. Disminuye el gap por género, aunque la proporción se mantiene más alta en las mujeres. La población de 50-64 años sufre la mayor incidencia en todo el periodo, si bien el mayor incremento (disminución) se da en los jóvenes (mayores). Los hogares con niños presentan una clara dualidad: dos adultos con uno o dos niños muestran los menores niveles de pobreza, mientras el resto sufren los mayores niveles. Las parejas sin niños son las únicas que muestran mejoría. Por regiones, se observan incrementos generalizados, a excepción de Extremadura y Galicia que reducen sus índices de pobreza. Los mayores incrementos se dan en Cantabria, Murcia y Canarias. Las dimensiones educación, económica y trabajo son las que más contribuyen a la pobreza, presentando la primera una clara mejoría en el período y la última un destacado incremento.

Palabras clave: índice de pobreza multidimensional, análisis empírico, España, regiones españolas, metodología Alkire y Foster.
\end{abstract}

Clasificación JEL: I32.

MSC2010: 91B82; 62H99; 62P2O. 


\title{
Multidimensional poverty in Spain. An application of the Alkire and Foster methodology. 2008 - 2015
}

\begin{abstract}
Considering poverty as a phenomenon that limits the capability of people development in all its dimensions, this work presents a multidimensional study based on the methodology of Alkire and Foster (2011). Its application to Spain, using Living Conditions Survey (ECV2008-ECV2015), generates new evidence on the measurement of multidimensional poverty and its sensitivity to the identification criteria, contributing to the debate on the relevance of this methodology as a reference.

The results conclude the increase in multidimensional poverty in the period studied, both in incidence and in intensity, regardless of the selected threshold. Changes in poverty profiles are also observed. Gender gap decreases, although the proportion remains higher in women. The population of 50-64 years suffers the highest incidence throughout the period, although the largest increase (decrease) occurs in young (old) people. Households with children have a clear duality: two adults with one or two children show the lowest levels of poverty, while the rest suffer the highest levels. Couples without children are the only ones showing improvement. By regions, there are widespread increases, with the exception of Extremadura and Galicia that reduce their poverty rates. Largest increases are in Cantabria, Murcia and the Canary Islands. The dimensions of education, economic and labour are the biggest contributors to poverty, with the former showing a clear improvement in the period and the latter a dramatic increase.
\end{abstract}

Keywords: multidimensional poverty index, empirical analysis, Spain, Spanish regions, Alkire and Foster methodology.

JEL classification: I32.

MSC2010: 91B82; 62H99; 62P2O.

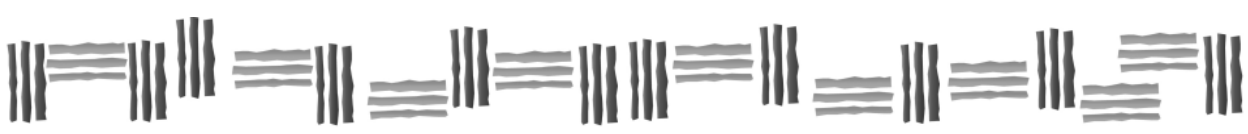




\section{Introducción.}

El debate sobre la medición de la pobreza se retrotrae a hace más de un siglo, con los estudios de Rowntree (1901) sobre la pobreza en York (Inglaterra) y, a pesar de que en estas casi doce décadas se han desarrollado diferentes propuestas de medición (métodos subjetivos vs. objetivos; análisis estático vs. dinámico; umbrales relativos vs. anclados; umbrales estatales vs. regionales; etc.), la discusión todavía sigue vigente (Zugasti \& Laparra, 2017). Aunque han sido muchos los estudios de pobreza que la han considerado como un fenómeno unidimensional cuantificándola en función de los ingresos, en la actualidad su carácter multidimensional ya no está en cuestión; no obstante, cómo elaborar un indicador óptimo de pobreza multidimensional todavía no goza del mismo consenso (Larrú, 2016). Es necesario encontrar el equilibrio entre el atractivo de disponer de un único valor de síntesis y sus limitaciones para representar conceptos complejos, ricos en matices, como el de bienestar o calidad de vida (López-Menéndez, 2015) o, como el que aquí nos ocupa, la pobreza.

En las últimas décadas se ha dado un fuerte incremento de la literatura que estudia este fenómeno. Se han aportado nuevos marcos teóricos, conceptualizaciones y metodologías de análisis y cuantificación. La mayoría de ellos utilizan como base el enfoque de las capacidades de Amartya Sen $(1983,1985)$ y aplican metodologías que permiten abordar simultáneamente varias dimensiones. En este marco multidimensional en el que la pobreza se entiende como privación de capacidades, la familia de índices de Alkire y Foster (2011) constituye una de las más interesantes propuestas por las propiedades que cumple. Muestra de ello es su creciente implementación empírica a la que este trabajo pretende contribuir elaborando un índice de pobreza multidimensional para España y sus regiones durante el periodo 2008-2015. Con esta aportación se pretende contribuir al debate sobre la pertinencia de esta metodología como referente para el análisis de la pobreza, especialmente por su capacidad para desagregar la pobreza por dimensiones, por características personales, del hogar o geográficas. Conocer el problema es necesario para poder proponer soluciones. Identificar qué población sufre qué privaciones, así como qué dimensiones son las principales responsables, son requisitos imprescindibles para poder diseñar propuestas adecuadamente enfocadas a revertir o paliar la situación de los colectivos más vulnerables.

El trabajo se estructura como sigue. Después de esta breve introducción, en el segundo punto se realiza una revisión de las propuestas recientes para abordar la medición multidimensional de la pobreza, enfocando más en detalle las aplicaciones de la metodología propuesta por Alkire y Foster $(2007 ; 2009 ; 2011)$ (metodología AF en adelante). En el tercero se presenta la metodología $\mathrm{AF}$, la base de datos y las decisiones normativas que intervienen en las distintas fases del proceso de construcción del índice. En el cuarto punto se lleva a cabo el análisis empírico de la pobreza en España en el periodo 2008-2015. Se obtiene el índice de pobreza multidimensional $\mathrm{M}_{0}(\mathrm{k})$ para diferentes valores de $k$, sus componentes $\mathrm{H}(\mathrm{k})$ y $\mathrm{A}(\mathrm{k})$, la descomposición por subgrupos (sexo, edad, tipología del hogar, regiones, etc.) y la desagregación por dimensiones. Finalmente, se presentan las principales conclusiones.

\section{La medición multidimensional de la pobreza.}

Diversos organismos han adoptado diferentes metodologías para evaluar la situación de la población en cuanto a bienestar social y pobreza. La Unión Europea (UE) ha desarrollado una metodología para monitorizar el objetivo pobreza o exclusión social de la Estrategia Europa 2020 desde una óptica multidimensional, la tasa AROPE (At Risk Of Poverty or Social Exclusion), que incluye tres dimensiones: la pobreza monetaria relativa, la privación material y la baja intensidad de empleo, construyéndose a partir de la unión de los individuos clasificados como pobres en al menos una de las dimensiones citadas. La Organización de las Naciones Unidas (ONU), en sus Informes de Desarrollo Humano (IDH), adoptó el Índice de Pobreza Multidimensional (IPM) 
desarrollado por Alkire y Santos (2010), con la metodología de Alkire y Foster (2007; 2009), y publicado por primera vez en el IDH de 2010 (PNUD, 2010). La Organización para la Cooperación y Desarrollo Económico (OCDE) emprendió la denominada Better life initiative que comprende la elaboración y análisis de un conjunto de indicadores de bienestar con nivel de desagregación regional (Para mayor información sobre esta iniciativa ver OECD (s.f) y Boarini \& d'Ercole (2013)). Un trabajo similar lo viene realizando también la oficina estadística de la Unión Europea (Eurostat) desde el 2011; a raíz de la conferencia Beyond GDP organizada por la Comisión Europea (EC, s.f.) en 2007 y en 2008, el Comité del Sistema Estadístico Europeo ha decidido trabajar en un conjunto de indicadores de calidad de vida (Eurostat, s.f.a.)).

Con el objetivo de implementar mediciones de pobreza multidimensional y compartir experiencias para poder optimizar y/o adaptar estas mediciones al contexto en el que se van a aplicar, en junio de 2013, se lanzó la Red Global para la Pobreza Multidimensional (Multidimensional Poverty Peer Network) (MPPN, s.f.) de la que participaron inicialmente 20 países y 5 organizaciones. El objetivo último es crear un IPM global (MPI 2015+) que se convierta en medida nacional u oficial de pobreza y pueda ser utilizado en el monitoreo de los Objetivos de Desarrollo Sostenible (ODS) contenidos en la Agenda 2030 de Desarrollo Sostenible aprobada por la ONU (2015). Para saber más sobre la medida propuesta, se puede ver en Alkire y Summer (2013). Los autores sugieren complementar el enfoque de la pobreza basado en el ingreso con un 'MPI 2.0' que podría ser creado con dimensiones, indicadores y puntos de corte que reflejen el consenso alcanzado para la nueva agenda. La OECD también viene trabajando desde el año 2016 en una nueva metodología para medir la distancia del punto de partida a los ODS, que ya se encuentra refinada y su cobertura ampliada en el tercer informe (OECD, 2019).

En España, Argüeso et al. (2014) han realizado varias propuestas para abordar la pobreza desde los organismos oficiales. Proponen dos alternativas en las que realizan índices compuestos de calidad de vida sintetizando, en la primera, información de diferentes fuentes de datos y, en la segunda, utilizando una única fuente. Al respecto mencionan que el primero tiene la ventaja de utilizar la mejor información disponible para cada dimensión, mientras que el segundo permite analizar las privaciones conjuntas, es decir, la acumulación o compensación de privaciones. Partiendo también de una única base de datos, pero aplicando otras metodologías de análisis multidimensional (en concreto, un análisis factorial de segundo orden) sobre variables tanto objetivas como subjetivas y tanto monetarias como de calidad de vida, Poza y Fernández (2010) construyen un indicador de pobreza multidimensional que les permite identificar los principales focos de riesgo de pobreza en España entre los años 1994 y 2001.

Parte de las propuestas ya citadas (OECD, Eurostat, etc.) no sintetizan la pobreza/bienestar en un único indicador y/o utilizan diferentes fuentes de información, no considerando algunas de las propiedades que un índice de pobreza multidimensional es deseable que cumpla, como la ordenación completa o el análisis de la distribución conjunta de las privaciones. Es por ello que la metodología propuesta por Alkire y Foster $(2007 ; 2009,2011)$, desde la Oxford Poverty \& Human Development Initiative (OPHI), ha tenido gran acogida. Entre sus numerosas aplicaciones, cabe destacar la del PNUD (2010) a nivel mundial y otras realizadas a nivel de países (Busch \& Peichl, 2010; Angulo et al., 2011; Mohanty, 2011; Suppa, 2015; Suppa, 2016; Castillo \& Jácome, 2015; Artavia, 2016; Rogan, 2016).

En el ámbito europeo, Whelan et al. (2012) aplicaron la metodología AF a los datos de la EU-SILC (European Union Statistics on Income and Living Conditions) de 2009 para 28 países (en esta edición se ha realizado un módulo especial sobre privación que contiene un mayor número de variables que el módulo básico anual por lo que incrementa las posibilidades del análisis). Los autores ponen el foco sobre cuatro dimensiones de privación (básica, de consumo, de salud y de entorno) y utilizan ponderaciones inversas a la tasa de privación de los indicadores porque consideran que estar privado de algo de lo que disfruta la mayoría de la población es más grave. En su estudio también consideran la tasa de riesgo de pobreza, pero sin incluirla en el índice multidimensional, sino analizando su correlación con la privación en las dimensiones de la 
medida multidimensional, así como realizando una comparación de los resultados de pobreza por países. Alkire et al. (2014) y Alkire y Apablaza (2016) ampliaron el estudio para el periodo 20062012 utilizando un menor número de indicadores y ponderaciones iguales por dimensión, ajustando los pesos relativos de los indicadores incluidos en cada una (nested weights). Uno de los objetivos que tenían las autoras es construir un índice que sirviese para monitorizar el objetivo de la Estrategia 2020 de reducción de la pobreza o exclusión social, por lo que incluyeron los indicadores de la tasa AROPE. El indicador de Baja Intensidad de Trabajo es ligeramente diferente al utilizado en la tasa AROPE como indican Alkire et al. (2014).

En el ámbito español, el trabajo realizado por Prieto et al. (2016), junto con las tesis doctorales de Martínez (2017) y de Corbelle (2017), constituyen aplicaciones pioneras sobre pobreza multidimensional aproximada desde el espacio de las capacidades para el Estado español y sus regiones. Prieto et al. (2016) utilizan diez indicadores clasificados en siete dimensiones (empleo, salud, educación, calidad de la vivienda y del entorno, acceso a determinados bienes y servicios y nivel de renta). Las ponderaciones son similares a las aplicadas por Whelan et al. (2012), asignando mayor peso cuando el porcentaje de privación es menor. El criterio de corte de la pobreza multidimensional es establecido de forma relativa, mediante un procedimiento similar al utilizado para elaborar los diagramas de caja. Martínez (2017) realiza dos aplicaciones, una para cinco países de la UE (España incluida) y Canadá y otra para España. En la primera aplica la metodología $\mathrm{AF}$ a los tres indicadores/dimensiones de la tasa AROPE, centrando el análisis en la diferencia entre nativos e inmigrantes para el periodo 2008-2011; en la segunda, utilizando cinco dimensiones, se centra en la evolución de la pobreza multidimensional por grupos de edad para los años 2008-2014. En ambos casos utiliza ponderaciones iguales para las dimensiones.

En este artículo se pretende dar continuidad a este tipo de estudios y elaborar, aplicando la metodología AF, una medida sencilla de interpretar, que permita una ordenación completa y que, además, cumpla con una serie de axiomas o propiedades que son deseables a este tipo de medidas, como ser desagregada tanto espacialmente como por dimensiones del bienestar/pobreza, de lo que se deduce que el enfoque axiomático, combinado con el de conteo (counting) en la fase de identificación, empleado por la metodología AF, puede ser uno de los más convenientes, siempre y cuando la fuente de información/datos sea única. Este enfoque, identificado como counting por Alkire y Foster (2011), implica identificar a las personas pobres a través del recuento de las dimensiones en las que un individuo está privado (se encuentra por debajo de un umbral determinado).

\section{Metodología AF, fuente de datos y decisiones normativas.}

\subsection{Metodología AF.}

Esta metodología se aplica en dos etapas, una de identificación y una de agregación. La primera se basa en la elección de un doble punto de corte para identificar la pobreza multidimensional. Para ello, en primer lugar, se define un criterio de corte por dimensión $z_{j}$ que permite identificar a los privados en dicha dimensión, recogiendo en un vector $z$ los puntos de corte de las distintas dimensiones. En segundo lugar, se determina el criterio de pobreza multidimensional $k$, que identifica el número de dimensiones (o el valor de privación) en las que hay que estar privado para ser considerado multidimensionalmente pobre. Este umbral de pobreza multidimensional $k$ será comparado con el valor suma de privaciones de cada individuo $c_{i}$ para identificar a los pobres multidimensionales, de manera que si $c_{i} \geq k$ el individuo es considerado pobre y si $c_{i}<k$ no lo es. El criterio de corte puede oscilar entre el de unión $(k=1)$ y el de intersección $(k=d$, siendo $d$ el número de dimensiones), permitiendo cualquier criterio intermedio entre ambos.

En la segunda etapa, es imperativa la elección o construcción de una medida de agregación que cuantifique la magnitud del fenómeno. Alkire y Foster $(2007 ; 2009 ; 2011)$ proponen una 
familia de índices $M \alpha(\alpha=0,1,2)$ a la que pertenece el índice utilizado en este trabajo, $M_{0}$, que se puede expresar de la siguiente forma:

$$
M_{0}(k)=\frac{1}{n} \sum_{i=1}^{n} \sum_{j=1}^{d} w_{j} g_{i j}^{0}(k)=\frac{1}{n} \sum_{i=1}^{n} c_{i}(k)=H(k) * A(k)
$$

donde $n$ es la población total; $w_{j}$ es la ponderación asignada a la dimensión $j$; $\mathrm{g}_{\mathrm{ij}}{ }^{0}$ es el elemento genérico de la matriz $\mathrm{g}^{0}$ que toma el valor 1 si el individuo $i$ está privado en la dimensión $j$ y toma el valor 0 si no lo está; $c_{i}$ identifica la suma de privaciones que sufre cada individuo $i, \mathrm{y}$ $k$ constituye el umbral de pobreza multidimensional o criterio de corte seleccionado. En el caso de emplear ponderaciones no normalizadas habría que dividir por $n d$, en lugar de $n$, para obtener $\operatorname{los} M_{0}(k)$.

La medida $M_{0}(k)$ se puede descomponer en el producto de dos nuevos índices. El índice de recuento multidimensional $H(k)=\frac{q(k)}{n}$, también llamado incidencia de la pobreza, siendo $q(k)$ el número de personas identificadas como multidimensionalmente pobres. Y el índice de intensidad de la pobreza $A(k)=\frac{1}{q} \sum_{i=1}^{q} c_{i}(k)$, o promedio de privaciones de los pobres multidimensionales, siendo $q$ el número de pobres multidimensionales y $c_{i}(k)$ la suma de las privaciones de cada individuo $i$. Entre las propiedades que satisface el índice $M_{0}(k)$ destacan, a nivel empírico, la descomposición aditiva por subgrupos poblacionales y la desagregación dimensional. La familia de índices de la metodología $\mathrm{AF}, \mathrm{M} \alpha(\alpha=1,2,3)$, satisface los axiomas (propiedades) de domino o foco (en la pobreza), simetría, invarianza ante réplicas poblacionales, monotonicidad (débil), monotonicidad para $\alpha>0$, transferencias (débil) para $\alpha \geq 1 \mathrm{y}$ descomposición aditiva. Además, como medida multidimensional, también satisface otros como los de dominio de la privación (independencia del índice con respecto a los valores de logro de los no privados), monotonicidad dimensional (si una persona pobre resulta privada en una dimensión adicional, el índice aumenta) y reordenamiento débil (un intercambio de logros en cualquier dimensión entre dos individuos pobres que lleva a una reducción de la desigualdad debe generar un nivel de pobreza igual o inferior al original).

La descomposición aditiva es de gran utilidad para analizar los resultados del índice $M_{0}(k)$ por características demográficas como sexo, edad y tipología del hogar y geográficas como la división regional. Esta propiedad permite demostrar que, clasificando la población en $m$ grupos excluyentes, el índice $M_{0}(k)$ puede ser calculado como un promedio ponderado de los índices de los $m$ grupos $\left(M_{0 m}(k)\right)$, tomando como ponderación la proporción de población en cada grupo $\left(n_{m} / n\right)$ :

$$
M_{0}(k)=\sum_{m=1}^{M} \frac{n_{m}}{n} M_{0 m}(k)=\sum_{m=1}^{M} \frac{n_{m}}{n} H_{m}(k) A_{m}(k)
$$

La desagregación por dimensiones (o por indicadores) del índice $M_{0}(k)$ permite desagregar éste como una suma (ponderada) de las privaciones (censuradas) de las dimensiones/indicadores (Alkire \& Foster, 2011; Alkire et al., 2015a):

$$
M_{0}(k)=\sum_{j=1}^{d} w_{j} H_{j}(k)
$$

Y la contribución de cada dimensión/indicador $j$ al índice $M_{0}(k)$ resulta ser:

$$
\phi_{j}^{0}(k)=w_{j} \frac{H_{j}(k)}{M_{0}(k)}
$$

siendo $H_{j}(k)$ las tasas de privación censuradas en una determinada dimensión/indicador $j$, esto es, la proporción de personas identificadas como multidimensionalmente pobres que están privadas en esa dimensión/indicador $j$. Estas privaciones contribuyen al índice $M_{0}(k)$ en función 
de su valor y de la ponderación asignada a cada una, por lo que $\phi_{j}^{0}(k)$ indica la proporción con la que la dimensión/indicador $j$ contribuye a la pobreza medida a través de $M_{0}(k)$.

A pesar de su gran aceptación, la aplicación de la metodología AF todavía está en fase de desarrollo y no está exenta de limitaciones. En palabras de la propia autora (Alkire, 2018), en la literatura existente todavía permanecen cuestiones fascinantes sobre las que se espera sean posibles avances significativos, en áreas como el diseño de la medición (la selección de dimensiones, indicadores, puntos de corte y ponderaciones), su aplicación a la pobreza infantil y su implementación usando datos de género. Precisamente, el diseño de la medición es el que parece ser objeto de un mayor número de críticas, muy especialmente por la arbitrariedad en algunas decisiones metodológicas que, en muchos casos, se basan en criterios subjetivos (Prieto et al., 2016). Sin embargo, las ventajas de esta metodología también son evidentes en términos de orientación para la política pública de lucha contra la pobreza y la exclusión, ya que permite: el análisis por subgrupos de población (descomposición aditiva); la desagregación por componentes del índice (incidencia e intensidad promedio de privaciones); la desagregación por dimensiones; realizar análisis longitudinales a través de series temporales o datos de panel; focalizar en los grupos más pobres; ser complementada con otras medidas (como la tasa de riesgo de pobreza) que no hayan sido incluidas como una dimensión más en el índice multidimensional.

\subsection{Fuente de datos y decisiones normativas.}

La información utilizada corresponde a los microdatos de la Encuesta de Condiciones de Vida (ECV) en sus olas de 2008 a 2015, cuyos datos sobre ingresos están referidos a los años inmediatamente anteriores (de 2007 a 2014). Se trata de una encuesta armonizada a nivel europeo, con muestras para España de entre 12.000 y 13.000 hogares (31.000 y 37.000 personas) en el periodo observado, que representan a 16-18 millones de hogares y 45-46 millones de personas.

La implementación del método AF requiere de ciertas decisiones (normativas) o juicios (Alkire et al., 2015b) que operan en diferentes niveles y se utilizan para justificar las decisiones que se toman en todo el proceso de implementación del método, desde la decisión misma del lanzamiento (o no) de una nueva medida, hasta la elección de dimensiones, indicadores, umbrales, criterios de corte, ponderaciones, etc. En este trabajo, la selección ha sido realizada en consonancia con la literatura existente y con los datos disponibles en la ECV.

\subsubsection{Unidad de análisis}

Se toma como unidad de análisis o unidad de identificación a los individuos de 16 y más años en el año de recogida de las rentas, ya que son estos los individuos para los que se tiene información acerca de las dimensiones de salud y educación (relevantes en este tipo de estudios). Esta población supone alrededor de 38 millones de personas por año entre los años 2008 y 2015. Las características identificativas del hogar (materiales, vivienda, entorno, etc.) son asignadas a cada individuo de 16 y más años residentes en el mismo, así como el ingreso por adulto equivalente del hogar construido con la escala de equivalencia de la OCDE modificada.

\subsubsection{Dimensiones e indicadores}

La metodología AF se ha desarrollado para analizar la pobreza desde un punto de vista multidimensional, adaptándose al enfoque de las capacidades. La información disponible, a menudo, se refiere a recursos por lo que el análisis en el espacio de los funcionamientos y capacidades es más limitado y, además, un recurso puede estar relacionado con más de una capacidad. Autores como Nussbaum (2000) definieron una lista de capacidades y otros como Suppa $(2015 ; 2016)$ realizaron el ejercicio de identificar capacidades y funcionamientos con variables recurso disponibles para un estudio de este tipo. Tanto en las capacidades identificadas como en las dimensiones seleccionadas se da un alto grado de coincidencia en la bibliografía existente. 
En este trabajo se consideran siete dimensiones constituyentes de la pobreza multidimensional (Tabla 1): económica, material, vivienda, entorno, salud, trabajo y educación. Estas dimensiones están integradas por uno o más indicadores que identifican privaciones en las capacidades de las personas. Es en estos indicadores donde se identificarán las privaciones (a través de umbrales). En su mayoría son indicadores cualitativos, a excepción de la renta.

La dimensión económica está representada en el índice por los ingresos disponibles por adulto equivalente del hogar con alquiler imputado (IDEI). Se le supone al hogar la redistribución interna de las rentas y economías de escala, aplicando la escala de equivalencias de la OCDE modificada. El alquiler imputado es el valor que deberían pagar los hogares por una vivienda de características similares a la suya en los casos en los que el hogar no tiene que hacer ningún desembolso adicional o lo hace por debajo del valor de mercado (viviendas en propiedad, cesión gratuita o renta antigua). La consideración de este alquiler imputado como parte del ingreso disponible, de especial relevancia en España por el alto porcentaje de viviendas en propiedad (Méndez et al., 2008), homogeneiza la capacidad económica de los hogares con independencia del régimen de tenencia de la vivienda al tener en cuenta el beneficio que supone el no tener que hacer desembolsos por alquiler o cuota hipotecaria, es decir, la mayor disponibilidad de renta de estos hogares con respecto de los que sí deben afrontar estos pagos. Como umbral de privación se utiliza el convencional, el $60 \%$ de la mediana de la distribución del IDEI, siendo las personas que se sitúan por debajo del mismo las consideradas privadas en la dimensión económica.

La dimensión material va a ser incluida en el modelo a través del índice de privación material severa $(P M S)$ utilizado por los organismos europeos para monitorizar la exclusión social y que forma parte de la tasa AROPE (la metodología del indicador PMS se puede consultar en Eurostat (s.f.b)).

La dimensión vivienda forma parte del modelo con cinco indicadores. El primero es un índice de hacinamiento o sobreocupación del espacio en la vivienda (la metodología del índice de Hacinamiento se puede consultar en Eurostat (s.f.c)). Además, se incluyen los indicadores dicotómicos de humedades, luz natural, ducha e inodoro como identificativos de privaciones básicas de las viviendas. En el primer caso, la presencia de humedades implica privación y, en los demás, es la escasez o ausencia de luz natural, la ausencia de ducha o bañera y la ausencia de inodoro la que identifica al hogar como privado. Los individuos son clasificados como privados en cada indicador si residen en una vivienda identificada como privada en el mismo.

La dimensión entorno hace referencia a las características de la zona en la que se ubica la vivienda. Se tienen en cuenta tres indicadores: ruidos, contaminación y delincuencia. Un individuo está privado en el indicador ruidos, si la vivienda tiene problemas de ruidos de vecinos o procedentes del exterior; en el de contaminación, si la zona de la vivienda tiene problemas de contaminación, suciedad u otros problemas medioambientales; y en el de delincuencia, si el entorno de la vivienda sufre de delincuencia, violencia o vandalismo. Al igual que en las dimensiones material y vivienda, estos indicadores identifican la privación del hogar, que es imputada a los individuos que lo habitan.

La dimensión salud consta de cinco indicadores: estado salud, problema crónico, limitación grave, acceso médico y acceso dentista. Los tres primeros se pueden identificar con el estado de salud del individuo y los dos restantes con el acceso a los servicios de salud. Las personas privadas de estado salud son aquellas que manifiestan tener un estado de salud malo o muy malo, y las privadas en problema crónico son aquellas que reportan la existencia de una enfermedad o problema crónico. De las personas que manifiestan limitación, en los últimos 6 meses, por problemas de salud para realizar actividades que habitualmente la gente hace, son identificadas como privadas las que están gravemente limitadas. En cuanto a los indicadores de acceso a la salud, se consideran privadas las personas que han necesitado atención de un médico o dentista en el último año, pero no han podido por ausencia de medios económicos, de transporte, de tiempo por trabajo o cuidado de personas dependientes, o por la existencia de listas de espera. 
En la dimensión trabajo se considera el indicador de Baja Intensidad de Trabajo (Low Work Intensity) (BIT) en el hogar, similar al de la tasa AROPE, pero recalculado para las personas en edad de trabajar en España (16 a 64 años). La metodología es la del indicador BIT de Eurostat (s.f.d) modificada de forma que se consideran personas en edad de trabajar las de 16-64 años de edad, excluyendo a los estudiantes de hasta 24 años, y se identificaron como estudiantes a los que reportan más de 6 meses estudiando en el año y a los que reportan 6 meses exactos y se encuentran estudiando en el último mes (diciembre). Al igual que en la AROPE, se identifica como privadas a las personas que viven en un hogar con una intensidad de trabajo por debajo de un umbral establecido en 0,20. Se entiende por intensidad de trabajo de un hogar la proporción del número total de meses (equivalentes) que conjuntamente los miembros de la familia en edad de trabajar han trabajado durante el año de referencia del ingreso en relación al total de meses que podrían haber trabajado teóricamente en el mismo período. BIT no aplica a las personas de $65 \mathrm{y}$ más años por lo que serán identificadas como no privadas, así como a los hogares compuestos sólo por niños, estudiantes de menos de 25 años y / o personas de 65 años o más. A las personas cuya situación es "Trabajando a Tiempo Completo" (variable PL030) y que no reportan información acerca de los meses trabajados se les imputan 12 meses de trabajo, es decir, su potencial, siendo incluidos de esta manera en el cálculo de la BIT.

El indicador manejado para integrar la dimensión de educación es el de estudios, identificando como privadas a las personas que tienen un nivel de estudios equivalente a primaria o inferior. Las personas analfabetas y las que saben leer y escribir pero que no tienen estudios reglados también son consideradas como privadas.

\subsubsection{Ponderaciones}

La literatura existente ofrece un rico menú de técnicas de ponderación, cada una de ellas con pros y contras. Se podrían clasificar en tres grupos: las equitativas que asignan ponderaciones iguales; las basadas en modelos estadísticos como el análisis factorial, análisis envolvente de datos, métodos de regresión, etc.; y las basadas en métodos participativos como los procesos de asignación presupuestaria, encuestas de opinión pública, procesos de jerarquía analítica, etc. Generalmente las ponderaciones tratan de reflejar la importancia relativa de las dimensiones e indicadores dentro del índice complejo, aunque en ocasiones también se podrían asignar en función de la calidad estadística de los datos, dando pesos más elevados a los indicadores más fiables de amplia cobertura (OECD, 2008).

Siguiendo a Alkire et al. (2014), y dada la falta de consenso en la literatura para aplicar un sistema concreto de ponderaciones, en este trabajo se ha optado por utilizar pesos iguales para las dimensiones seleccionadas (Tabla 1), criterio que Atkinson et al. (2002) resaltan que facilita la interpretación de los indicadores.

La ponderación de cada dimensión es igualmente distribuida entre los indicadores que la integran. Así, los indicadores de las dimensiones económica, material, educación y trabajo tienen un peso de $1 / 7$ por ser los únicos integrantes de las mismas. Los indicadores de las dimensiones de vivienda y salud, cinco en cada una, se ponderan por $1 / 35$. Por último, la dimensión entorno está formada por tres indicadores que pesan $1 / 21$ cada uno. De esta forma, todas las dimensiones consideradas tendrán la misma importancia o peso (igual a 1/7) en la construcción de la medida de pobreza.

\subsubsection{Umbrales}

El criterio de corte de la pobreza multidimensional $k$ representa la suma ponderada de indicadores en los que un individuo debe estar privado para ser considerado multidimensionalmente pobre. Para analizar la sensibilidad de los resultados al umbral de pobreza, se ha trabajado con diferentes puntos de corte $(k=1 / 7,2 / 7$ y $3 / 7)$. En términos intuitivos, estos puntos de corte equivaldrían a estar privado en 1, 2 y 3 dimensiones completas de las 7 consideradas. Los cálculos han sido 
realizados para $\mathrm{k}=1 / 7,2 / 7, \ldots, 7 / 7$, pero con valores de corte elevados la muestra de pobres se vuelve insignificante o inexistente como en el caso de $\mathrm{k}=7 / 7$. Con valores elevados también se dificulta la descomposición en subgrupos de población por la limitación o inexistencia de muestra en algunos subgrupos, sobre todo con $k=5 / 7$ o superior. Además, cuanto mayor sea el valor de $\mathrm{k}$, más exigente sería el umbral de pobreza multidimensional, identificando como pobres sólo a la población que está privada en todas o casi todas las dimensiones (lo que podríamos considerar como un indicador de pobreza excesivamente extrema).

Tabla 1. Dimensiones, indicadores, umbrales y ponderaciones de la medida $\mathrm{M}_{0}$.

\begin{tabular}{|c|c|c|}
\hline $\begin{array}{c}\text { Dimensión } \\
\left(\text { peso } w_{i}\right)\end{array}$ & $\begin{array}{l}\text { Indicador } \\
\left(\text { peso } w_{i}\right)\end{array}$ & Consideración de privación (Umbral $z_{j}$ ) \\
\hline $\begin{array}{c}\text { Económica } \\
(1 / 7)\end{array}$ & $\begin{array}{l}\text { IDEI } \\
(1 / 7)\end{array}$ & Tener ingresos inferiores al $60 \%$ de la mediana del IDEI \\
\hline $\begin{array}{c}\text { Material } \\
(1 / 7)\end{array}$ & $\begin{array}{l}\text { PMS } \\
(1 / 7)\end{array}$ & Estar privado de 4 o más ítems de una lista de 9 \\
\hline \multirow{5}{*}{$\begin{array}{l}\text { Vivienda } \\
\quad(1 / 7)\end{array}$} & $\begin{array}{l}\text { Hacinamiento } \\
\qquad(1 / 35)\end{array}$ & $\begin{array}{l}\text { Vivir en un hogar que no tiene a su disposición un número de habitaciones } \\
\text { igual a: un cuarto para la familia; un cuarto por pareja; un cuarto por } \\
\text { persona } \geq 18 \text { años no incluidas previamente; un cuarto por par de personas } \\
\text { solteras del mismo sexo entre } 12 \text { y } 17 \text { años no incluidas previamente; un } \\
\text { cuarto por persona entre } 12 \text { y } 17 \text { años no incluidas en la categoría anterior; } \\
\text { y un cuarto por par de niños/as }<12 \text { años no incluidas en categorías } \\
\text { anteriores }\end{array}$ \\
\hline & $\begin{array}{c}\text { Humedades } \\
(1 / 35)\end{array}$ & $\begin{array}{l}\text { Vivir en un hogar con presencia de goteras o humedades en paredes, suelos, } \\
\text { techos y/o cimientos; o podredumbre en suelos, marcos de ventanas y/o } \\
\text { puertas }\end{array}$ \\
\hline & $\begin{array}{c}\text { Luz natural } \\
(1 / 35)\end{array}$ & Vivir en un hogar con escasez de luz natural \\
\hline & $\begin{array}{l}\text { Ducha } \\
(1 / 35)\end{array}$ & Vivir en un hogar sin disponibilidad de bañera o ducha \\
\hline & $\begin{array}{l}\text { Inodoro } \\
(1 / 35)\end{array}$ & Vivir en un hogar sin disponibilidad de inodoro \\
\hline \multirow{3}{*}{$\begin{array}{c}\text { Entorno } \\
(1 / 7)\end{array}$} & $\begin{array}{l}\text { Ruidos } \\
(1 / 21)\end{array}$ & $\begin{array}{l}\text { Vivir en un hogar con presencia de ruidos producidos por los vecinos o } \\
\text { procedentes del exterior }\end{array}$ \\
\hline & $\begin{array}{l}\text { Contaminación } \\
(1 / 21)\end{array}$ & $\begin{array}{l}\text { Vivir en un hogar con problemas de contaminación, suciedad u otros } \\
\text { problemas medioambientales en la zona }\end{array}$ \\
\hline & $\begin{array}{l}\text { Delincuencia } \\
\qquad(1 / 21)\end{array}$ & $\begin{array}{l}\text { Vivir en un hogar con problemas de delincuencia, violencia o vandalismo } \\
\text { en la zona }\end{array}$ \\
\hline \multirow{4}{*}{$\begin{array}{l}\text { Salud } \\
(1 / 7)\end{array}$} & $\begin{array}{l}\text { Estado salud } \\
(1 / 35)\end{array}$ & Tener estado de salud malo o muy malo \\
\hline & $\begin{array}{l}\text { Problema crónico } \\
\qquad(1 / 35)\end{array}$ & Tener problemas de salud crónicos \\
\hline & $\begin{array}{l}\text { Limitación grave } \\
\qquad(1 / 35)\end{array}$ & Estar gravemente limitado por problemas de salud \\
\hline & $\begin{array}{l}\text { Acceso médico } \\
\qquad(1 / 35)\end{array}$ & $\begin{array}{l}\text { No ir al médico cuando lo necesitaba porque: no se lo podía permitir; estaba } \\
\text { en una lista de espera o no tenía volante; no disponía de tiempo debido al } \\
\text { trabajo, al cuidado de niños o de otras personas; o estaba demasiado lejos } \\
\text { para viajar o sin medios de transporte }\end{array}$ \\
\hline
\end{tabular}




\begin{tabular}{|c|c|l|}
\hline $\begin{array}{c}\text { Dimensión } \\
\left(\text { peso } \boldsymbol{w}_{\boldsymbol{i}}\right)\end{array}$ & $\begin{array}{c}\text { Indicador } \\
\left(\text { peso } \boldsymbol{w}_{\boldsymbol{i}}\right)\end{array}$ & \multicolumn{1}{c|}{ Consideración de privación (Umbral $\left.z_{j}\right)$} \\
\hline & $\begin{array}{c}\text { Acceso dentista } \\
(1 / 35)\end{array}$ & $\begin{array}{c}\text { No ir al dentista cuando lo necesitaba porque: no se lo podía permitir; estaba } \\
\text { en una lista de espera o no tenía volante; no disponía de tiempo debido al } \\
\text { trabajo, al cuidado de niños o de otras personas; o estaba demasiado lejos } \\
\text { para viajar o sin medios de transporte }\end{array}$ \\
\hline $\begin{array}{c}\text { Trabajo } \\
(1 / 7)\end{array}$ & $\begin{array}{c}\text { BIT } \\
(1 / 7)\end{array}$ & Vivir en un hogar con baja intensidad de trabajo \\
\hline $\begin{array}{c}\text { Educación } \\
(1 / 7)\end{array}$ & $\begin{array}{c}\text { Estudios } \\
(1 / 7)\end{array}$ & Tener estudios primarios o sin estudios \\
\hline
\end{tabular}

Fuente: Elaboración propia.

\section{Análisis empírico de la pobreza multidimensional en España. 2008-2015.}

\subsection{Incidencia de las privaciones.}

Una primera aproximación al fenómeno de la pobreza multidimensional se puede obtener analizando las privaciones (no censuradas) en los indicadores que van a integrar las dimensiones del índice $\mathrm{M}_{0}$ (Tabla A1 del Anexo).

Las tasas de privación más elevadas del período 2008-2015 se observan en el indicador estudios y en el de problema crónico de la dimensión salud, ambas moviéndose en torno al $30 \%$. Presentan también porcentajes de privación elevados (generalmente superiores al 15\%) los indicadores ruidos y humedades de la dimensión vivienda, así como la dimensión económica. Con niveles bajos de privación, como era de esperar, se encuentran las variables de la dimensión vivienda relativas a la disponibilidad de inodoro y ducha (ambas con tasas que no superan el $0,12 \%$ ), seguidas de hacinamiento y acceso médico, con tasas en torno al $2,5 \%$ o inferiores. En términos de dimensiones, la de educación muestra las mayores tasas de privación y la de vivienda presenta las menores tasas en varios de sus indicadores.

Las distintas dimensiones han evolucionado de manera diferente a lo largo del periodo de estudio (Gráfico 1b). Mientras las tasas de privación se han elevado en las dimensiones económica, material y trabajo, han seguido la tendencia contraria en las de entorno, salud y educación (a excepción del indicador problema crónico en la dimensión salud e inodoro en la de vivienda que incrementan su privación en 2015 con respecto al 2008, aunque la variación relativa es pequeña).

De 2008 a 2015, las tasas de privación de la dimensión trabajo son las que más se han incrementado. BIT casi duplica la tasa de privación alcanzando un $14 \%$ en 2015 , lo que constituye un reflejo claro del deterioro en el mercado laboral derivado del desempleo. Partiendo de niveles más bajos, la privación material severa (PMS) también ha sufrido un fuerte aumento, pasando del $3 \%$ a casi el $6 \%$. Menor variación relativa ha sido la experimentada por la tasa de pobreza monetaria (dimensión económica), calculada a partir del IDEI, que se ha incrementado en casi 3 puntos porcentuales, pasando del 15\% en 2008 al $18 \%$ en 2015.

La dimensión vivienda parece mejorar en general. De los cinco indicadores que la integran, cuatro se han reducido con respecto a 2008. Las tasas de variación relativa de 2008 a 2015 muestran claramente este descenso en el indicador de hacinamiento y en el de luz natural, alcanzando en 2015 niveles del 1\% y 3,8\% respectivamente. También desciende la privación en humedades que alcanza un nivel final del $14,8 \%$ y es la variable con mayor incidencia de esta dimensión, y en ducha cuya privación es la segunda más baja (en torno al 0,09\%), solo por detrás de la privación en inodoro que, a pesar de ver incrementado su nivel, alcanza el 0,08\%. 
Gráfico 1. a) Tasas de privación (no censuradas) por indicador. 2008 (\%) y b) Tasas de variación relativa de las privaciones (no censuradas) por indicador. 2015 vs. 2008 (\%).

a)

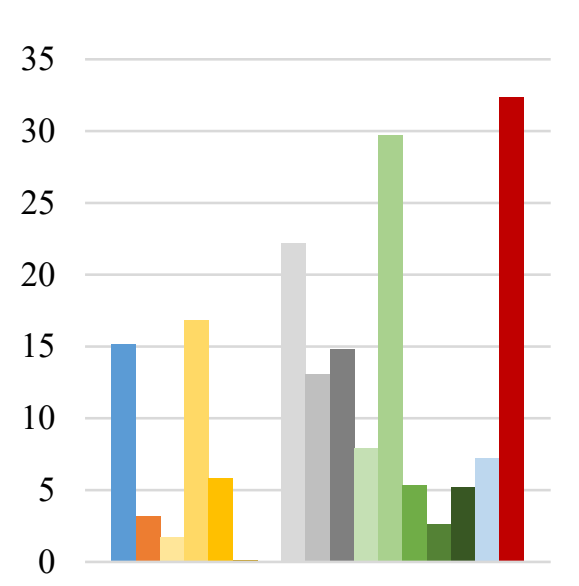

b)

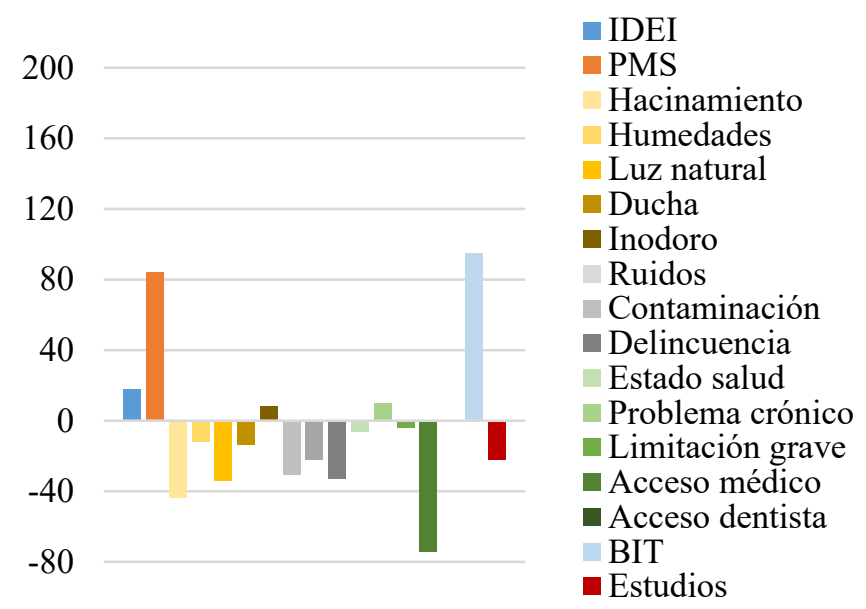

Fuente: Elaboración propia.

La dimensión entorno muestra una clara tendencia hacia la reducción de la privación en los tres indicadores, disminuyendo entre el $20 \%$ y el $30 \%$. Ruidos es el indicador de mayor privación de los tres en todos los años, con un $15 \%$ en el 2015. Contaminación parte con el menor nivel, pero el mayor descenso de delincuencia hace que se inviertan sus posiciones en 2015, situándose ambas tasas en torno al $10 \%$.

En la dimensión salud priman las reducciones. El indicador acceso médico es el que muestra un mayor descenso relativo, siendo su incidencia la más baja de los cinco indicadores, alcanzando en 2015 el $0,7 \%$. Estado salud, limitación grave y acceso dentista también han reducido la privación, situándose en 2015 en el 7,4\%, 5,1\% y 5,2\% respectivamente. Por el contrario, problema crónico incrementa la tasa de privación que ya era una de las más elevadas (no solo de la dimensión) y termina por ser la más elevada con un 32,7\%. A pesar de la mayor incidencia en el reporte de enfermedades crónicas, lo que supone o puede suponer un empeoramiento en el estado de salud, se comprueba que el acceso a los servicios médicosanitarios, poco limitado de partida, reporta una mejoría, resultado ciertamente extraño en un período de crisis caracterizado por políticas de austeridad que afectaron a los servicios públicos. A dar explicación a este hecho contribuyen Urbanos y Puig-Junoy (2014) afirmando que puede deberse a que la salud está siendo evaluada en términos relativos, de manera que, en un contexto de problemas económicos y altas tasas de desempleo, la salud se situaría por detrás de otras preocupaciones de los individuos.

Por último, la dimensión educación, la de mayor privación en 2008, también experimenta una clara mejoría. La incidencia de la privación en estudios se ha reducido en 7 puntos porcentuales, situándose en 2015 en el $25 \%$, dejando de ser el indicador de mayor privación. Esta evolución muestra un comportamiento positivo en cuanto al nivel educativo de las nuevas generaciones, si bien tendría interés analizar hasta qué punto esta mejoría tiene carácter coyuntural (debido al efecto de la crisis sobre el empleo) o es estructural (como se pretende desde la Estrategia Europa 2020). El cuarto punto de la Estrategia Europa 2020 (EC, 2010) está referido a educación y pretende lograr tasas de abandono escolar prematuro por debajo del $10 \%$ ( $15 \%$ para España) y que al menos un 40\% (44\% para España) de las personas de 30 a 34 años de edad completen estudios de nivel terciario. 
A modo de reflexión, se debe tener en cuenta la subjetividad y relatividad en las respuestas, es decir, puede que ni el entorno, ni la vivienda, ni la salud se encuentren en mejor situación en 2015 que en el 2008 y que la mejoría reflejada por las respuestas tenga más que ver con el mayor empeoramiento relativo de otras capacidades o funcionamientos de las personas que hace que relativicen ciertas privaciones que en otro contexto tenían mayor relevancia.

\section{2. Índice de pobreza multidimensional y sus componentes.}

Con el objeto de analizar no sólo los niveles de pobreza multidimensional, sino también su sensibilidad al umbral de pobreza $k$ seleccionado, se obtiene el índice $M_{0}$ (Tabla A2 del Anexo) para umbrales de privación $k$ cuyos valores equivalen a la privación en una, dos y tres dimensiones $(k=1 / 7,2 / 7,3 / 7)$. Esto no significa que los individuos pobres lo sean por la privación en todos los indicadores de una, dos o tres dimensiones, sino porque la suma ponderada de indicadores privados tiene un peso equivalente al de una dimensión para $k=1 / 7$, dos dimensiones para $k=$ $2 / 7$ y tres dimensiones para $k=3 / 7$. También se obtienen las componentes de la medida $M_{0}$, esto es, el subíndice $H$, que es la incidencia de la pobreza multidimensional, y el subíndice $A$, que es la intensidad de la pobreza medida como el promedio de los valores de privación en la población multidimensionalmente pobre.

Evidentemente, cuando se incrementa el criterio de corte $k$ desciende el nivel de pobreza, es decir, a mayor exigencia sobre el nivel de privación, menor es la medida $M_{0}$ (Gráfico 2). Sin embargo, la evolución de $M_{0}$ en el periodo analizado es similar para los tres criterios de corte $k$. Para todos ellos se observa un constante incremento de la pobreza de 2008 a 2013-14 (años que parecen marcar un punto de inflexión), descendiendo levemente en 2015. Este descenso es generalizado para casi todas las privaciones de las personas consideradas multidimensionalmente pobres (Tabla A7 del Anexo), a excepción de las correspondientes a los indicadores ducha y problema crónico cuya contribución conjunta a $M_{0}$ (Tabla A8 del Anexo) no tiene el peso suficiente para compensar las reducciones en las demás privaciones. Esta evolución coincide con la mostrada por Llano (2018) quien evidencia un descenso en la tasa AROPE vinculado a las reducciones en la población con baja intensidad de trabajo por hogar (BITH) y en la privación material severa (PMS).

Gráfico 2. Evolución 2008-2015 del índice $M_{0}(k)$ para k=1/7, 2/7, 3/7.

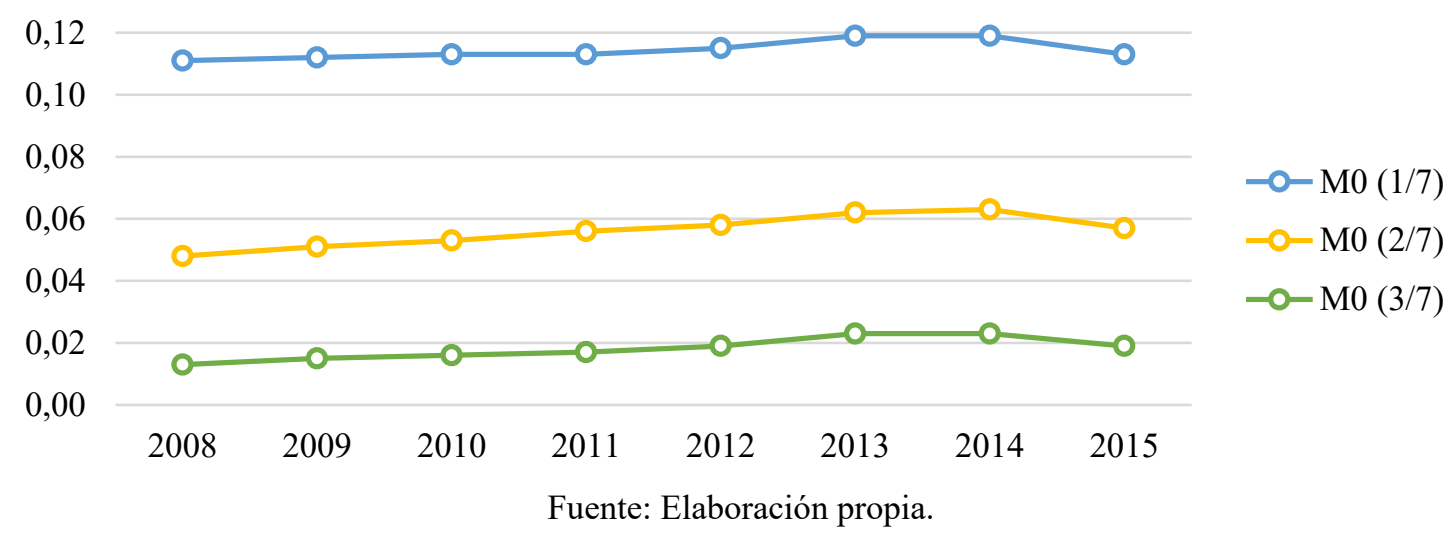

El índice $M_{0}(k)$ es descomponible en dos subíndices, uno que mide la incidencia de la pobreza, $H(k)$ (Gráfico 3a), y otro que mide la intensidad de la misma, $A$ (k) (Gráfico 3b), entendida como el promedio de privaciones de los pobres. Los dos subíndices tienen un comportamiento claro con el incremento del parámetro $k$, descendiendo la incidencia y 
aumentando la intensidad. La incidencia desciende debido a una mayor exigencia de privación, es decir, si se le exige a la población estar más privada para ser considerada multidimensionalmente pobre, el porcentaje va a ser menor. El subíndice $H$ puede ser interpretado en términos porcentuales, como un determinado porcentaje de la población objeto de estudio, mientras que con $A$ y $M_{0}$ no sucede lo mismo.

La evolución temporal de la incidencia en estos años también varía en función del valor del umbral de pobreza multidimensional $k$. Cuando se exige una suma ponderada de privaciones equivalente al de una dimensión $(k=1 / 7)$ para ser considerado en pobreza, se observa un leve descenso en la proporción de pobres, pasando de un 47\% en 2008 a un $46 \%$ en 2015 . Al contrario, cuando el umbral de pobreza $k$ es más exigente, la proporción de pobres aumenta de 2008 a 2015 , pasando del $13 \%$ al $15 \%$ con $k=2 / 7$ y del $3 \%$ al $4 \%$ con $k=3 / 7$. Bien es cierto que, al igual que con los $M_{0}(k)$, los años 2013 y 2014 suponen un punto de inflexión en $H(k)$, presentando 2015 mejores cifras (más evidente con valores de $k$ más elevados). Estos porcentajes suponen en términos poblacionales, alrededor de 18 millones de personas multidimensionalmente pobres con $k=1 / 7$, en torno a 6 millones con $k=2 / 7$ y entre 1 y 2 millones con $k=3 / 7$. Para poder situar estas cifras en su contexto, la tasa de riesgo de pobreza o exclusión social (AROPE) para las personas de 16 y más años es de 22,7\% en 2008 y 27,8\% en 2015 (Eurostat, 2008-2016), lo que equivale a 8,7 y 10,7 millones de personas respectivamente. Se puede ver que el número de personas identificadas como pobres o en riesgo de exclusión por la tasa AROPE (que incluye tres dimensiones: económica, material y laboral) es más próxima a los valores del subíndice H (2/7), y lo sería todavía más si los ingresos considerados para elaborar la tasa de pobreza monetaria que integra la AROPE incorporasen el alquiler imputado como así sucede con las medidas calculadas en este trabajo.

La intensidad de la pobreza multidimensional (Gráfico 3b) aumenta con el incremento de $k$ porque las personas que se van excluyendo a medida que $k$ aumenta son las de menor valor de privación. Esto es, los pobres identificados con criterios de corte más elevados son menos, pero son los que presentan unos valores de privación mayores y, por lo tanto, el promedio del valor de sus privaciones también es mayor. A nivel longitudinal, el incremento del umbral de corte $k$ no cambia las tendencias de incremento de la intensidad entre 2008 y 2015, a pesar de presentar este último año cifras claramente inferiores a las del año anterior.

Gráfico 3. Subíndices. a) H (k) y b) A (k).

a)

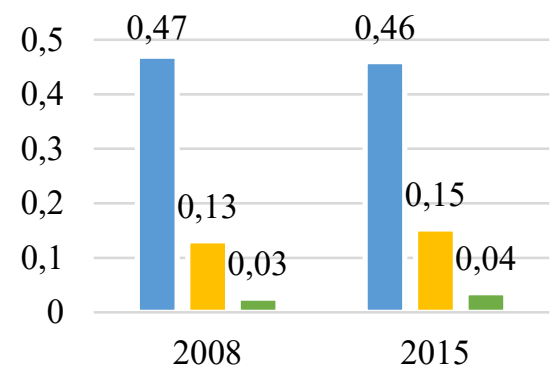

b)

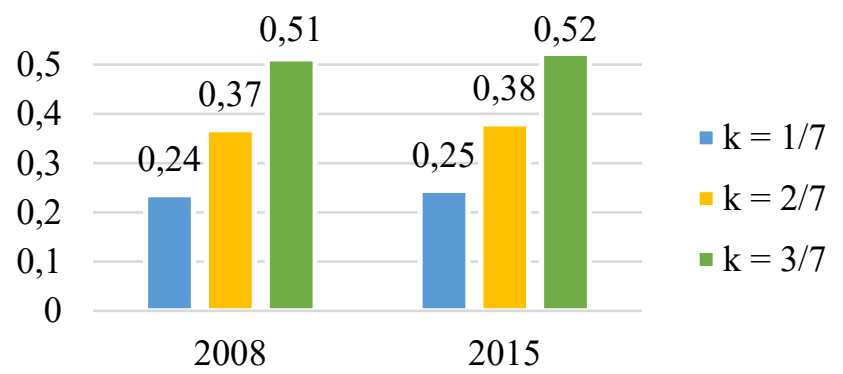

Fuente: Elaboración propia. 


\subsection{Descomposición aditiva por grupos poblacionales.}

Los cálculos han sido realizados para los tres umbrales (Tablas A3, A4, A5 y A6 en el Anexo). No obstante, la explicación en el texto de todos los resultados calculados alargaría en exceso este apartado, por tal motivo se ha optado por comentar los obtenidos con $k=2 / 7$, incluyendo algunas referencias al resto de los casos cuando se ha considerado oportuno.

\subsubsection{Descomposición por sexo}

Los niveles de pobreza medidos por $M_{0}(2 / 7)$ son más elevados en las mujeres que en los hombres (Gráfico 4), entre un $8 \%$ y un $15 \%$ superior en los primeros cuatro años y entre un $2 \%$ y un $6 \%$ superior al final del periodo. La componente $H(2 / 7)$ manifiesta el mismo comportamiento que el índice de pobreza multidimensional, con porcentajes más altos de incidencia en las mujeres. Por el contario, la intensidad es mayor en los hombres, a excepción del año 2009. Además, en el 2013 se da un pico de intensidad en los hombres que es el principal causante del gran acercamiento de la medida $M_{0}(2 / 7)$ para ambos sexos (Gráfico 4).

\section{Gráfico 4. Evolución 2008-2015 del índice a) $M_{0}(k)$ y subíndices b) H (k) y c) A (k); para k= 2/7 y por sexo.}

a)

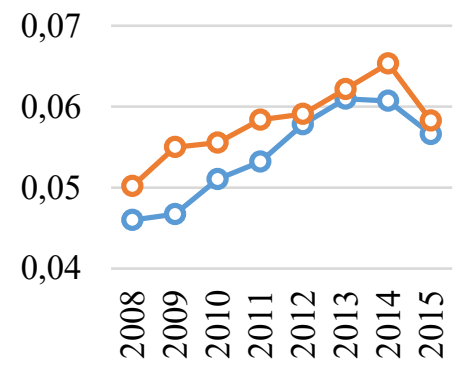

b)

$$
\begin{aligned}
& 0,18 \\
& 0,16 \\
& 0,14 \\
& 0,12 \\
& 0,10
\end{aligned}
$$

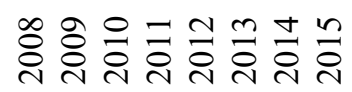

$$
\begin{aligned}
& -0 \text {-Hombres }-0-\text { Mujeres }
\end{aligned}
$$

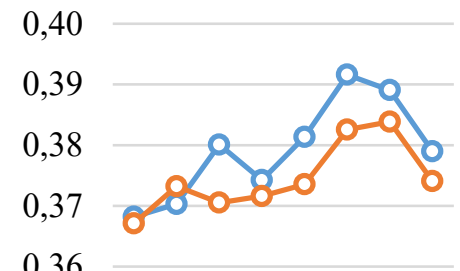

0,36

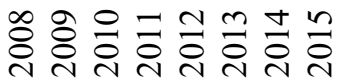

Fuente: Elaboración propia.

Entre el año 2008 y 2015 se ha producido un empobrecimiento generalizado en ambos grupos (Gráfico 5). En los hombres el incremento de la pobreza es mayor que en las mujeres, tanto para $M_{0}(2 / 7)$ como para sus componentes. El incremento de pobreza está en torno al $23 \%$ para los hombres ( $20 \%$ en incidencia) y $16 \%$ para las mujeres (14\% en incidencia). La intensidad también se ha incrementado más en los hombres (3\%) que en las mujeres $(2 \%)$, pero en ambos casos la variación es pequeña. Con el umbral de pobreza más bajo $(k=1 / 7)$ los resultados muestran reducciones de la pobreza multidimensional relacionadas con el descenso en la incidencia. A pesar de los incrementos de pobreza observados, y como ya se había identificado, el año 2014 supone un punto de inflexión que se manifiesta con mayor claridad en el grupo de mujeres (en la intensidad el punto de inflexión está en 2013 y se presenta con mayor importancia en el grupo de hombres). 
Gráfico 5. Tasas de variación relativa de 2015 vs. 2008 (\%) de $M_{0}(\mathrm{k})$, H (k) y A (k); para k= 2/7 y por sexo.

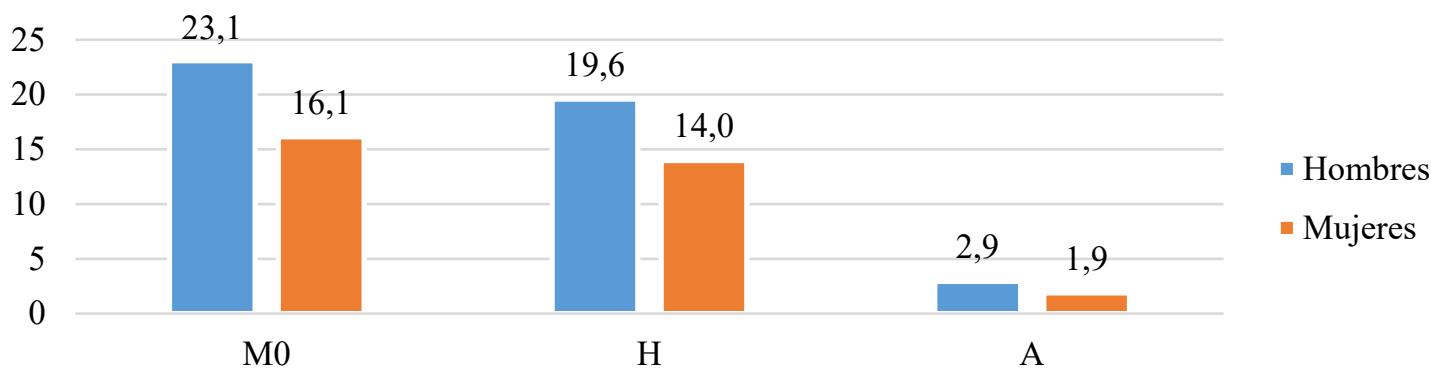

Fuente: Elaboración propia.

\subsubsection{Descomposición por grupos de edad}

En 2008, con $\mathrm{k}=2 / 7$, el grupo de edad con menor pobreza multidimensional es el de 25 a 34 años, mientras que el de mayor pobreza se corresponde con las personas de 50 a 64 años, seguido por las de 65 o más (Gráfico 6). Analizando las tasas de privación (censuradas) por grupos de edad (Tabla A9 del Anexo), se observa que los mayores niveles de pobreza que sufren las personas de 50 o más años en 2008 se deben fundamentalmente a la contribución de la dimensión educación (con los porcentajes más elevados de privación (censurada) de todos los grupos, durante todo el periodo), de la dimensión salud (especialmente por las privaciones en los indicadores estado de salud, problema crónico y limitación grave, que correlacionan positivamente con la edad como era de esperar) y de la dimensión entorno. Además, el grupo de 50 a 64 años parte en el 2008 de un porcentaje de privación en la dimensión trabajo que más que triplica el de los otros grupos (a excepción de los mayores de 65 para los que no aplica). Resaltar que la clasificación por edad varía mucho en función del umbral k seleccionado. Con $k=1 / 7$, el grupo de mayor edad es el que presenta mayores valores del índice de pobreza, mientras que con $k=3 / 7$ es el que tiene los menores niveles.

El comportamiento del subíndice $H(k)$ es muy similar al de $M_{0}(k)$, y los subgrupos a destacar, tanto por sus mayores niveles de pobreza como por los más bajos, son los mismos. Con $k=2 / 7$, la mayor incidencia se encuentra entre las personas de 50 a 64 años de las que un $19 \%$ son identificadas como multidimensionalmente pobres en 2008 (cerca de 1,5 millones de personas). Por otro lado, la intensidad para cada grupo, medida por $A(k)$, es muy similar independientemente de $k$. Se puede resaltar que el grupo de mayor edad es el que presenta menores valores de intensidad de la pobreza multidimensional para los diferentes $k$. 
a)

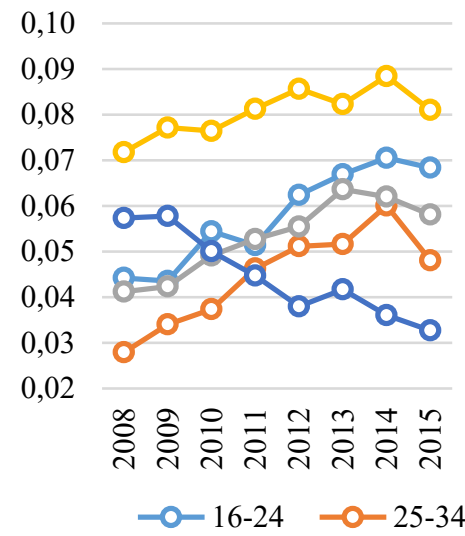

b)

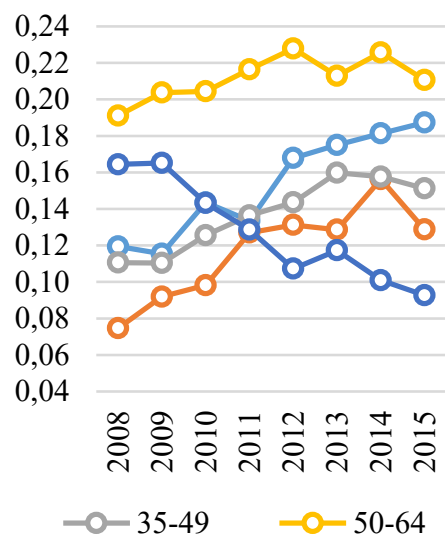

c)

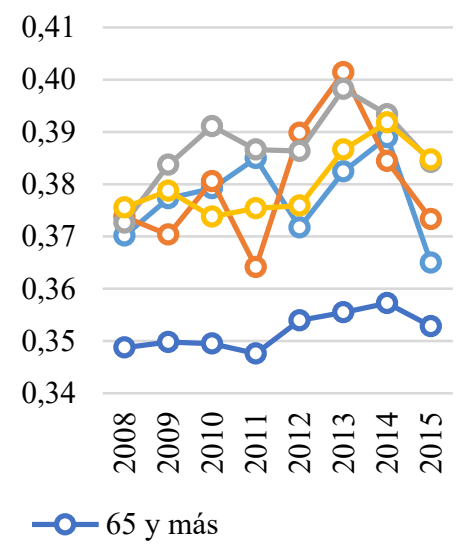

Fuente: Elaboración propia.

Los cambios entre el 2008 y el 2015 (Gráfico 7) han sido más fuertes en los grupos de edad más jóvenes y en el de personas mayores. Las personas mayores son el único grupo que mejora su situación con respecto a 2008. De hecho, esta mejoría hace que en 2015 sean el grupo con menor pobreza multidimensional cuando partían de ser el segundo grupo en peor situación. Esta evolución parece deberse más a un efecto estadístico que a la mejoría real de su situación, dado que, en un contexto de descenso generalizado de las rentas (y del umbral de pobreza), la estabilidad de las pensiones (Argüeso et al., 2014; Llano, 2015) y la mayor tasa de tenencia de la vivienda hacen que la dimensión económica (una de las que más contribuye al índice) presente una importante mejoría relativa respecto a los demás grupos. También se debe tener en cuenta que a este grupo no le influye la situación del mercado laboral (su contribución al índice es del $0 \%$ ) mientras que la privación en la dimensión trabajo se viene incrementando para los demás grupos durante el periodo observado (Tabla A9 del Anexo). El grupo de 25 a 34 años, a pesar de ser el que más empeora su situación, sigue siendo uno de los de menores niveles de pobreza en 2015 (en 2008 tenía el menor índice). Las personas de 50 a 64 años, a pesar de haber sufrido un incremento inferior al de otros grupos, siguen manteniéndose como el más pobre en 2015. El incremento del valor del índice está muy relacionado con el empeoramiento de la situación económica que se manifiesta de forma evidente en el incremento de privaciones para las dimensiones económicas y trabajo (Tabla A9 del Anexo). Como se puede ver (Gráfico 6b), el comportamiento de la incidencia $H(k)$ a lo largo del periodo de estudio es muy similar al de $M_{0}$ $(k)$, ya que las variaciones en la intensidad son muy pequeñas. Esto hace que los grupos de edad mantengan la posición que se ha referido sobre $M_{0}(k)$, es decir, en 2015 los grupos de mayor (menor) incidencia de la pobreza son los de mayor (menor) pobreza multidimensional.

La intensidad no ha cambiado mucho entre el 2008 y el 2015 (Gráfico 7c). Se pueden identificar dos comportamientos, el descenso de la intensidad en los grupos jóvenes (16-24 y 2534 años) y el incremento en el resto, especialmente en el grupo de 35-49 años. A pesar de estos cambios de diferente magnitud y signo, en 2015 se mantiene la ordenación de 2008, con los más mayores, de 65 y más años, como el grupo de menor intensidad y los de 50 a 64 como el de mayor intensidad. El punto de inflexión detectado en el año 2014 para otras clasificaciones y para el índice general no se refleja claramente en la clasificación por edad a excepción del grupo de 25 a 34 años. 
Gráfico 7. Tasas de variación relativa de 2015 vs. 2008 (\%) a) $M_{0}(\mathrm{k})$, b) H (k) y c) A (k) con k= 2/7 $y$ por grupos de edad.

a)

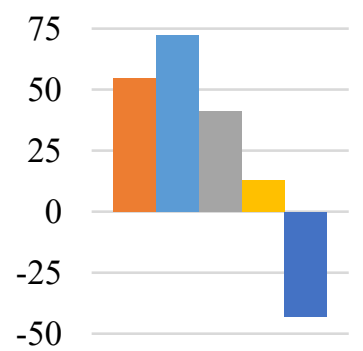

b)

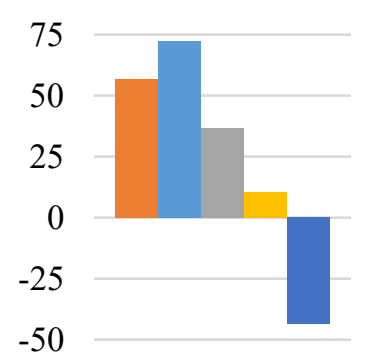

c)

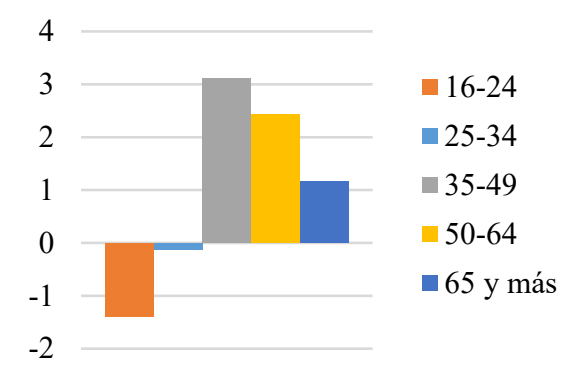

Fuente: Elaboración propia.

\subsubsection{Descomposición por tipología del hogar}

Los hogares con mayores valores del índice $M_{0}(2 / 7)$ en 2008 (tabla A5 anexo) son los tipos 7 y 4 , que se corresponden con las parejas con tres o más niños dependientes y los monoparentales (0,10 y 0,09 respectivamente). Los tipo 8 , otros hogares con niños dependientes, ocupan el tercer lugar a bastante distancia $(0,06)$. Por el contrario, las parejas con menos de 3 niños (tipos 5 y 6 ) son las menos afectadas por la pobreza multidimensional en $2008(0,03)$. Los grupos identificados, tanto los de mayor como los de menor pobreza, mantienen en general su posición con otros umbrales de pobreza $k$. La incidencia de la pobreza también se manifiesta mayor en los mismos grupos. En 2008, las parejas con tres o más niños tienen un $28 \%$ de incidencia y los hogares monoparentales un $24 \%$, lo que significa que alrededor de la cuarta parte de las personas que viven en estos tipos de hogar son multidimensionalmente pobres (300.000 y 100.000 personas respectivamente). El tipo 8, también es el tercero en incidencia con un $17 \%$, pero en este caso se corresponde con un millón de personas. Las parejas sin niños, a pesar de tener un $H(2 / 7)$ del $15 \%$, son el grupo con más personas pobres con una cifra por encima de 1,4 millones. La intensidad no varía mucho por tipo de hogar (entre 0,35 del tipo 6 y 0,38 del tipo 4 en 2008) si bien, una vez más, es mayor en los hogares monoparentales, en los que vive una pareja con tres o más niños, y en otros hogares con niños.

Los índices de pobreza multidimensional entre el 2008 y 2015 (Gráfico 8a) se han incrementado con mayor o menor magnitud, a excepción de los de las parejas sin niños. Los hogares en los que la variación relativa es mayor son las parejas con dos niños, aunque siguen siendo uno de los tipos de hogar con menor índice de pobreza, y los tipos 3 y 8 que son otros hogares sin y con niños. El incremento de pobreza en otros hogares con niños hace que en 2015 se sitúen mucho más cerca de los monoparentales y las familias numerosas que siguen siendo los más pobres. La incidencia (Gráfico 8b) se ha incrementado en todos los grupos excepto en las parejas sin niños (que claramente ha disminuido) y en los formados por dos adultos con tres o más niños. Con estos cambios, en 2015 las parejas sin niños se sitúan entre los tipos de hogar con menor incidencia de la pobreza, por detrás de los demás hogares sin niños (unipersonales y otros). Los hogares monoparentales, con un $27 \%$ de incidencia, alcanzan el primer puesto en proporción de pobres, superando levemente a las familias con 3 o más niños.

La intensidad de la pobreza (Gráfico 8c) se ha incrementado claramente en los hogares con niños. De hecho, en los hogares con tres o más niños este incremento es el que hace que $\mathrm{M}_{0}$ también aumente pues la incidencia ha descendido. También es relevante el incremento de la intensidad sufrido por las parejas sin hijos, pero esto no ha conseguido variar en el mismo sentido 
el índice de pobreza pues el descenso en la proporción de pobres ejerce mayor influencia sobre el mismo.

\section{Gráfico 8. Tasas de variación relativa de 2015 vs. 2008 (\%) a) $M_{0}(k)$, b) H (k) y c) A(k); para k= 2/7 y por tipología del hogar.}

a)

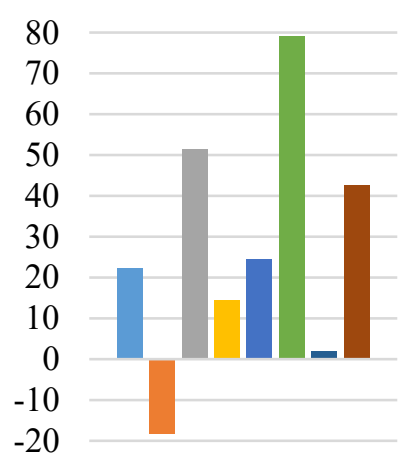

b)

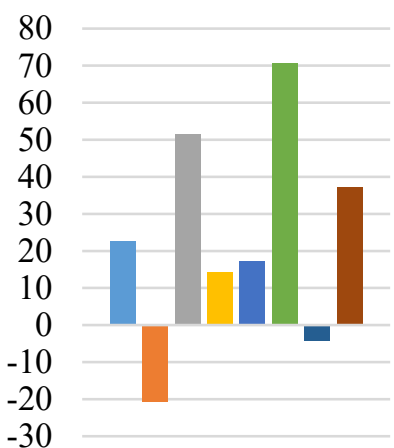

c)

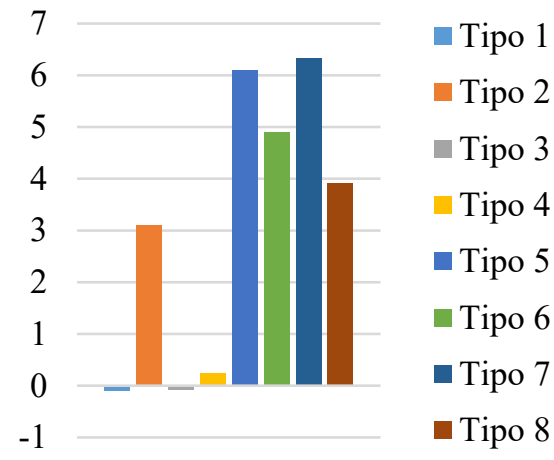

Nota: Tipo 1: Unipersonales (Una persona: hombre de menos de 30 años, Una persona: hombre de entre 30 y 64 años, Una persona: hombre de 65 o más años, Una persona: mujer de menos de 30 años, Una persona: mujer de entre 30 y 64 años, y Una persona: mujer de 65 o más años); Tipo 2: Parejas sin niños dependientes ( 2 adultos sin niños dependientes económicamente, al menos una persona de 65 o más años; y 2 adultos sin niños dependientes económicamente, teniendo ambos menos de 65 años); Tipo 3: Otros hogares sin niños dependientes económicamente; Tipo 4: Un adulto con al menos un niño dependiente; Tipo 5: Dos adultos con un niño dependiente; Tipo 6: Dos adultos con dos niños dependientes; Tipo 7: Dos adultos con tres o más niños dependientes; y Tipo 8: Otros hogares con niños dependientes.

Nota 2: Son niños dependientes económicamente todos los menores de 18 años y los que tienen 18 y más años, pero menos de 25 y que son económicamente inactivos.

Fuente: Elaboración propia.

\subsubsection{Descomposición regional}

El índice $M_{0}(2 / 7)$ para 2008 nos muestra (Gráfico 9a) que las regiones más pobres son, por este orden, Extremadura, Andalucía, Castilla-La Mancha y Canarias con valores por encima de 0,06. En el extremo opuesto se encuentran, de menor a mayor, las regiones de Cantabria, Navarra, Aragón y el País Vasco con valores por debajo o en torno a 0,02. Cuando se varía el criterio de corte, las regiones que destacan por mayores y menores índices de pobreza siguen siendo las mismas.

El subíndice $H(2 / 7)$ (Tabla A6 del Anexo) muestra que la incidencia es más alta en las mismas regiones en las que el índice de pobreza es mayor, con valores por encima del $16 \%$, siendo para Extremadura, la región más pobre en 2008, del 20\%. La incidencia más baja se muestra también en las mismas regiones con menor índice, con la salvedad de que Navarra presenta la menor tasa de incidencia con un 5\%. La intensidad de la pobreza, $A(2 / 7)$, nos muestra resultados un poco diferentes. Las regiones con mayor intensidad son Andalucía y Canarias, que ya estaban entre las de mayor índice de pobreza e incidencia, seguidas de Murcia y el País Vasco. Esta última es de las que presentaba índices de pobreza e incidencia más bajos lo que nos muestra que los pobres son pocos, pero están muy privados. En el otro extremo, con menor intensidad, se 
encuentran Baleares y Castilla y León, que presentan niveles medios de pobreza con los índices anteriores, seguidas de Cantabria, con niveles bajos de pobreza e incidencia, y La Rioja.

Gráfico 9. a) Índice $M_{0}(k)$ y b) tasas de variación relativa de 2015 vs. 2008 (\%); para k= 2/7 y por
regiones.

a)

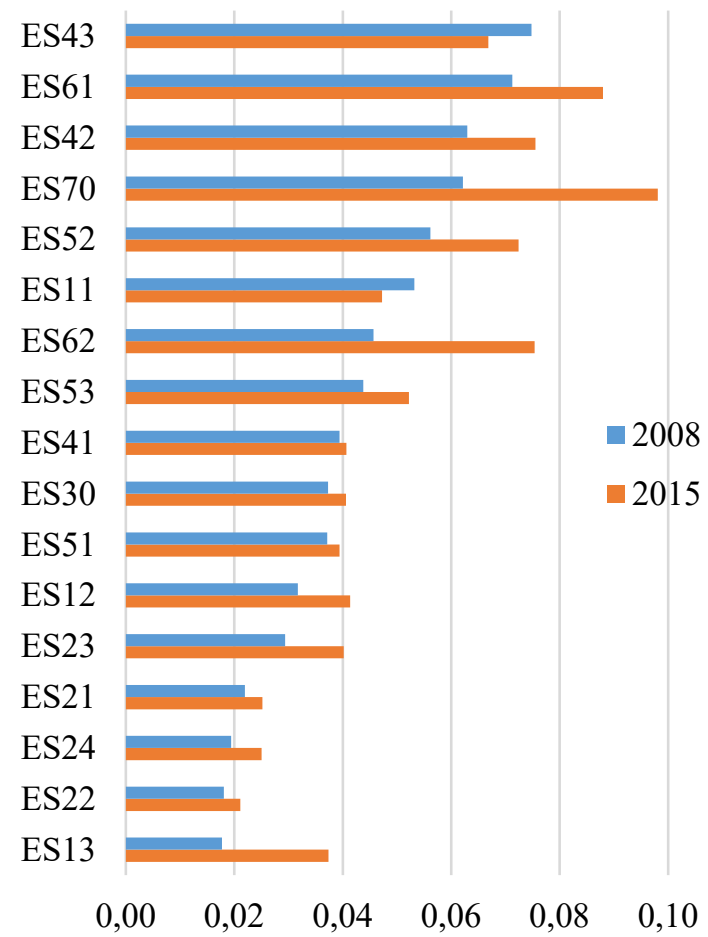

b)

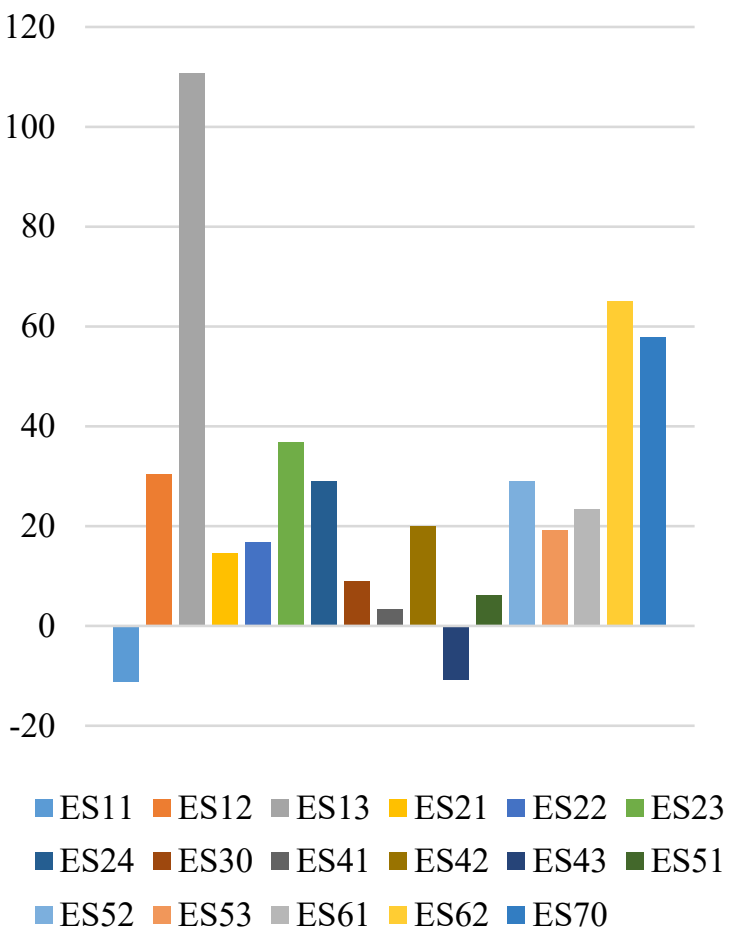

Nota 1: ES11: Galicia, ES12: Principado de Asturias, ES13: Cantabria, ES21: País Vasco, ES22: Comunidad Foral de Navarra, ES23: La Rioja, ES24: Aragón, ES30: Comunidad de Madrid, ES41: Castilla y León, ES42: Castilla - La Mancha, ES43: Extremadura, ES51: Cataluña, ES52: Comunidad Valenciana, ES53: Illes Balears, ES61: Andalucía, ES62: Región de Murcia, y ES70: Canarias.

Nota 2: ES63: Ciudad Autónoma de Ceuta, ES64: Ciudad Autónoma de Melilla, excluidas.

Fuente: Elaboración propia.

Las tasas de variación de la pobreza multidimensional (Gráfico 9b) nos muestran el incremento casi generalizado de pobreza en 2015 respecto a 2008, a excepción de Galicia y Extremadura cuyos índices descienden cerca de un $10 \%$. Con este descenso, Extremadura deja de ser una de las cinco regiones más pobres y Galicia mejora dos posiciones situándose como la octava región más pobre ( $\sin$ tener en cuenta las ciudades autónomas). De las regiones en las que aumenta la pobreza destacan Cantabria, que duplica su índice, aunque sigue siendo de las de menor pobreza; y Murcia y Canarias, cuyos incrementos superiores al $50 \%$ provocan que la primera ascienda tres posiciones, situándose como la cuarta región en pobreza, y la región isleña se coloque a la cabeza como la más pobre en 2015 con un valor de 0,1 .

Las tasas de variación de la incidencia (Gráfico 10a) muestran, al igual que el índice de pobreza, incrementos generalizados del porcentaje de personas pobres salvo en Galicia y 
Extremadura. Como se puede observar en el Gráfico 10, en estas dos regiones el descenso de la pobreza se debe a la disminución de la incidencia y no a una menor intensidad de la misma, ya que el índice $A(2 / 7)$ ha aumentado. En 2015, las regiones con mayor incidencia de la pobreza siguen siendo las mismas que en 2008, con la salvedad de Extremadura. El incremento de la incidencia en Canarias la sitúa como la región con mayor porcentaje de personas pobres con un $24 \%$. La intensidad de la pobreza presenta una variabilidad mayor, con regiones en las que se incrementa y otras en las que desciende (Gráfico 10b). El incremento de la intensidad destaca en Baleares, siendo el causante del aumento del índice de pobreza multidimensional en esta región, ya que la incidencia no ha variado. La mayor disminución se ha dado en Aragón, aunque no ha sido suficiente para que descienda la pobreza ya que la incidencia se ha incrementado.

Gráfico 10. Tasas de variación relativa de 2015 vs. 2008 (\%) de a) H (k) y A (k); para k= 2/7 y por regiones.

a)

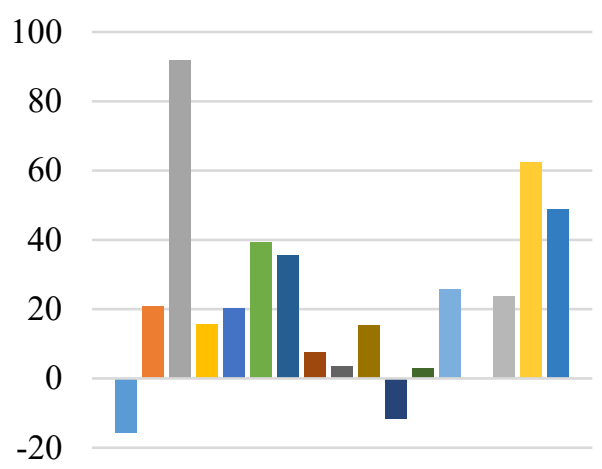

b)

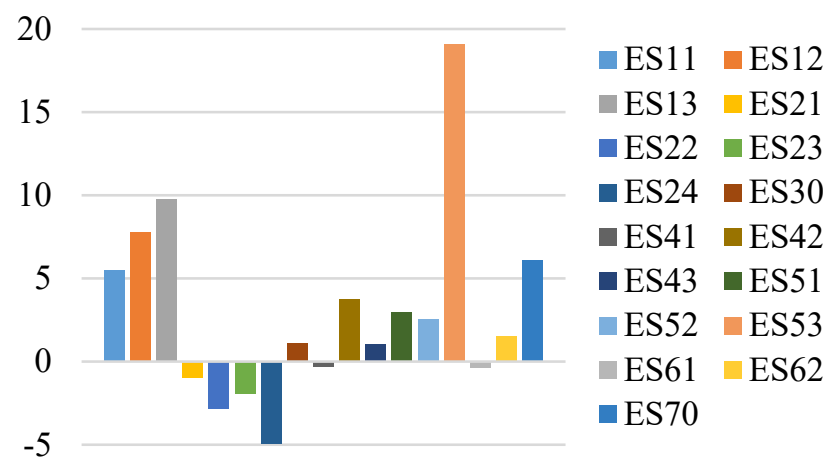

Nota 1: ES11: Galicia, ES12: Principado de Asturias, ES13: Cantabria, ES21: País Vasco, ES22: Comunidad Foral de Navarra, ES23: La Rioja, ES24: Aragón, ES30: Comunidad de Madrid, ES41: Castilla y León, ES42: Castilla - La Mancha, ES43: Extremadura, ES51: Cataluña, ES52: Comunidad Valenciana, ES53: Illes Balears, ES61: Andalucía, ES62: Región de Murcia, y ES70: Canarias.

Nota 2: ES63: Ciudad Autónoma de Ceuta, ES64: Ciudad Autónoma de Melilla, excluidas.

Fuente: Elaboración propia.

\subsection{Desagregación dimensional y contribuciones a la pobreza.}

La desagregación por dimensiones/indicadores es una de las propiedades más interesantes del índice $M_{0}(k)$, ya que permite conocer la contribución de cada dimensión/indicador al índice de pobreza. Se obtiene a partir de las tasas de privación censuradas que muestran la proporción de personas identificadas como multidimensionalmente pobres que están privadas en una determinada dimensión/indicador.

Las mayores tasas de privación censuradas se muestran en los indicadores de las dimensiones educación y económica, a las que se suma la dimensión trabajo en 2015 (Gráfico 11). 
Gráfico 11. Tasas de privación de los indicadores censurados para $M_{0}(k) \operatorname{con} k=2 / 7(\%)$.

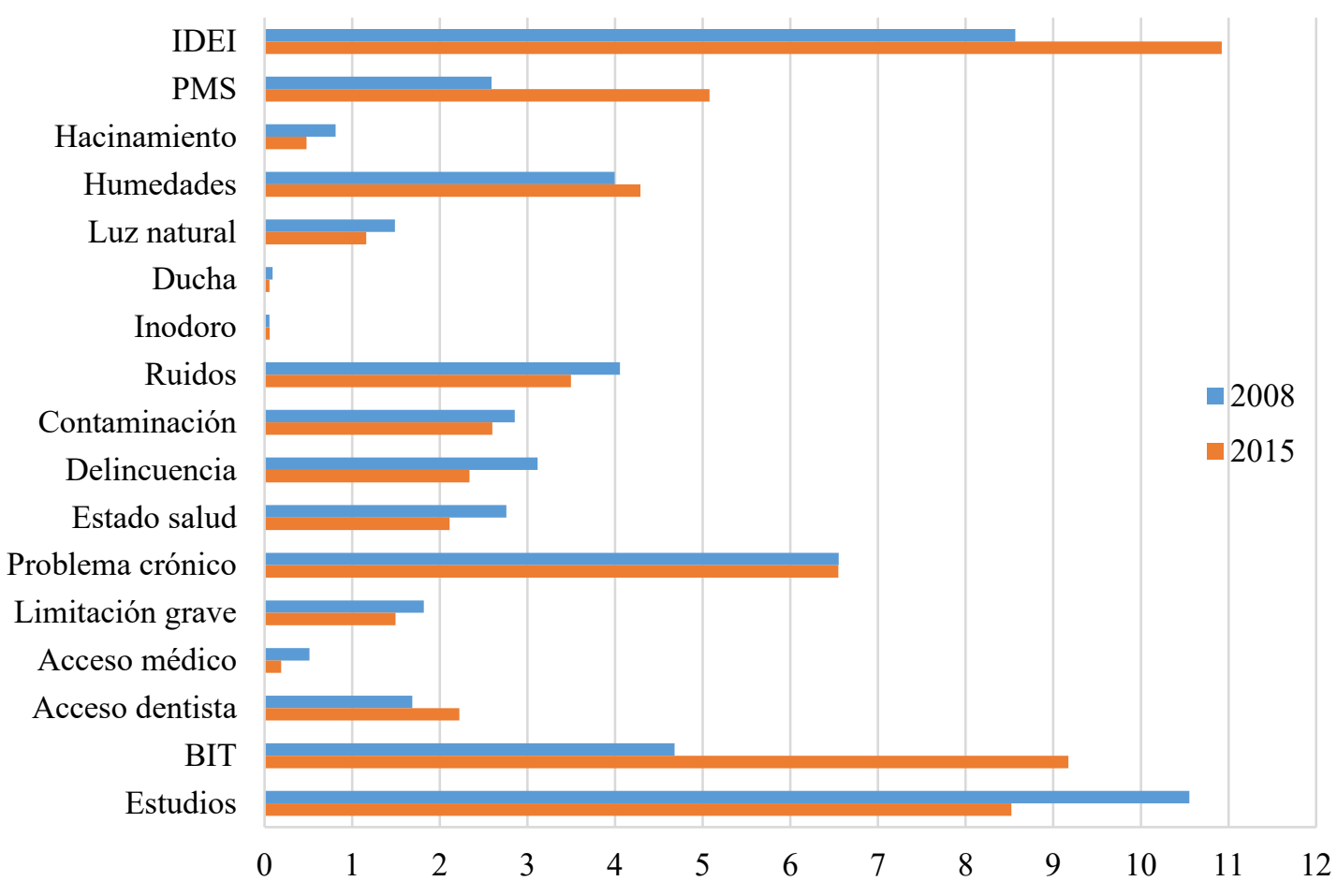

Fuente: Elaboración propia.

Así mismo, la primera muestra el mayor descenso de la incidencia, lo que evidencia una mejora en la educación, mientras que el fuerte incremento del indicador BIT visualiza el claro empeoramiento del mercado laboral. En la dimensión entorno también se produce una mejoría ya que desciende la privación en los tres indicadores que la integran. En 2015, casi el 11\% de las personas multidimensionalmente pobres están privadas en la dimensión económica, un $9,2 \%$ en la dimensión trabajo, un $8,5 \%$ en educación y, a mayor distancia, un $6,5 \%$ en el indicador problema crónico de la dimensión salud, un $5,1 \%$ en la dimensión material y un $4,3 \%$ en el indicador humedades de la dimensión vivienda.

Las dimensiones que más influyen en el índice de pobreza multidimensional $\mathrm{M}_{0}(2 / 7)$ (Gráfico 12a) se corresponden en gran medida con las que mostraban una mayor privación. Esto es así porque las ponderaciones son iguales para todas las dimensiones. En 2008, la privación en la dimensión educación es la que más contribuye al índice de pobreza multidimensional con más de un $31 \%$, seguida de la dimensión económica con más de un $25 \%$. Cerca de un $60 \%$ del comportamiento de $\mathrm{M}_{0}$ está explicado por las privaciones en estas dos dimensiones. A mayor distancia se encuentran, con cerca de un $14 \%$, la dimensión trabajo, con un $10 \%$ la dimensión entorno, con un $9 \%$, cada una, las dimensiones salud y material y, con la menor contribución al índice, menos de un $4 \%$, la dimensión vivienda.

Las contribuciones de los indicadores que componen las dimensiones vivienda, entorno y salud se representan en el Gráfico 13. En 2008, en la dimensión vivienda destaca la contribución de la presencia de humedades o goteras en la vivienda con un $2,4 \%$ seguida de la escasez de luz natural con un $0,9 \%$. Las contribuciones restantes tienen muy poca incidencia en el índice, un $0,6 \%$ en conjunto. Los indicadores de la dimensión entorno tienen contribuciones bastante parecidas. La mayor está en la presencia de ruidos, seguida de delincuencia en la zona y contaminación con contribuciones del $4 \%, 3,1 \%$ y $2,8 \%$ respectivamente. El $8 \%$ con el que 
contribuye la dimensión salud tiene su mayor exponente en la presencia de enfermedades crónicas en las personas con cerca de un 4\%. Las contribuciones restantes son del $1,6 \%$ en estado salud, del 1,1\% en limitación grave, del 1\% en acceso al dentista y del $0,3 \%$ en acceso al médico.

Las contribuciones de las dimensiones a la pobreza multidimensional han variado durante el periodo de estudio (Gráfico 12b). En las dimensiones material y trabajo se ha incrementado en más de un $60 \%$. La dimensión económica también presenta el mismo signo pero, en este caso, el incremento es mucho más moderado, por debajo del 7\%. Las demás dimensiones disminuyen su contribución al índice entre un $20 \%$ y un $30 \%$. Estos cambios sitúan, en 2015, a la dimensión económica como la de mayor contribución con un $27 \%$, en segundo lugar, a la dimensión trabajo con un $23 \%$, en tercer lugar, a la dimensión educación, que antes era la de mayor contribución, con un $21 \%$, y en cuarto lugar la privación material con un $13 \%$. Las privaciones en las demás dimensiones contribuyen menos de un 10\%, y su contribución disminuye de 2008 a 2015. Dentro de cada una de estas dimensiones (Gráfico 13), los indicadores que más contribuyen son humedades en vivienda, ruidos en entorno y problema crónico en salud, cuyas contribuciones al índice también disminuyen en el período.

\section{Gráfico 12. a) Contribución de cada dimensión a $M_{0}(\mathrm{k})(\%)$ y b) tasas de variación relativa de $M_{0}$} (k) de 2015 vs. $2008(\%)$; para $k=2 / 7$.

a)

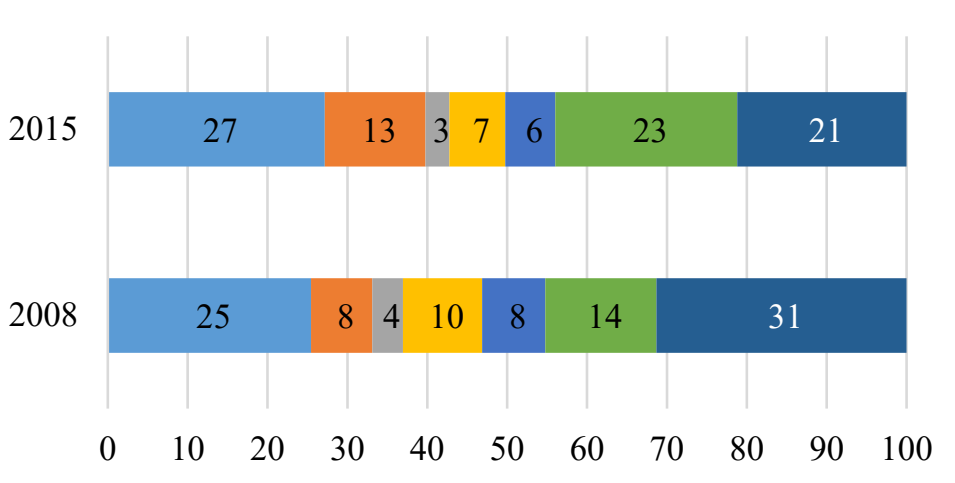

b)

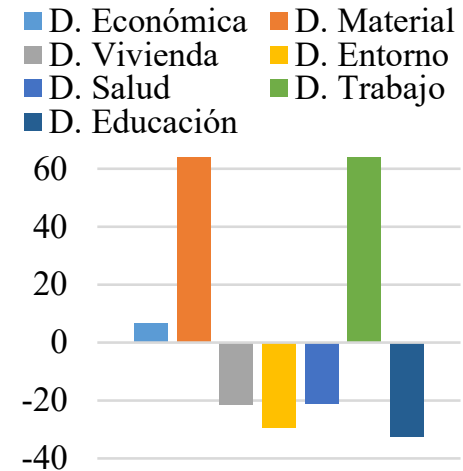

Fuente: Elaboración propia. 
a)

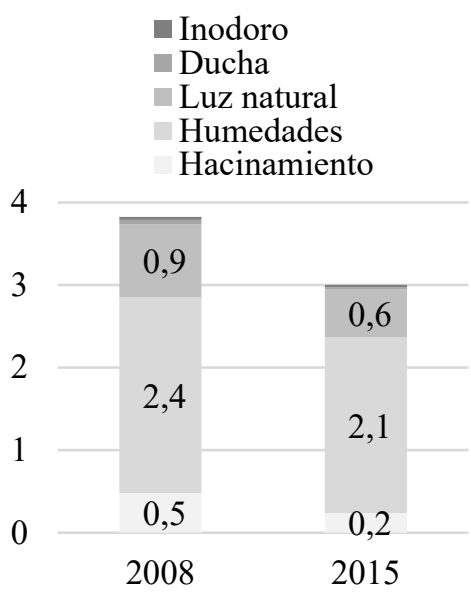

b)

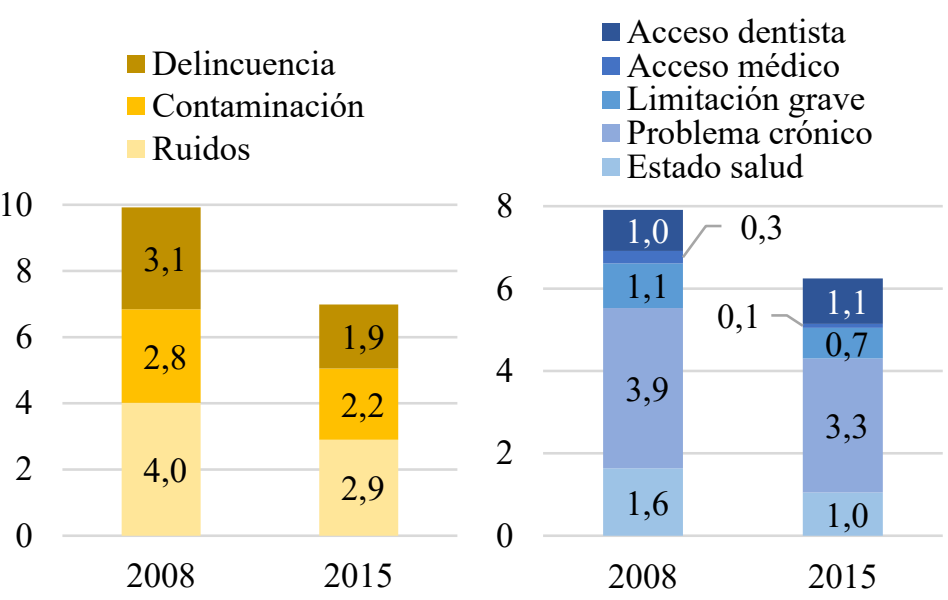

Fuente: Elaboración propia.

\section{Conclusiones.}

El interés por superar las limitaciones de los análisis unidimensionales de pobreza junto con el desarrollo de nuevos marcos normativos y metodologías multidimensionales han llevado a diversos organismos internacionales (OCDE, ONU, UE, OPHI), gobiernos nacionales y personal académico a implementar estudios de este tipo para monitorizar objetivos de bienestar y de lucha contra la pobreza y la exclusión social.

La metodología de Alkire y Foster, desarrollada sobre el enfoque de las capacidades de Sen, constituye una interesante propuesta en el ámbito multidimensional avalada tanto por sus buenas propiedades como por su creciente implementación empírica, en la que existe un alto grado de consenso tanto en las capacidades identificadas como en las dimensiones seleccionadas para dotar de contenido al índice.

Entre sus propiedades, la medida $M_{0}(k)$ permite ser expresada como el producto de dos intuitivos índices, la proporción de individuos pobres $H(k)$ y la privación media que sufren los mismos $A(k)$. También permite ser descompuesta por grupos poblacionales y por dimensiones/indicadores.

El análisis empírico se realizó a partir de los microdatos de la ECV para la población de 16 y más años. Se seleccionaron deferentes indicadores que dotaron de contenido las dimensiones económica, material, vivienda, entorno, salud, trabajo y educación (igualmente ponderadas). En cada indicador se definieron umbrales de privación en consonancia con la literatura existente. En base a ésta, también se establecieron diferentes criterios de corte $k(k=1 / 7,2 / 7,3 / 7)$ para identificar quién es multidimensionalmente pobre, lo que permitió hacer análisis de sensibilidad a los umbrales seleccionados.

Las tasas de privación (no censuradas) más elevadas en 2008 (y también en 2015) se encuentran en estudios, problema crónico y ruidos; las menos elevadas en ducha e inodoro. De 2008 a 2015, los mayores incrementos se dan en las dimensiones trabajo (BIT), material (PMS) y económica (IDEI); las principales reducciones tienen lugar en el indicador acceso médico, y en las dimensiones vivienda, entorno y estudios. Llamativa es la fuerte reducción de la incidencia en el indicador acceso médico en un periodo caracterizado por importantes ajustes presupuestarios 
que afectaron a los servicios públicos. Como posible explicación, cabe destacar la subjetividad y relatividad en las respuestas proporcionadas por los individuos en la encuesta, siendo probable que el fuerte empeoramiento en las dimensiones trabajo, material y económica difuminen el sentimiento de privación en otras dimensiones o indicadores, relativizándolo.

En el periodo 2008-2015 el comportamiento general ha sido el incremento del índice pobreza multidimensional $M_{0}(k)$, independientemente del criterio de corte $k$, alcanzando sus niveles más altos en el bienio 2013-2014. La incidencia (salvo para $k=1 / 7$ ) y la intensidad también aumentan. El número de personas identificadas como multidimensionalmente pobres en 2015 se aproxima a 18 millones para $k=1 / 7$, roza los 6 millones para $k=2 / 7$ y es de 1,4 millones para $k=3 / 7$. Como era de esperar, los incrementos del umbral $k$ provocan descensos del índice $M_{0}(k)$ y de la proporción de pobres $H(k)$ e incrementos en la intensidad $A(k)$; esto es, reflejan la reducción de la pobreza multidimensional provocada por el descenso en la proporción de personas multidimensionalmente pobres (incidencia), permaneciendo identificados como tal aquellos cuyas privaciones son más elevadas (intensidad).

Descomponiendo $M_{0}(2 / 7)$ por sexo, las mujeres sufren índices de pobreza y de incidencia más altos, produciéndose un proceso de convergencia del 2008 al 2015, sin que haya sido suficiente para el catch up. La intensidad no sólo es mayor en los hombres, sino que su incremento en el periodo también es superior, provocando mayor divergencia en 2015.

Por grupos de edad, el que muestra índices más elevados es el de 50 a 64 años, seguido en 2008 por el de 65 y más años que, dada su fuerte reducción de la pobreza en el período, en 2015 se sitúa como el grupo menos pobre. Los mayores niveles de privación de estos grupos se deben a que parten de tasas de privación (censuradas) más elevadas en las dimensiones educación y salud (y trabajo en el grupo de 50 a 64 años) que, salvo salud, son de las que más contribuyen (después de la económica) a la pobreza multidimensional. La gran mejoría del grupo de 65 y más años se observa de forma generalizada en casi todas las dimensiones e indicadores; otro curioso ejemplo de cómo el sentimiento de relatividad puede estar afectando a los resultados. Los demás grupos incrementan sus indicadores de pobreza. El grupo de 16-24 años se sitúa en 2015 como el segundo más pobre a consecuencia de los incrementos de privación en las dimensiones económica y de trabajo. El comportamiento de la incidencia es similar al del índice de pobreza. En intensidad destaca la población mayor con tasas bastante inferiores al resto de los grupos.

Por tipología de hogar, la mayor presencia de pobreza se da en las familias monoparentales y en las parejas con 3 o más niños/as dependientes, y la menor en las parejas con menos de tres niños/as dependientes, en general durante todo el periodo de análisis y para los diferentes umbrales $k$. Los índices se han incrementado en todos los grupos, a excepción de las parejas sin niños. La intensidad también es mayor en los mismos tipos de hogar (monoparentales, parejas con 3 o más niños/as dependientes y otros hogares con niños/as), incrementándose de 2008 a 2015 en todas las tipologías de hogares con niños dependientes, a excepción de los monoparentales.

Por regiones, emerge el conocido patrón espacial norte-sur. Las más pobres son Extremadura, Andalucía, Castilla-La Mancha y Canarias y, a excepción de Extremadura, se mantienen todo el periodo. Los menores valores los presentan Cantabria, Navarra, Aragón y el País Vasco, manteniéndose también todo el periodo, aunque no en el mismo orden. Extremadura y Galicia son las únicas en las que baja el índice de pobreza, lo que hace que la primera deje de ser la región más pobre y se sitúe en 2015 en posiciones intermedias. Cantabria, Murcia y Canarias sufren los mayores incrementos. La intensidad de la pobreza en 2008 se manifiesta con más fuerza en Canarias y Andalucía; Baleares sufre el mayor aumento, pasando de ocupar la mejor posición en 2008 a situarse en 2015 entre las de mayor intensidad, solo superada por Canarias.

Descomponiendo por dimensiones, las tasas de privación censuradas más altas se dan en las dimensiones educación, económica y trabajo durante todo el periodo. En salud, la privación por existencia de un problema crónico también es alta. Los mayores aumentos se han dado en la 
dimensión trabajo y en la de privación material, y la reducción más fuerte en la dimensión educación. Las dimensiones de educación y económica son las que más contribuyen a la pobreza (casi un 60\%) y la que menos es la dimensión vivienda. El descenso de la privación en educación conjuntamente con el fuerte incremento en la de la dimensión trabajo provocan que en 2015 la segunda supere en contribución a la primera, situándose en segundo lugar, por detrás de la económica.

\section{Referencias}

Alkire, A. (2018). The Research Agenda on Multidimensional Poverty Measurement: Important and As-yet Unanswered Questions. OPHI Working Paper, 119. University of Oxford.

Alkire, S., \& Apablaza, M. (2016). Multidimensional poverty in Europe 2006-2012: illustrating a methodology. OPHI Working paper, 74. Recuperado de http://www.ophi.org.uk/

Alkire, S., Apablaza, M., \& Jung, E. (2014). Multidimensional Poverty Measurement for EUSILC Countries. OPHI Research in Progress, 36c. Recuperado de http://www.ophi.org.uk/

Alkire, S., Foster, J., Seth, S., Santos, M., Roche, J., \& Ballon, P. (2015a). Multidimensional Poverty Measurement and Analysis: The Alkire-Foster Counting Methodology. OPHI Working paper, 86. Recuperado de http://www.ophi.org.uk/

Alkire, S., Foster, J., Seth, S., Santos, M., Roche, J., \& Ballon, P. (2015b). Multidimensional Poverty Measurement and Analysis: Normative Choices in Measurement Design. OPHI Working Paper, 87. Recuperado de http://www.ophi.org.uk/

Alkire, S., \& Foster, J. (2007). Counting and multidimensional poverty measurement. OPHI Working Paper, 7. University of Oxford.

Alkire, S., \& Foster, J. (2009). Counting and Multidimensional Poverty Measurement (revised and updated). OPHI Working Paper, 32. University of Oxford.

Alkire, S., \& Foster, J. (2011). Counting and multidimensional poverty measurement. Journal of Public Economics, 95(7-8), 476-487.

Alkire, S., \& Santos, M. (2010). Acute Multidimensional Poverty: A New Index for Developing Countries. Human Development Research Paper (11). Recuperado de http://hdr.undp.org/sites/default/files/hdrp_2010_11.pdf

Alkire, S., \& Summer, A. (2013). Multidimensional poverty and the post-2015 MDGs. Development, 56(1), 46-51.

Angulo, R.C., Díaz, Y., \& Pardo, R. (2011). Índice de Pobreza Multidimensional para Colombia. Archivos de Economía, 382. Departamento Nacional de Planeación.

Argüeso, A., Escudero, T., Méndez, J.M., \& Izquierdo, M.J. (2014). Alternativas en la construcción de un indicador multidimensional de calidad de vida. Estadística Española, 56(184), 147-196. 
Artavia, M. (2016). Medición multidimensional de la pobreza: una propuesta exploratoria para Costa Rica. Revista Estudios de Politicas Públicas, 1(1), 138-159.

Atkinson, A. B., Marlier, T., Nolan, B.c, \& Vandenbroucke, F. (2002). Social indicators: The EU and social inclusion. Oxford: Oxford University Press.

Boarini, R., \& d'Ercole, M.M. (2013). Going beyond GDP: An OECD perspective. Fiscal Studies, 34(3), 289-314.

Busch, C., \& Peichl, A. (2010). The Development of Multidimensional Poverty in Germany 19852007. IZA Discussion paper series, 4922, 1-43. Recuperado de http://legacy.iza.org/

Castillo, R., \& Jácome, F. (2015). Medición de la Pobreza Multidimensional en Ecuador. INEC, 1, 15-25.

Corbelle, F. (2017). Pobreza: conceptos, enfoques y métodos de análisis. Tres ensayos de medición aplicada: España y eurorregión Galicia-Norte de Portugal (tesis doctoral). Universidad de Santiago de Compostela, Santiago de Compostela, España. Recuperado de https://minerva.usc.es/xmlui/handle/10347/15678

European Commission (EC) (s.f.). Beyond GDP: Measuring progress, true wealth, and wellbeing. 2007 conference. Recuperado de http://ec.europa.eu/environment/beyond_gdp/2007_conference_en.html

European Commission (EC) (2010). Comunicación de la Comisión. Europa 2020. Una estrategia para un crecimiento inteligente, sostenible e integrador. Bruselas, 3.3.2010 COM(2010) 2020 final. Recuperado de https:/eurlex.europa.eu/LexUriServ/LexUriServ.do?uri=COM:2010:2020:FIN:ES:PDF

Eurostat (s.f.a). Quality of life. Recuperado de http://ec.europa.eu/eurostat/cache/infographs/qol/index_en.html

Eurostat (s.f.b). Statistics explained. Material deprivation statistics - early results. Recuperado de https://ec.europa.eu/eurostat/statisticsexplained/index.php?title=Material_deprivation_statistics_-_early_results

Eurostat (s.f.c). Statistics explained. Glossary: Overcrowding rate. Recuperado de https://ec.europa.eu/eurostat/statistics-explained/index.php/Glossary:Overcrowding_rate

Eurostat (s.f.d). Statistics explained. Glossary:Persons living in households with low work intensity. Recuperado de https://ec.europa.eu/eurostat/statisticsexplained/index.php/Glossary:Persons_living_in_households_with_low_work_intensity

Eurostat (2008 - 2016). European Union Statistics On Income And Living Conditions (EU-SILC). European Commission: Luxembourg. Recuperado de http://ec.europa.eu/eurostat/

INE (2005). Metodología ECV. Revisada 2013. Recuperado de http://www.ine.es/daco/daco42/condivi/ecv_metodo.pdf el 13/01/2017

INE (2008-2015). Encuesta de Condiciones de Vida (ECV). Recuperado de http://www.ine.es/ 
Larrú, J.M. (2016). Medición multidimensional de la pobreza: estado de la cuestión y aplicación al ODS-1. Revista Internacional de Cooperación y Desarrollo, 3(1), 4-34.

Llano, J.C. (2015). El estado de la pobreza. Seguimiento del indicador de pobreza y exclusión social en España 2009-2014. Madrid, España: EAPN ESPAÑA. Recuperado de https://www.eapn.es/estadodepobreza/ARCHIVO/documentos/Informe_AROPE_2015.pdf

Llano, J.C. (2018). El estado de la pobreza. Seguimiento del indicador de pobreza y exclusión social en España 2008-2017. Madrid, España: EAPN ESPAÑA. Recuperado de https://www.eapn.es/estadodepobreza/ARCHIVO/documentos/Informe_AROPE_2018.pdf

López-Menéndez, A.J. (2015). Reflexiones, retos y experiencias en la medición del bienestar y el buen vivir. En INEC (Ed.). Experiencias y metodologías internacionales de medición del bienestar: una referencia para el Buen Vivir de Ecuador (pp.197-216). Instituto Nacional de Estadística y Censos, Quito.

Martínez, R. (2017). Multidimensional deprivation and poverty: three essays based on EU-SILC data (tesis de doctorado). Universidad Rey Juan Carlos, Madrid, España. Recuperado de https://www.educacion.gob.es/teseo/imprimirFicheroTesis.do?idFichero=sqSFgWieiLQ\%3 $\mathrm{D}$

Méndez, J.M., Paniagua, M.M., \& Sánchez, M. (2008). La incidencia del alquiler o la propiedad de la vivienda en la medición de la pobreza en España. Economistas, 117, 93-98.

Mohanty, S.K. (2011). Multidimensional poverty and child survival in India. PLoS ONE 6(10): e26857.

Multidimensional Poverty Peer Network (MPPN) (s.f.). Red de pobreza multidimensional. Recuperado de https://www.mppn.org/es/

Nussbaum, M. (2000). Women and Human Development: the capabilities approach. New York: Cambridge University Press.

OECD/EU/JRC (2008). Handbook on Constructing Composite Indicators: Methodology and User Guide. OECD Publishing, Paris. DOI: 10.1787/9789264043466-en.

OECD (s.f.). Measuring Well-being and Progress: Well-being Research. Recuperado de http://www.oecd.org/statistics/measuring-well-being-and-progress.htm.

OECD (2019). Measuring Distance to the SDG Targets 2019. An Assessment of Where OECD Countries Stand. París: OECD Publishing.

ONU (2015). Transformar nuestro mundo: la Agenda 2030 para el Desarrollo Sostenible. Resolución: A/RES/70/1, pp. 1-40. Recuperado de http://www.un.org/es/comun/docs/?symbol=A/RES/70/1

PNUD (2010). Human Development Report. New York: Palgrave Macmillan. 
Poza, C., \& Fernández, J.A. (2010). Una aproximación a la construcción de un indicador de pobreza multidimensional. ¿Cuáles son los focos de riesgo en España? Revista de Métodos Cuantitativos para la Economía y la Empresa, 10, 43-72.

Prieto, M., González, Y., \& García, C. (2016). La pobreza en España desde una perspectiva multidimensional. Revista de economía aplicada, 24(70), 77-110.

Rogan, M. (2016). Gender and multidimensional poverty in South Africa: Applying the global multidimensional poverty index (MPI). Social Indicators Research, 126(3), 987-1006.

Rowntree, B.S. (1901). A Study of Town Life. London: Macmillan.

Sen, A. (1983). Poor, relatively speaking. Oxford Economic Papers, 35, 153-169.

Sen, A. (1985). Commodities and capabilities. Oxford: Elsevier Science.

Suppa, N. (2015). Towards a Multidimensional Poverty Index for Germany. OPHI Working papers, 98, University of Oxford. Recuperado de http://www.ophi.org.uk/

Suppa, N. (2016). Comparing monetary and multidimensional poverty in Germany. OPHI Working Paper, 103, University of Oxford. Recuperado de http://www.ophi.org.uk/

Urbanos, R., \& Puig-Junoy, J. (2014). Políticas de austeridad y cambios en las pautas de uso de los servicios sanitarios. Informe SESPAS 2014. Gaceta Sanitaria, 28 (Supl. 1), 81-88.

Whelan, C., Nolan, B., \& Maître, B. (2012). Multidimensional poverty measurement in Europe: An application of the adjusted headcount approach. UCD Discussion Paper Series, WP2012/11. Recuperado de http://www.ucd.ie/

Zugasti, N., \& Laparra, M. (2017). Midiendo la pobreza a nivel autonómico en España. Una propuesta reflexiva. Revista Española de Investigaciones Sociológicas, 158, 117-134. 


\section{Anexo}

Tabla A1. Tasas de privación (\%).

\begin{tabular}{|c|c|c|c|c|c|c|c|c|c|c|c|}
\hline Dimensión & Indicador & 2008 & 2009 & 2010 & 2011 & 2012 & 2013 & 2014 & 2015 & Diferencias 15 vs. 08 (pp.) & TV 15 vs.08 (\%) \\
\hline Económica & IDEI & 15,12 & 15,36 & 15,94 & 16,09 & 17,30 & 17,18 & 18,06 & 17,84 & 2,71 & 17,94 \\
\hline Material & PMS & 3,20 & 4,09 & 4,50 & 4,37 & 5,52 & 5,71 & 6,59 & 5,89 & 2,69 & 84,09 \\
\hline \multirow[t]{5}{*}{ Vivienda } & Hacinamiento & 1,71 & 1,34 & 0,94 & 1,57 & 1,33 & 1,23 & 1,07 & 0,96 & $-0,75$ & $-43,87$ \\
\hline & Humedades & 16,84 & 18,14 & 21,52 & 15,78 & 11,98 & 16,42 & 16,79 & 14,81 & $-2,03$ & $-12,06$ \\
\hline & Luz natural & 5,78 & 6,95 & 5,50 & 4,35 & 4,25 & 6,39 & 4,95 & 3,81 & $-1,97$ & $-34,03$ \\
\hline & Ducha & 0,11 & 0,01 & 0,00 & 0,02 & 0,08 & 0,10 & 0,12 & 0,09 & $-0,01$ & $-13,76$ \\
\hline & Inodoro & 0,07 & 0,01 & 0,00 & 0,01 & 0,08 & 0,10 & 0,11 & 0,08 & 0,01 & 8,37 \\
\hline \multirow[t]{3}{*}{ Entorno } & Ruidos & 22,18 & 22,66 & 18,29 & 15,73 & 14,92 & 18,36 & 15,98 & 15,38 & $-6,81$ & $-30,69$ \\
\hline & Contaminación & 13,07 & 13,60 & 10,58 & 8,17 & 7,94 & 9,86 & 9,98 & 10,15 & $-2,92$ & $-22,35$ \\
\hline & Delincuencia & 14,80 & 16,55 & 12,91 & 10,90 & 10,31 & 14,58 & 11,80 & 9,96 & $-4,84$ & $-32,72$ \\
\hline \multirow[t]{5}{*}{ Salud } & Estado salud & 7,92 & 8,56 & 8,03 & 7,36 & 8,03 & 8,36 & 8,21 & 7,41 & $-0,51$ & $-6,44$ \\
\hline & Problema crónico & 29,72 & 30,17 & 29,38 & 22,93 & 26,08 & 31,50 & 29,64 & 32,74 & 3,02 & 10,16 \\
\hline & Limitación grave & 5,35 & 5,61 & 5,34 & 4,70 & 5,10 & 5,36 & 5,36 & 5,14 & $-0,21$ & $-3,88$ \\
\hline & Acceso médico & 2,59 & 2,67 & 2,24 & 1,93 & 2,36 & 2,67 & 1,97 & 0,66 & $-1,93$ & $-74,43$ \\
\hline & Acceso dentista & 5,21 & 5,52 & 5,81 & 4,45 & 7,25 & 8,26 & 8,16 & 5,18 & $-0,03$ & $-0,56$ \\
\hline Trabajo & BIT & 7,20 & 8,06 & 10,66 & 13,09 & 13,68 & 14,38 & 15,12 & 14,04 & 6,84 & 95,04 \\
\hline Educación & Estudios & 32,35 & 30,94 & 30,08 & 30,87 & 28,65 & 27,15 & 25,62 & 25,26 & $-7,09$ & $-21,92$ \\
\hline
\end{tabular}

Nota: pp. - puntos porcentuales.

Fuente: Elaboración propia a partir de los microdatos de la ECV. 
Tabla A2. Índice de pobreza multidimensional M0 (k), subíndices H (k) y A (k) y nº de personas multidimensionalmente pobres.

\begin{tabular}{|c|c|c|c|c|c|c|c|c|c|c|c|c|}
\hline \multirow[b]{2}{*}{$\mathrm{k}$} & \multicolumn{4}{|c|}{2008} & \multicolumn{4}{|c|}{2009} & \multicolumn{4}{|c|}{2010} \\
\hline & $\mathrm{N}^{\circ}$ personas & $\mathrm{H}$ & $\mathrm{A}$ & $\mathrm{M}_{0}$ & $\mathrm{~N}^{\circ}$ personas & $\mathrm{H}$ & $\mathrm{A}$ & $\mathrm{M}_{0}$ & $\mathrm{~N}^{\circ}$ personas & $\mathrm{H}$ & $\mathrm{A}$ & $\mathrm{M}_{0}$ \\
\hline $1 / 7$ & 17.949 .768 & 0,47 & 0,236 & 0,111 & 17.968 .841 & 0,466 & 0,24 & 0,112 & 18.168 .060 & 0,469 & 0,241 & 0,113 \\
\hline $2 / 7$ & 5.003 .565 & 0,131 & 0,368 & 0,048 & 5.284 .266 & 0,137 & 0,372 & 0,051 & 5.508 .538 & 0,142 & 0,375 & 0,053 \\
\hline \multirow[t]{2}{*}{$3 / 7$} & 992.044 & 0,026 & 0,512 & 0,013 & 1.080 .254 & 0,028 & 0,522 & 0,015 & 1.215 .886 & 0,031 & 0,521 & 0,016 \\
\hline & \multicolumn{4}{|c|}{2011} & \multicolumn{4}{|c|}{2012} & \multicolumn{4}{|c|}{2013} \\
\hline $\mathrm{k}$ & $\mathrm{N}^{\circ}$ personas & $\mathrm{H}$ & $\mathrm{A}$ & $\mathrm{M}_{0}$ & $\mathrm{~N}^{\circ}$ personas & $\mathrm{H}$ & $\mathrm{A}$ & $\mathrm{M}_{0}$ & $\mathrm{~N}^{\circ}$ personas & $\mathrm{H}$ & $\mathrm{A}$ & $\mathrm{M}_{0}$ \\
\hline $1 / 7$ & 18.542 .001 & 0,478 & 0,237 & 0,113 & 18.413 .106 & 0,474 & 0,243 & 0,115 & 18.354 .955 & 0,474 & 0,252 & 0,119 \\
\hline $2 / 7$ & 5.812 .701 & 0,15 & 0,373 & 0,056 & 6.021 .194 & 0,155 & 0,377 & 0,058 & 6.165 .685 & 0,159 & 0,387 & 0,062 \\
\hline \multirow[t]{2}{*}{$3 / 7$} & 1.218 .593 & 0,031 & 0,529 & 0,017 & 1.356 .792 & 0,035 & 0,532 & 0,019 & 1.661 .953 & 0,043 & 0,531 & 0,023 \\
\hline & \multicolumn{4}{|c|}{2014} & \multicolumn{4}{|c|}{2015} & & & & \\
\hline $\mathrm{k}$ & $\mathrm{N}^{\circ}$ personas & $\mathrm{H}$ & $\mathrm{A}$ & $\mathrm{M}_{0}$ & $\mathrm{~N}^{\circ}$ personas & $\mathrm{H}$ & $\mathrm{A}$ & $\mathrm{M}_{0}$ & & & & \\
\hline $1 / 7$ & 18.116 .149 & 0,471 & 0,252 & 0,119 & 17.707 .618 & 0,46 & 0,245 & 0,113 & & & & \\
\hline $2 / 7$ & 6.284 .372 & 0,163 & 0,386 & 0,063 & 5.880 .498 & 0,153 & 0,38 & 0,057 & & & & \\
\hline $3 / 7$ & 1.687 .611 & 0,044 & 0,531 & 0,023 & 1.394 .708 & 0,036 & 0,523 & 0,019 & & & & \\
\hline
\end{tabular}

Fuente: Elaboración propia a partir de los microdatos de la ECV. 
Tabla A3. M0 (k), H (k), A (k) y nº de personas multidimensionalmente pobres. Clasificación subgrupos: sexo.

\begin{tabular}{|c|c|c|c|c|c|c|c|c|c|c|c|c|c|}
\hline & & & 2008 & & & & 2009 & & & & 2010 & & \\
\hline $\mathrm{k}$ & Subgrupo & $\mathrm{N}^{\circ}$ personas & $\mathrm{H}$ & A & $\mathrm{M}_{0}$ & $\mathrm{~N}^{\circ}$ personas & $\mathrm{H}$ & $\mathrm{A}$ & $\mathrm{M}_{0}$ & $\mathrm{~N}^{\circ}$ personas & $\mathrm{H}$ & A & $\mathrm{M}_{0}$ \\
\hline \multirow{2}{*}{$1 / 7$} & Hombres & 8.318 .382 & 0,443 & 0,235 & 0,104 & 8.351 .321 & 0,44 & 0,237 & 0,104 & 8.480 .050 & 0,446 & 0,241 & 0,108 \\
\hline & Mujeres & 9.631 .386 & 0,496 & 0,236 & 0,117 & 9.617 .521 & 0,49 & 0,243 & 0,119 & 9.688 .010 & 0,491 & 0,242 & 0,119 \\
\hline \multirow{2}{*}{$2 / 7$} & Hombres & 2.346 .971 & 0,125 & 0,368 & 0,046 & 2.392 .507 & 0,126 & 0,37 & 0,047 & 2.552 .634 & 0,134 & 0,38 & 0,051 \\
\hline & Mujeres & 2.656 .593 & 0,137 & 0,367 & 0,05 & 2.891 .759 & 0,147 & 0,373 & 0,055 & 2.955 .904 & 0,15 & 0,371 & 0,056 \\
\hline \multirow{2}{*}{$3 / 7$} & Hombres & 473.341 & 0,025 & 0,515 & 0,013 & 488.302 & 0,026 & 0,525 & 0,014 & 613.240 & 0,032 & 0,524 & 0,017 \\
\hline & Mujeres & 518.703 & 0,027 & 0,508 & 0,014 & 591.952 & 0,03 & 0,519 & 0,016 & 602.646 & 0,031 & 0,518 & 0,016 \\
\hline & & \multicolumn{4}{|c|}{2011} & \multicolumn{4}{|c|}{2012} & \multicolumn{4}{|c|}{2013} \\
\hline $\mathrm{k}$ & Subgrupo & $\mathrm{N}^{\circ}$ personas & $\mathrm{H}$ & A & $\mathrm{M}_{0}$ & $\mathrm{~N}^{\circ}$ personas & $\mathrm{H}$ & A & $\mathrm{M}_{0}$ & $\mathrm{~N}^{\circ}$ personas & $\mathrm{H}$ & A & $\mathrm{M}_{0}$ \\
\hline \multirow{2}{*}{$1 / 7$} & Hombres & 8.658 .553 & 0,455 & 0,236 & 0,107 & 8.552 .829 & 0,45 & 0,245 & 0,11 & 8.613 .808 & 0,455 & 0,253 & 0,115 \\
\hline & Mujeres & 9.883 .448 & 0,5 & 0,238 & 0,119 & 9.860 .277 & 0,497 & 0,241 & 0,12 & 9.741 .147 & 0,492 & 0,251 & 0,123 \\
\hline \multirow{2}{*}{$2 / 7$} & Hombres & 2.704 .338 & 0,142 & 0,374 & 0,053 & 2.883 .253 & 0,152 & 0,381 & 0,058 & 2.946 .439 & 0,156 & 0,392 & 0,061 \\
\hline & Mujeres & 3.108 .363 & 0,157 & 0,372 & 0,058 & 3.137 .941 & 0,158 & 0,374 & 0,059 & 3.219 .246 & 0,163 & 0,383 & 0,062 \\
\hline \multirow{2}{*}{$3 / 7$} & Hombres & 585.197 & 0,031 & 0,528 & 0,016 & 687.209 & 0,036 & 0,534 & 0,019 & 873.786 & 0,046 & 0,527 & 0,024 \\
\hline & Mujeres & 633.396 & 0,032 & 0,529 & 0,017 & 669.583 & 0,034 & 0,53 & 0,018 & 788.167 & 0,04 & 0,536 & 0,021 \\
\hline & & \multicolumn{4}{|c|}{2014} & \multicolumn{4}{|c|}{2015} & & & & \\
\hline $\mathrm{k}$ & Subgrupo & $\mathrm{N}^{\circ}$ personas & $\mathrm{H}$ & A & $\mathrm{M}_{0}$ & $\mathrm{~N}^{\circ}$ personas & $\mathrm{H}$ & $\mathrm{A}$ & $\mathrm{M}_{0}$ & & & & \\
\hline \multirow{2}{*}{$1 / 7$} & Hombres & 8.347 .049 & 0,445 & 0,252 & 0,112 & 8.267 .413 & 0,441 & 0,246 & 0,108 & & & & \\
\hline & Mujeres & 9.769 .101 & 0,495 & 0,252 & 0,125 & 9.440 .206 & 0,478 & 0,244 & 0,117 & & & & \\
\hline \multirow{2}{*}{$2 / 7$} & Hombres & 2.927.288 & 0,156 & 0,389 & 0,061 & 2.803 .472 & 0,149 & 0,379 & 0,057 & & & & \\
\hline & Mujeres & 3.357 .085 & 0,17 & 0,384 & 0,065 & 3.077 .025 & 0,156 & 0,374 & 0,058 & & & & \\
\hline \multirow{2}{*}{$3 / 7$} & Hombres & 789.392 & 0,042 & 0,535 & 0,023 & 707.427 & 0,038 & 0,523 & 0,02 & & & & \\
\hline & Mujeres & 898.219 & 0,046 & 0,528 & 0,024 & 687.282 & 0,035 & 0,524 & 0,018 & & & & \\
\hline
\end{tabular}

Fuente: Elaboración propia a partir de los microdatos de la ECV. 
Tabla A4. M0 (k), H (k), A (k) y nº de personas multidimensionalmente pobres. Clasificación subgrupos: grupos de edad.

\begin{tabular}{|c|c|c|c|c|c|c|c|c|c|c|c|c|c|c|c|c|c|}
\hline \multirow[b]{2}{*}{$\mathrm{k}$} & \multirow[b]{2}{*}{ Subgrupo } & \multicolumn{4}{|c|}{2008} & \multicolumn{4}{|c|}{2009} & \multicolumn{4}{|c|}{2010} & \multicolumn{4}{|c|}{2011} \\
\hline & & $\begin{array}{c}\mathrm{N}^{\circ} \\
\text { personas }\end{array}$ & $\mathrm{H}$ & A & $\mathrm{M}_{0}$ & $\begin{array}{c}\mathrm{N}^{\circ} \\
\text { personas }\end{array}$ & $\mathrm{H}$ & A & $\mathrm{M}_{0}$ & $\mathrm{~N}^{\circ}$ personas & $\mathrm{H}$ & A & $\mathrm{M}_{0}$ & $\begin{array}{c}\mathrm{N}^{\circ} \\
\text { personas }\end{array}$ & $\mathrm{H}$ & A & $\mathrm{M}_{0}$ \\
\hline \multirow{5}{*}{$1 / 7$} & $16-24$ años & 1.682 .767 & 0,361 & 0,241 & 0,087 & 1.647 .903 & 0,36 & 0,241 & 0,087 & 1.733 .903 & 0,389 & 0,248 & 0,096 & 1.653 .495 & 0,381 & 0,242 & 0,092 \\
\hline & 25 - 34 años & 2.082 .772 & 0,269 & 0,231 & 0,062 & 2.102 .599 & 0,275 & 0,242 & 0,067 & 2.222 .909 & 0,299 & 0,243 & 0,073 & 2.297 .612 & 0,321 & 0,247 & 0,079 \\
\hline & 35 - 49 años & 3.866 .084 & 0,357 & 0,24 & 0,086 & 3.841 .302 & 0,348 & 0,246 & 0,085 & 3.939 .904 & 0,351 & 0,255 & 0,09 & 4.043 .824 & 0,356 & 0,253 & 0,09 \\
\hline & 50 - 64 años & 4.514 .919 & 0,586 & 0,246 & 0,144 & 4.554 .212 & 0,578 & 0,254 & 0,146 & 4.426 .935 & 0,55 & 0,253 & 0,139 & 4.546 .047 & 0,553 & 0,252 & 0,14 \\
\hline & 65 y más & 5.803 .227 & 0,796 & 0,224 & 0,179 & 5.822 .825 & 0,784 & 0,226 & 0,177 & 5.844 .410 & 0,772 & 0,221 & 0,17 & 6.001 .023 & 0,777 & 0,209 & 0,163 \\
\hline \multirow{5}{*}{$2 / 7$} & $16-24$ años & 556.621 & 0,119 & 0,37 & 0,044 & 528.888 & 0,115 & 0,377 & 0,044 & 639.950 & 0,144 & 0,379 & 0,054 & 579.593 & 0,133 & 0,385 & 0,051 \\
\hline & 25 - 34 años & 577.783 & 0,075 & 0,374 & 0,028 & 703.151 & 0,092 & 0,37 & 0,034 & 729.241 & 0,098 & 0,381 & 0,037 & 909.425 & 0,127 & 0,364 & 0,046 \\
\hline & 35 - 49 años & 1.197 .469 & 0,111 & 0,373 & 0,041 & 1.219 .391 & 0,11 & 0,384 & 0,042 & 1.408 .415 & 0,126 & 0,391 & 0,049 & 1.550 .124 & 0,136 & 0,387 & 0,053 \\
\hline & 50 - 64 años & 1.473 .177 & 0,191 & 0,376 & 0,072 & 1.606 .541 & 0,204 & 0,379 & 0,077 & 1.647 .080 & 0,204 & 0,374 & 0,076 & 1.780 .520 & 0,216 & 0,375 & 0,081 \\
\hline & 65 y más & 1.198 .514 & 0,164 & 0,349 & 0,057 & 1.226 .295 & 0,165 & 0,35 & 0,058 & 1.083 .853 & 0,143 & 0,349 & 0,05 & 993.039 & 0,129 & 0,348 & 0,045 \\
\hline \multirow{5}{*}{$3 / 7$} & $16-24$ años & 114.049 & 0,024 & 0,51 & 0,012 & 125.325 & 0,027 & 0,515 & 0,014 & 175.074 & 0,039 & 0,511 & 0,02 & 156.145 & 0,036 & 0,533 & 0,019 \\
\hline & 25 - 34 años & 160.241 & 0,021 & 0,494 & 0,01 & 173.059 & 0,023 & 0,504 & 0,011 & 165.020 & 0,022 & 0,526 & 0,012 & 157.893 & 0,022 & 0,519 & 0,011 \\
\hline & 35 - 49 años & 279.251 & 0,026 & 0,524 & 0,014 & 300.950 & 0,027 & 0,545 & 0,015 & 409.256 & 0,036 & 0,529 & 0,019 & 385.785 & 0,034 & 0,538 & 0,018 \\
\hline & 50 - 64 años & 317.027 & 0,041 & 0,518 & 0,021 & 383.992 & 0,049 & 0,519 & 0,025 & 360.260 & 0,045 & 0,523 & 0,023 & 422.166 & 0,051 & 0,53 & 0,027 \\
\hline & 65 y más & 121.475 & 0,017 & 0,494 & 0,008 & 96.927 & 0,013 & 0,505 & 0,007 & 106.277 & 0,014 & 0,492 & 0,007 & 96.604 & 0,013 & 0,492 & 0,006 \\
\hline
\end{tabular}

\begin{tabular}{|c|c|c|c|c|c|c|c|c|c|c|c|c|c|c|c|c|c|}
\hline \multirow[b]{2}{*}{$\mathrm{k}$} & \multirow[b]{2}{*}{ Subgrupo } & \multicolumn{4}{|c|}{2012} & \multicolumn{4}{|c|}{2013} & \multicolumn{4}{|c|}{2014} & \multicolumn{4}{|c|}{2015} \\
\hline & & $\begin{array}{c}\mathrm{N}^{\circ} \\
\text { personas }\end{array}$ & $\mathrm{H}$ & A & $\mathrm{M}_{0}$ & $\begin{array}{c}\mathrm{N}^{\circ} \\
\text { personas }\end{array}$ & $\mathrm{H}$ & A & $\mathrm{M}_{0}$ & $\mathrm{~N}^{\circ}$ personas & $\mathrm{H}$ & A & $\mathrm{M}_{0}$ & $\mathrm{~N}^{\circ}$ personas & $\mathrm{H}$ & A & $\mathrm{M}_{0}$ \\
\hline \multirow{5}{*}{$1 / 7$} & $16-24$ años & 1.713 .468 & 0,403 & 0,254 & 0,102 & 1.702 .673 & 0,41 & 0,263 & 0,108 & 1.621 .164 & 0,4 & 0,268 & 0,107 & 1.671 .634 & 0,416 & 0,256 & 0,107 \\
\hline & 25 - 34 años & 2.216 .522 & 0,324 & 0,259 & 0,084 & 2.181 .302 & 0,336 & 0,26 & 0,087 & 2.142 .924 & 0,35 & 0,27 & 0,094 & 1.885 .183 & 0,322 & 0,254 & 0,082 \\
\hline & 35 - 49 años & 4.023 .234 & 0,35 & 0,261 & 0,091 & 4.095 .217 & 0,355 & 0,277 & 0,098 & 4.094 .666 & 0,356 & 0,273 & 0,097 & 3.869 .696 & 0,337 & 0,268 & 0,09 \\
\hline & 50 - 64 años & 4.555 .957 & 0,542 & 0,259 & 0,14 & 4.544 .493 & 0,531 & 0,264 & 0,14 & 4.554 .512 & 0,525 & 0,269 & 0,141 & 4.489 .345 & 0,506 & 0,264 & 0,134 \\
\hline & 65 y más & 5.903 .925 & 0,753 & 0,209 & 0,158 & 5.831 .269 & 0,731 & 0,217 & 0,159 & 5.702 .883 & 0,7 & 0,211 & 0,148 & 5.791 .761 & 0,699 & 0,209 & 0,146 \\
\hline \multirow{3}{*}{$2 / 7$} & $16-24$ años & 713.192 & 0,168 & 0,372 & 0,062 & 726.370 & 0,175 & 0,382 & 0,067 & 735.185 & 0,181 & 0,389 & 0,071 & 752.551 & 0,187 & 0,365 & 0,068 \\
\hline & 25 - 34 años & 898.984 & 0,131 & 0,39 & 0,051 & 835.811 & 0,129 & 0,401 & 0,052 & 955.713 & 0,156 & 0,384 & 0,06 & 754.509 & 0,129 & 0,373 & 0,048 \\
\hline & 35 - 49 años & 1.651 .518 & 0,144 & 0,386 & 0,055 & 1.845 .494 & 0,16 & 0,398 & 0,064 & 1.812 .504 & 0,158 & 0,393 & 0,062 & 1.735 .609 & 0,151 & 0,384 & 0,058 \\
\hline
\end{tabular}




\begin{tabular}{|c|c|c|c|c|c|c|c|c|c|c|c|c|c|c|c|c|c|}
\hline & \multirow{2}{*}{$\begin{array}{c}50 \text { - } 64 \text { años } \\
65 \text { y más }\end{array}$} & 1.915 .997 & 0,228 & 0,376 & 0,086 & 1.821 .697 & 0,213 & 0,387 & 0,082 & 1.959 .172 & 0,226 & 0,392 & 0,088 & 1.870 .074 & 0,211 & 0,385 & 0,081 \\
\hline & & 841.502 & 0,107 & 0,354 & 0,038 & 936.312 & 0,117 & 0,355 & 0,042 & 821.798 & 0,101 & 0,357 & 0,036 & 767.754 & 0,093 & 0,353 & 0,033 \\
\hline \multirow{5}{*}{$3 / 7$} & 16 - 24 años & 161.791 & 0,038 & 0,507 & 0,019 & 203.188 & 0,049 & 0,52 & 0,025 & 210.565 & 0,052 & 0,525 & 0,027 & 155.260 & 0,039 & 0,517 & 0,02 \\
\hline & 25 - 34 años & 255.154 & 0,037 & 0,543 & 0,02 & 283.110 & 0,044 & 0,533 & 0,023 & 259.988 & 0,043 & 0,524 & 0,022 & 177.792 & 0,03 & 0,518 & 0,016 \\
\hline & 35 - 49 años & 426.056 & 0,037 & 0,535 & 0,02 & 603.054 & 0,052 & 0,529 & 0,028 & 559.993 & 0,049 & 0,537 & 0,026 & 479.456 & 0,042 & 0,531 & 0,022 \\
\hline & 50 - 64 años & 418.409 & 0,05 & 0,536 & 0,027 & 452.478 & 0,053 & 0,545 & 0,029 & 549.305 & 0,063 & 0,538 & 0,034 & 494.852 & 0,056 & 0,524 & 0,029 \\
\hline & 65 y más & 95.382 & 0,012 & 0,513 & 0,006 & 120.123 & 0,015 & 0,502 & 0,008 & 107.760 & 0,013 & 0,501 & 0,007 & 87.348 & 0,011 & 0,499 & 0,005 \\
\hline
\end{tabular}

Fuente: Elaboración propia a partir de los microdatos de la ECV. 
Tabla A5. $\mathbf{M}_{0}(\mathrm{k}), \mathrm{H}(\mathrm{k}), \mathrm{A}(\mathrm{k})$ y $\mathrm{n}^{\circ}$ de personas multidimensionalmente pobres. Clasificación subgrupos: tipología del hogar.

\begin{tabular}{|c|c|c|c|c|c|c|c|c|c|c|c|c|c|c|c|c|c|}
\hline \multirow[b]{2}{*}{$\mathrm{k}$} & \multirow[b]{2}{*}{ Subgrupo } & \multicolumn{4}{|c|}{2008} & \multicolumn{4}{|c|}{2009} & \multicolumn{4}{|c|}{2010} & \multicolumn{4}{|c|}{2011} \\
\hline & & $\begin{array}{c}\mathrm{N}^{\circ} \\
\text { personas }\end{array}$ & $\mathrm{H}$ & A & $\mathrm{M}_{0}$ & $\begin{array}{c}\mathrm{N}^{\circ} \\
\text { personas }\end{array}$ & $\mathrm{H}$ & A & $\mathrm{M}_{0}$ & $\begin{array}{c}\mathrm{N}^{\circ} \\
\text { personas }\end{array}$ & $\mathrm{H}$ & A & $\mathrm{M}_{0}$ & $\begin{array}{c}\mathrm{N}^{\circ} \\
\text { personas }\end{array}$ & $\mathrm{H}$ & A & $\mathrm{M}_{0}$ \\
\hline \multirow{8}{*}{$1 / 7$} & Tipo 1 & 2.192 .340 & 0,583 & 0,236 & 0,137 & 2.226 .834 & 0,569 & 0,238 & 0,135 & 2.342 .887 & 0,58 & 0,24 & 0,139 & 2.369 .747 & 0,576 & 0,235 & 0,136 \\
\hline & Tipo 2 & 4.911 .933 & 0,535 & 0,239 & 0,128 & 5.044 .417 & 0,528 & 0,24 & 0,127 & 5.227 .994 & 0,532 & 0,236 & 0,125 & 5.512 .902 & 0,553 & 0,229 & 0,126 \\
\hline & Tipo 3 & 4.409 .604 & 0,486 & 0,222 & 0,108 & 4.243 .608 & 0,479 & 0,228 & 0,109 & 4.235 .935 & 0,492 & 0,23 & 0,113 & 4.272 .180 & 0,517 & 0,237 & 0,123 \\
\hline & Tipo 4 & 221.558 & 0,468 & 0,283 & 0,132 & 250.595 & 0,554 & 0,285 & 0,158 & 341.812 & 0,541 & 0,313 & 0,169 & 340.984 & 0,506 & 0,268 & 0,135 \\
\hline & Tipo 5 & 1.353 .451 & 0,325 & 0,226 & 0,073 & 1.294 .092 & 0,308 & 0,248 & 0,076 & 1.230 .020 & 0,284 & 0,239 & 0,068 & 1.390 .722 & 0,309 & 0,234 & 0,072 \\
\hline & Tipo 6 & 1.304 .148 & 0,293 & 0,218 & 0,064 & 1.571 .757 & 0,337 & 0,225 & 0,076 & 1.581 .582 & 0,336 & 0,24 & 0,081 & 1.588 .129 & 0,327 & 0,233 & 0,076 \\
\hline & Tipo 7 & 545.770 & 0,506 & 0,283 & 0,143 & 534.644 & 0,503 & 0,275 & 0,138 & 532.604 & 0,506 & 0,272 & 0,138 & 561.659 & 0,498 & 0,264 & 0,131 \\
\hline & Tipo 8 & 3.010 .964 & 0,498 & 0,25 & 0,124 & 2.802 .895 & 0,478 & 0,256 & 0,123 & 2.673 .668 & 0,485 & 0,257 & 0,125 & 2.502 .950 & 0,472 & 0,252 & 0,119 \\
\hline \multirow{8}{*}{$2 / 7$} & Tipo 1 & 536.258 & 0,143 & 0,371 & 0,053 & 582.379 & 0,149 & 0,377 & 0,056 & 666.790 & 0,165 & 0,371 & 0,061 & 651.361 & 0,158 & 0,384 & 0,061 \\
\hline & Tipo 2 & 1.415 .365 & 0,154 & 0,365 & 0,056 & 1.494 .684 & 0,156 & 0,363 & 0,057 & 1.424 .420 & 0,145 & 0,368 & 0,053 & 1.499 .665 & 0,15 & 0,363 & 0,055 \\
\hline & Tipo 3 & 937.822 & 0,103 & 0,363 & 0,038 & 1.011 .713 & 0,114 & 0,354 & 0,04 & 1.028 .757 & 0,12 & 0,373 & 0,045 & 1.294 .326 & 0,157 & 0,374 & 0,059 \\
\hline & Tipo 4 & 112.614 & 0,238 & 0,384 & 0,091 & 110.469 & 0,244 & 0,408 & 0,1 & 195.030 & 0,309 & 0,413 & 0,127 & 170.628 & 0,253 & 0,364 & 0,092 \\
\hline & Tipo 5 & 365.418 & 0,088 & 0,357 & 0,031 & 437.579 & 0,104 & 0,377 & 0,039 & 386.381 & 0,089 & 0,38 & 0,034 & 460.163 & 0,102 & 0,365 & 0,037 \\
\hline & Tipo 6 & 318.830 & 0,072 & 0,351 & 0,025 & 434.803 & 0,093 & 0,352 & 0,033 & 505.853 & 0,107 & 0,377 & 0,04 & 534.244 & 0,11 & 0,363 & 0,04 \\
\hline & Tipo 7 & 297.416 & 0,276 & 0,372 & 0,103 & 243.360 & 0,229 & 0,389 & 0,089 & 262.326 & 0,249 & 0,374 & 0,093 & 273.962 & 0,243 & 0,366 & 0,089 \\
\hline & Tipo 8 & 1.019 .842 & 0,169 & 0,379 & 0,064 & 969.279 & 0,165 & 0,4 & 0,066 & 1.038 .981 & 0,188 & 0,379 & 0,071 & 928.353 & 0,175 & 0,393 & 0,069 \\
\hline \multirow{8}{*}{$3 / 7$} & Tipo 1 & 93.219 & 0,025 & 0,52 & 0,013 & 124.526 & 0,032 & 0,513 & 0,016 & 137.527 & 0,034 & 0,518 & 0,018 & 172.646 & 0,042 & 0,526 & 0,022 \\
\hline & Tipo 2 & 239.668 & 0,026 & 0,519 & 0,014 & 211.827 & 0,022 & 0,518 & 0,011 & 251.991 & 0,026 & 0,524 & 0,013 & 243.228 & 0,024 & 0,536 & 0,013 \\
\hline & Tipo 3 & 166.820 & 0,018 & 0,508 & 0,009 & 133.844 & 0,015 & 0,512 & 0,008 & 196.415 & 0,023 & 0,523 & 0,012 & 267.657 & 0,032 & 0,521 & 0,017 \\
\hline & Tipo 4 & 31.564 & 0,067 & 0,516 & 0,034 & 40.360 & 0,089 & 0,515 & 0,046 & 77.403 & 0,122 & 0,525 & 0,064 & 39.586 & 0,059 & 0,535 & 0,031 \\
\hline & Tipo 5 & 57.390 & 0,014 & 0,506 & 0,007 & 109.974 & 0,026 & 0,512 & 0,013 & 91.259 & 0,021 & 0,535 & 0,011 & 81.162 & 0,018 & 0,524 & 0,009 \\
\hline & Tipo 6 & 48.517 & 0,011 & 0,504 & 0,005 & 69.472 & 0,015 & 0,505 & 0,008 & 140.860 & 0,03 & 0,509 & 0,015 & 88.393 & 0,018 & 0,53 & 0,01 \\
\hline & Tipo 7 & 76.496 & 0,071 & 0,524 & 0,037 & 67.433 & 0,063 & 0,559 & 0,035 & 69.213 & 0,066 & 0,496 & 0,033 & 53.926 & 0,048 & 0,526 & 0,025 \\
\hline & Tipo 8 & 278.370 & 0,046 & 0,504 & 0,023 & 322.817 & 0,055 & 0,533 & 0,029 & 251.218 & 0,046 & 0,525 & 0,024 & 271.995 & 0,051 & 0,531 & 0,027 \\
\hline
\end{tabular}

Fuente: Elaboración propia a partir de los microdatos de la ECV. 
Tabla A5. Mo (k), H (k), A (k) y nº de personas multidimensionalmente pobres. Clasificación subgrupos: tipología del hogar (continuación).

\begin{tabular}{|c|c|c|c|c|c|c|c|c|c|c|c|c|c|c|c|c|c|}
\hline \multirow[b]{2}{*}{$\mathrm{k}$} & \multirow[b]{2}{*}{ Subgrupo } & \multicolumn{4}{|c|}{2012} & \multicolumn{4}{|c|}{2013} & \multicolumn{4}{|c|}{2014} & \multicolumn{4}{|c|}{2015} \\
\hline & & $\begin{array}{c}\mathrm{N}^{\circ} \\
\text { personas }\end{array}$ & $\mathrm{H}$ & A & $\mathrm{M}_{0}$ & $\begin{array}{c}\mathrm{N}^{\circ} \\
\text { personas }\end{array}$ & $\mathrm{H}$ & A & $\mathrm{M}_{0}$ & $\begin{array}{c}\mathrm{N}^{\circ} \\
\text { personas }\end{array}$ & $\mathrm{H}$ & A & $\mathrm{M}_{0}$ & $\begin{array}{l}\mathrm{N}^{\circ} \\
\text { personas }\end{array}$ & $\mathrm{H}$ & A & $\mathrm{M}_{0}$ \\
\hline \multirow{8}{*}{$1 / 7$} & Tipo 1 & 2.474 .276 & 0,589 & 0,245 & 0,144 & 2.523 .887 & 0,584 & 0,246 & 0,144 & 2.647 .028 & 0,585 & 0,249 & 0,146 & 2.696 .289 & 0,578 & 0,242 & 0,14 \\
\hline & Tipo 2 & 5.479 .674 & 0,533 & 0,23 & 0,123 & 5.714 .657 & 0,543 & 0,237 & 0,129 & 5.445 .797 & 0,524 & 0,233 & 0,122 & 5.321 .335 & 0,512 & 0,228 & 0,117 \\
\hline & Tipo 3 & 4.082 .400 & 0,503 & 0,232 & 0,117 & 3.796 .314 & 0,495 & 0,243 & 0,12 & 3.693 .851 & 0,485 & 0,247 & 0,12 & 3.767 .876 & 0,485 & 0,24 & 0,117 \\
\hline & Tipo 4 & 380.251 & 0,508 & 0,286 & 0,146 & 413.179 & 0,532 & 0,26 & 0,138 & 440.222 & 0,53 & 0,302 & 0,16 & 456.376 & 0,525 & 0,282 & 0,148 \\
\hline & Tipo 5 & 1.542 .501 & 0,332 & 0,244 & 0,081 & 1.534 .469 & 0,322 & 0,256 & 0,083 & 1.540 .013 & 0,332 & 0,251 & 0,083 & 1.241 .407 & 0,274 & 0,251 & 0,069 \\
\hline & Tipo 6 & 1.558 .355 & 0,315 & 0,243 & 0,076 & 1.470 .148 & 0,297 & 0,263 & 0,078 & 1.556 .476 & 0,325 & 0,257 & 0,084 & 1.546 .668 & 0,313 & 0,248 & 0,078 \\
\hline & Tipo 7 & 513.020 & 0,482 & 0,282 & 0,136 & 459.485 & 0,455 & 0,34 & 0,155 & 493.657 & 0,479 & 0,309 & 0,148 & 499.848 & 0,482 & 0,295 & 0,142 \\
\hline & Tipo 8 & 2.382 .630 & 0,491 & 0,275 & 0,135 & 2.436 .447 & 0,517 & 0,278 & 0,143 & 2.299 .106 & 0,493 & 0,282 & 0,139 & 2.173 .340 & 0,505 & 0,275 & 0,139 \\
\hline \multirow{8}{*}{$2 / 7$} & Tipo 1 & 759.490 & 0,181 & 0,382 & 0,069 & 724.907 & 0,168 & 0,395 & 0,066 & 862.152 & 0,191 & 0,382 & 0,073 & 814.242 & 0,175 & 0,371 & 0,065 \\
\hline & Tipo 2 & 1.548 .346 & 0,151 & 0,357 & 0,054 & 1.545 .556 & 0,147 & 0,377 & 0,055 & 1.404 .177 & 0,135 & 0,376 & 0,051 & 1.271 .842 & 0,122 & 0,376 & 0,046 \\
\hline & Tipo 3 & 1.116 .268 & 0,137 & 0,375 & 0,052 & 1.123 .755 & 0,146 & 0,381 & 0,056 & 1.192 .058 & 0,157 & 0,389 & 0,061 & 1.216 .593 & 0,157 & 0,363 & 0,057 \\
\hline & Tipo 4 & 198.223 & 0,265 & 0,387 & 0,103 & 156.333 & 0,201 & 0,385 & 0,078 & 230.935 & 0,278 & 0,409 & 0,114 & 236.182 & 0,271 & 0,385 & 0,105 \\
\hline & Tipo 5 & 528.612 & 0,114 & 0,379 & 0,043 & 586.238 & 0,123 & 0,378 & 0,047 & 584.003 & 0,126 & 0,371 & 0,047 & 465.875 & 0,103 & 0,379 & 0,039 \\
\hline & Tipo 6 & 566.954 & 0,115 & 0,377 & 0,043 & 625.587 & 0,126 & 0,383 & 0,048 & 631.077 & 0,132 & 0,378 & 0,05 & 603.343 & 0,122 & 0,368 & 0,045 \\
\hline & Tipo 7 & 265.219 & 0,249 & 0,391 & 0,097 & 283.875 & 0,281 & 0,438 & 0,123 & 289.760 & 0,281 & 0,404 & 0,114 & 273.918 & 0,264 & 0,396 & 0,105 \\
\hline & Tipo 8 & 1.038 .082 & 0,214 & 0,4 & 0,086 & 1.119 .434 & 0,237 & 0,396 & 0,094 & 1.090 .211 & 0,234 & 0,403 & 0,094 & 996.010 & 0,232 & 0,394 & 0,091 \\
\hline \multirow{8}{*}{$3 / 7$} & Tipo 1 & 161.564 & 0,038 & 0,538 & 0,021 & 201.391 & 0,047 & 0,533 & 0,025 & 201.187 & 0,044 & 0,544 & 0,024 & 187.798 & 0,04 & 0,513 & 0,021 \\
\hline & Tipo 2 & 245.333 & 0,024 & 0,522 & 0,012 & 321.610 & 0,031 & 0,545 & 0,017 & 305.026 & 0,029 & 0,538 & 0,016 & 292.213 & 0,028 & 0,529 & 0,015 \\
\hline & Tipo 3 & 225.109 & 0,028 & 0,548 & 0,015 & 294.100 & 0,038 & 0,525 & 0,02 & 322.442 & 0,042 & 0,531 & 0,022 & 238.751 & 0,031 & 0,504 & 0,015 \\
\hline & Tipo 4 & 43.519 & 0,058 & 0,548 & 0,032 & 45.332 & 0,058 & 0,509 & 0,03 & 82.978 & 0,1 & 0,561 & 0,056 & 47.337 & 0,054 & 0,55 & 0,03 \\
\hline & Tipo 5 & 134.319 & 0,029 & 0,528 & 0,015 & 141.065 & 0,03 & 0,522 & 0,015 & 117.772 & 0,025 & 0,528 & 0,013 & 114.758 & 0,025 & 0,545 & 0,014 \\
\hline & Tipo 6 & 137.389 & 0,028 & 0,536 & 0,015 & 180.232 & 0,036 & 0,52 & 0,019 & 171.091 & 0,036 & 0,503 & 0,018 & 137.770 & 0,028 & 0,51 & 0,014 \\
\hline & Tipo 7 & 84.999 & 0,08 & 0,521 & 0,042 & 132.016 & 0,131 & 0,548 & 0,072 & 100.354 & 0,097 & 0,545 & 0,053 & 81.985 & 0,079 & 0,547 & 0,043 \\
\hline & Tipo 8 & 324.560 & 0,067 & 0,527 & 0,035 & 346.207 & 0,073 & 0,528 & 0,039 & 386.761 & 0,083 & 0,524 & 0,043 & 293.531 & 0,068 & 0,528 & 0,036 \\
\hline
\end{tabular}

pona: hombre de 65 o más años, Una 
dependientes económicamente, al menos una persona de 65 o más años; y 2 adultos sin niños dependientes económicamente, teniendo ambos menos de 65 años). Tipo 3: Otros hogares sin niños dependientes económicamente. Tipo 4: Un adulto con al menos un niño dependiente. Tipo 5: Dos adultos con un niño dependiente. Tipo 6: Dos adultos con dos niños dependientes. Tipo 7: Dos adultos con tres o más niños dependientes. Tipo 8: Otros hogares con niños dependientes. Nota 2: Son niños dependientes económicamente todos los menores de 18 años y los que tienen 18 y más años pero menos de 25 y que son económicamente inactivos.

Fuente: Elaboración propia a partir de los microdatos de la ECV. 
Tabla A6. M0 (k), H (k), A (k) y nº de personas multidimensionalmente pobres. Clasificación subgrupos: regiones.

\begin{tabular}{|c|c|c|c|c|c|c|c|c|c|c|c|c|c|c|c|c|c|}
\hline \multirow[b]{2}{*}{$\mathrm{k}$} & \multirow[b]{2}{*}{ Subgrupo } & \multicolumn{4}{|c|}{2008} & \multicolumn{4}{|c|}{2009} & \multicolumn{4}{|c|}{2010} & \multicolumn{4}{|c|}{2011} \\
\hline & & $\begin{array}{c}\mathrm{N}^{\circ} \\
\text { personas }\end{array}$ & $\mathrm{H}$ & A & $\mathrm{M}_{0}$ & $\begin{array}{c}\mathrm{N}^{\circ} \\
\text { personas }\end{array}$ & $\mathrm{H}$ & A & $\mathrm{M}_{0}$ & $\begin{array}{c}\mathrm{N}^{\circ} \\
\text { personas }\end{array}$ & $\mathrm{H}$ & A & $\mathrm{M}_{0}$ & $\begin{array}{c}\mathrm{N}^{\circ} \\
\text { personas }\end{array}$ & $\mathrm{H}$ & A & $\mathrm{M}_{0}$ \\
\hline \multirow{17}{*}{$1 / 7$} & ES11 & 1.306 .481 & 0,544 & 0,229 & 0,125 & 1.319 .644 & 0,545 & 0,239 & 0,13 & 1.262 .965 & 0,524 & 0,241 & 0,126 & 1.203 .480 & 0,501 & 0,236 & 0,118 \\
\hline & ES12 & 427.367 & 0,454 & 0,215 & 0,098 & 420.584 & 0,444 & 0,213 & 0,095 & 391.753 & 0,417 & 0,206 & 0,086 & 399.140 & 0,424 & 0,202 & 0,086 \\
\hline & ES13 & 166.515 & 0,328 & 0,205 & 0,067 & 169.010 & 0,325 & 0,212 & 0,069 & 174.559 & 0,348 & 0,226 & 0,079 & 202.093 & 0,403 & 0,214 & 0,086 \\
\hline & ES21 & 544.473 & 0,299 & 0,221 & 0,066 & 542.066 & 0,296 & 0,222 & 0,066 & 626.267 & 0,337 & 0,235 & 0,079 & 689.607 & 0,372 & 0,234 & 0,087 \\
\hline & ES22 & 182.869 & 0,361 & 0,202 & 0,073 & 193.333 & 0,374 & 0,209 & 0,078 & 205.132 & 0,388 & 0,206 & 0,08 & 199.862 & 0,375 & 0,214 & 0,08 \\
\hline & ES23 & 119.859 & 0,453 & 0,211 & 0,096 & 124.070 & 0,468 & 0,211 & 0,099 & 124.632 & 0,47 & 0,213 & 0,1 & 119.956 & 0,448 & 0,219 & 0,098 \\
\hline & ES24 & 491.731 & 0,437 & 0,201 & 0,088 & 454.142 & 0,402 & 0,194 & 0,078 & 474.981 & 0,421 & 0,204 & 0,086 & 461.131 & 0,411 & 0,211 & 0,087 \\
\hline & ES30 & 2.058 .796 & 0,396 & 0,233 & 0,092 & 1.960 .429 & 0,372 & 0,236 & 0,088 & 1.900 .322 & 0,358 & 0,228 & 0,081 & 1.914 .173 & 0,363 & 0,219 & 0,08 \\
\hline & ES41 & 1.068 .486 & 0,492 & 0,221 & 0,109 & 1.039 .720 & 0,475 & 0,228 & 0,108 & 1.043 .492 & 0,48 & 0,234 & 0,112 & 1.009 .986 & 0,464 & 0,221 & 0,103 \\
\hline & ES42 & 863.709 & 0,517 & 0,24 & 0,124 & 831.556 & 0,488 & 0,242 & 0,118 & 872.942 & 0,514 & 0,239 & 0,123 & 948.308 & 0,545 & 0,224 & 0,122 \\
\hline & ES43 & 484.268 & 0,533 & 0,249 & 0,133 & 486.054 & 0,535 & 0,245 & 0,131 & 516.774 & 0,556 & 0,271 & 0,15 & 505.694 & 0,545 & 0,244 & 0,133 \\
\hline & ES51 & 2.732 .076 & 0,448 & 0,226 & 0,101 & 2.765 .632 & 0,449 & 0,233 & 0,105 & 2.799 .027 & 0,455 & 0,238 & 0,109 & 2.895 .867 & 0,468 & 0,236 & 0,11 \\
\hline & ES52 & 2.134 .351 & 0,516 & 0,245 & 0,126 & 2.022 .087 & 0,489 & 0,24 & 0,117 & 2.035 .410 & 0,491 & 0,24 & 0,118 & 1.950 .116 & 0,471 & 0,232 & 0,109 \\
\hline & ES53 & 396.650 & 0,452 & 0,234 & 0,106 & 403.301 & 0,453 & 0,229 & 0,104 & 424.496 & 0,48 & 0,236 & 0,113 & 417.425 & 0,468 & 0,251 & 0,118 \\
\hline & ES61 & 3.504 .615 & 0,526 & 0,253 & 0,133 & 3.594 .274 & 0,534 & 0,259 & 0,138 & 3.685 .660 & 0,543 & 0,257 & 0,139 & 3.927 .056 & 0,575 & 0,26 & 0,15 \\
\hline & ES62 & 523.675 & 0,454 & 0,232 & 0,105 & 618.855 & 0,528 & 0,247 & 0,13 & 682.927 & 0,568 & 0,264 & 0,15 & 662.060 & 0,56 & 0,238 & 0,133 \\
\hline & ES70 & 883.810 & 0,534 & 0,245 & 0,131 & 967.798 & 0,576 & 0,269 & 0,155 & 885.931 & 0,52 & 0,25 & 0,13 & 979.968 & 0,57 & 0,253 & 0,144 \\
\hline \multirow{12}{*}{$2 / 7$} & ES11 & 357.464 & 0,149 & 0,357 & 0,053 & 374.889 & 0,155 & 0,363 & 0,056 & 346.705 & 0,144 & 0,378 & 0,054 & 343.186 & 0,143 & 0,371 & 0,053 \\
\hline & ES12 & 84.266 & 0,09 & 0,354 & 0,032 & 84.627 & 0,089 & 0,351 & 0,031 & 72.570 & 0,077 & 0,331 & 0,026 & 68.187 & 0,072 & 0,335 & 0,024 \\
\hline & ES13 & 26.091 & 0,051 & 0,345 & 0,018 & 30.612 & 0,059 & 0,354 & 0,021 & 36.536 & 0,073 & 0,39 & 0,028 & 45.112 & 0,09 & 0,345 & 0,031 \\
\hline & ES21 & 107.650 & 0,059 & 0,372 & 0,022 & 132.280 & 0,072 & 0,348 & 0,025 & 152.820 & 0,082 & 0,387 & 0,032 & 201.931 & 0,109 & 0,372 & 0,041 \\
\hline & ES22 & 25.824 & 0,051 & 0,355 & 0,018 & 33.577 & 0,065 & 0,351 & 0,023 & 29.952 & 0,057 & 0,368 & 0,021 & 44.418 & 0,083 & 0,358 & 0,03 \\
\hline & ES23 & 22.535 & 0,085 & 0,345 & 0,029 & 24.111 & 0,091 & 0,34 & 0,031 & 29.066 & 0,11 & 0,357 & 0,039 & 28.467 & 0,106 & 0,364 & 0,039 \\
\hline & ES24 & 59.897 & 0,053 & 0,365 & 0,019 & 57.112 & 0,051 & 0,332 & 0,017 & 85.822 & 0,076 & 0,343 & 0,026 & 103.437 & 0,092 & 0,345 & 0,032 \\
\hline & ES30 & 522.362 & 0,1 & 0,371 & 0,037 & 478.514 & 0,091 & 0,377 & 0,034 & 464.451 & 0,087 & 0,357 & 0,031 & 465.733 & 0,088 & 0,356 & 0,031 \\
\hline & ES41 & 250.048 & 0,115 & 0,342 & 0,039 & 305.852 & 0,14 & 0,342 & 0,048 & 284.988 & 0,131 & 0,37 & 0,049 & 255.970 & 0,118 & 0,362 & 0,043 \\
\hline & ES42 & 292.443 & 0,175 & 0,36 & 0,063 & 269.892 & 0,158 & 0,367 & 0,058 & 321.884 & 0,19 & 0,35 & 0,066 & 263.464 & 0,152 & 0,357 & 0,054 \\
\hline & ES43 & 186.166 & 0,205 & 0,365 & 0,075 & 171.845 & 0,189 & 0,362 & 0,068 & 214.040 & 0,23 & 0,388 & 0,089 & 190.860 & 0,206 & 0,361 & 0,074 \\
\hline & ES51 & 623.766 & 0,102 & 0,363 & 0,037 & 732.530 & 0,119 & 0,356 & 0,042 & 792.656 & 0,129 & 0,378 & 0,049 & 927.537 & 0,15 & 0,374 & 0,056 \\
\hline
\end{tabular}




\begin{tabular}{|c|c|c|c|c|c|c|c|c|c|c|c|c|c|c|c|c|}
\hline ES52 & 633.059 & 0,153 & 0,367 & 0,056 & 580.858 & 0,14 & 0,372 & 0,052 & 610.533 & 0,147 & 0,373 & 0,055 & 551.428 & 0,133 & 0,374 & 0,05 \\
\hline ES53 & 115.383 & 0,132 & 0,333 & 0,044 & 106.416 & 0,12 & 0,346 & 0,041 & 125.249 & 0,141 & 0,372 & 0,053 & 136.185 & 0,153 & 0,402 & 0,061 \\
\hline ES61 & 1.253 .673 & 0,188 & 0,379 & 0,071 & 1.314 .621 & 0,195 & 0,389 & 0,076 & 1.311 .601 & 0,193 & 0,387 & 0,075 & 1.553 .548 & 0,228 & 0,386 & 0,088 \\
\hline ES62 & 140.225 & 0,122 & 0,376 & 0,046 & 194.217 & 0,166 & 0,382 & 0,063 & 269.591 & 0,224 & 0,397 & 0,089 & 223.956 & 0,19 & 0,382 & 0,072 \\
\hline $\mathrm{S} 70$ & 271.741 & 0,164 & 0,379 & 0,062 & 361.545 & 0,215 & 0,403 & 0,087 & 330.288 & 0,194 & 0,361 & 0,07 & 389.098 & 0,226 & 0,364 & 0,082 \\
\hline
\end{tabular}


Tabla A6. $\mathrm{M}_{0}(\mathrm{k}), \mathrm{H}(\mathrm{k}), \mathrm{A}(\mathrm{k})$ y $\mathrm{n}^{\circ}$ de personas multidimensionalmente pobres. Clasificación subgrupos: regiones (continuación).

\begin{tabular}{|c|c|c|c|c|c|c|c|c|c|c|c|c|c|c|c|c|c|}
\hline \multirow[b]{2}{*}{$\mathrm{k}$} & \multirow[b]{2}{*}{ Subgrupo } & \multicolumn{4}{|c|}{2008} & \multicolumn{4}{|c|}{2009} & \multicolumn{4}{|c|}{2010} & \multicolumn{4}{|c|}{2011} \\
\hline & & $\begin{array}{r}\mathrm{N}^{\circ} \\
\text { personas }\end{array}$ & $\mathrm{H}$ & A & $\mathrm{M}_{0}$ & $\begin{array}{r}\mathrm{N}^{\circ} \\
\text { personas }\end{array}$ & $\mathrm{H}$ & A & $\mathrm{M}_{0}$ & $\begin{array}{r}\mathrm{N}^{\circ} \\
\text { personas }\end{array}$ & $\mathrm{H}$ & A & $\mathrm{M}_{0}$ & $\begin{array}{r}\mathrm{N}^{\circ} \\
\text { personas }\end{array}$ & $\mathrm{H}$ & A & $\mathrm{M}_{0}$ \\
\hline \multirow{18}{*}{$3 / 7$} & ES11 & 66.603 & 0,028 & 0,502 & 0,014 & 59.738 & 0,025 & 0,5 & 0,012 & 64.897 & 0,027 & 0,53 & 0,014 & 87.386 & 0,036 & 0,498 & 0,018 \\
\hline & ES12 & 10.257 & 0,011 & 0,525 & 0,006 & 11.442 & 0,012 & 0,507 & 0,006 & 6.672 & 0,007 & 0,517 & 0,004 & 4.746 & 0,005 & 0,503 & 0,003 \\
\hline & ES13 & 3.809 & 0,008 & 0,49 & 0,004 & 7.042 & 0,014 & 0,468 & 0,006 & 9.884 & 0,02 & 0,559 & 0,011 & 4.290 & 0,009 & 0,516 & 0,004 \\
\hline & ES21 & 22.412 & 0,012 & 0,507 & 0,006 & 18.376 & 0,01 & 0,502 & 0,005 & 42.624 & 0,023 & 0,554 & 0,013 & 40.395 & 0,022 & 0,553 & 0,012 \\
\hline & ES22 & 4.684 & 0,009 & 0,489 & 0,005 & 3.256 & 0,006 & 0,52 & 0,003 & 6.476 & 0,012 & 0,509 & 0,006 & 2.809 & 0,005 & 0,508 & 0,003 \\
\hline & ES23 & 2.794 & 0,011 & 0,516 & 0,005 & 2.257 & 0,009 & 0,474 & 0,004 & 3.545 & 0,013 & 0,516 & 0,007 & 5.161 & 0,019 & 0,532 & 0,01 \\
\hline & ES24 & 12.932 & 0,012 & 0,49 & 0,006 & 3.063 & 0,003 & 0,508 & 0,001 & 11.132 & 0,01 & 0,495 & 0,005 & 14.463 & 0,013 & 0,492 & 0,006 \\
\hline & ES30 & 118.250 & 0,023 & 0,493 & 0,011 & 96.517 & 0,018 & 0,539 & 0,01 & 73.059 & 0,014 & 0,525 & 0,007 & 59.822 & 0,011 & 0,522 & 0,006 \\
\hline & ES41 & 16.639 & 0,008 & 0,504 & 0,004 & 34.473 & 0,016 & 0,505 & 0,008 & 51.580 & 0,024 & 0,555 & 0,013 & 45.385 & 0,021 & 0,535 & 0,011 \\
\hline & ES42 & 38.173 & 0,023 & 0,505 & 0,012 & 43.998 & 0,026 & 0,539 & 0,014 & 48.018 & 0,028 & 0,498 & 0,014 & 46.984 & 0,027 & 0,507 & 0,014 \\
\hline & ES43 & 30.677 & 0,034 & 0,517 & 0,017 & 25.748 & 0,028 & 0,523 & 0,015 & 64.067 & 0,069 & 0,524 & 0,036 & 35.001 & 0,038 & 0,495 & 0,019 \\
\hline & ES51 & 125.707 & 0,021 & 0,501 & 0,01 & 118.489 & 0,019 & 0,497 & 0,01 & 152.459 & 0,025 & 0,524 & 0,013 & 194.063 & 0,031 & 0,523 & 0,016 \\
\hline & ES52 & 108.212 & 0,026 & 0,522 & 0,014 & 134.613 & 0,033 & 0,513 & 0,017 & 153.148 & 0,037 & 0,51 & 0,019 & 108.102 & 0,026 & 0,537 & 0,014 \\
\hline & ES53 & 5.592 & 0,006 & 0,501 & 0,003 & 8.796 & 0,01 & 0,526 & 0,005 & 30.862 & 0,035 & 0,504 & 0,018 & 43.323 & 0,049 & 0,531 & 0,026 \\
\hline & ES61 & 330.130 & 0,05 & 0,514 & 0,025 & 350.352 & 0,052 & 0,531 & 0,028 & 344.465 & 0,051 & 0,517 & 0,026 & 407.153 & 0,06 & 0,535 & 0,032 \\
\hline & ES62 & 31.185 & 0,027 & 0,538 & 0,015 & 38.655 & 0,033 & 0,519 & 0,017 & 83.110 & 0,069 & 0,524 & 0,036 & 47.516 & 0,04 & 0,583 & 0,023 \\
\hline & ES70 & 49.119 & 0,03 & 0,55 & 0,016 & 110.176 & 0,066 & 0,535 & 0,035 & 59.102 & 0,035 & 0,516 & 0,018 & 66.596 & 0,039 & 0,522 & 0,02 \\
\hline & & \multicolumn{4}{|c|}{2012} & \multicolumn{4}{|c|}{2013} & \multicolumn{4}{|c|}{2014} & \multicolumn{4}{|c|}{2015} \\
\hline $\mathrm{k}$ & Subgrupo & $\begin{array}{r}\mathrm{N}^{\circ} \\
\text { personas }\end{array}$ & $\mathrm{H}$ & A & $\mathrm{M}_{0}$ & $\begin{array}{r}\mathrm{N}^{\circ} \\
\text { personas }\end{array}$ & $\mathrm{H}$ & A & $\mathrm{M}_{0}$ & $\begin{array}{r}\mathrm{N}^{\circ} \\
\text { personas }\end{array}$ & $\mathrm{H}$ & A & $\mathrm{M}_{0}$ & $\begin{array}{r}\mathrm{N}^{\circ} \\
\text { personas }\end{array}$ & $\mathrm{H}$ & A & $\mathrm{M}_{0}$ \\
\hline \multirow{9}{*}{$1 / 7$} & ES11 & 1.181 .422 & 0,493 & 0,24 & 0,118 & 1.206 .903 & 0,507 & 0,235 & 0,119 & 1.155 .818 & 0,489 & 0,245 & 0,12 & 1.125 .913 & 0,477 & 0,238 & 0,114 \\
\hline & ES12 & 444.098 & 0,476 & 0,216 & 0,103 & 397.759 & 0,428 & 0,228 & 0,097 & 401.664 & 0,439 & 0,224 & 0,098 & 421.158 & 0,46 & 0,223 & 0,103 \\
\hline & ES13 & 212.636 & 0,424 & 0,222 & 0,094 & 229.669 & 0,462 & 0,212 & 0,098 & 247.710 & 0,497 & 0,213 & 0,106 & 202.863 & 0,411 & 0,222 & 0,091 \\
\hline & ES21 & 730.846 & 0,397 & 0,23 & 0,091 & 702.347 & 0,381 & 0,241 & 0,092 & 573.835 & 0,316 & 0,224 & 0,071 & 618.051 & 0,34 & 0,213 & 0,072 \\
\hline & ES22 & 188.915 & 0,359 & 0,216 & 0,078 & 168.607 & 0,32 & 0,2 & 0,064 & 167.074 & 0,321 & 0,214 & 0,069 & 164.476 & 0,316 & 0,21 & 0,066 \\
\hline & ES23 & 117.619 & 0,429 & 0,218 & 0,094 & 105.424 & 0,397 & 0,231 & 0,092 & 106.009 & 0,411 & 0,234 & 0,096 & 102.413 & 0,397 & 0,229 & 0,091 \\
\hline & $\mathrm{ES} 24$ & 429.857 & 0,384 & 0,221 & 0,085 & 454.575 & 0,408 & 0,23 & 0,094 & 442.278 & 0,4 & 0,222 & 0,089 & 418.826 & 0,38 & 0,206 & 0,078 \\
\hline & ES30 & 1.919 .331 & 0,361 & 0,234 & 0,084 & 2.069 .941 & 0,392 & 0,262 & 0,103 & 1.935 .519 & 0,368 & 0,246 & 0,091 & 1.938 .220 & 0,366 & 0,241 & 0,088 \\
\hline & ES41 & 971.482 & 0,452 & 0,218 & 0,099 & 930.697 & 0,436 & 0,218 & 0,095 & 918.526 & 0,435 & 0,227 & 0,099 & 940.207 & 0,449 & 0,215 & 0,097 \\
\hline
\end{tabular}




\begin{tabular}{rrrrrrrrrrrrrrrrr} 
ES42 & 969.878 & 0,559 & 0,225 & 0,126 & 979.420 & 0,565 & 0,25 & 0,141 & 959.886 & 0,564 & 0,239 & 0,135 & 927.230 & 0,551 & 0,25 & 0,138 \\
ES43 & 508.911 & 0,546 & 0,228 & 0,125 & 535.791 & 0,587 & 0,251 & 0,147 & 525.995 & 0,579 & 0,259 & 0,15 & 495.265 & 0,533 & 0,247 & 0,132 \\
ES51 & 2.815 .362 & 0,456 & 0,245 & 0,112 & 2.656 .228 & 0,433 & 0,243 & 0,105 & 2.611 .936 & 0,427 & 0,237 & 0,101 & 2.449 .817 & 0,4 & 0,232 & 0,093 \\
ES52 & 2.046 .258 & 0,496 & 0,245 & 0,121 & 1.992 .518 & 0,482 & 0,249 & 0,12 & 2.091 .963 & 0,514 & 0,264 & 0,136 & 1.975 .110 & 0,486 & 0,257 & 0,125 \\
ES53 & 391.785 & 0,434 & 0,231 & 0,1 & 448.933 & 0,49 & 0,248 & 0,121 & 390.355 & 0,423 & 0,246 & 0,104 & 401.032 & 0,43 & 0,249 & 0,107 \\
ES61 & 3.739 .816 & 0,545 & 0,261 & 0,142 & 3.830 .363 & 0,559 & 0,27 & 0,151 & 3.885 .081 & 0,568 & 0,273 & 0,155 & 3.926 .650 & 0,575 & 0,257 & 0,148 \\
ES62 & 668.061 & 0,566 & 0,255 & 0,144 & 642.536 & 0,544 & 0,272 & 0,148 & 655.779 & 0,555 & 0,283 & 0,157 & 590.465 & 0,503 & 0,264 & 0,133 \\
ES70 & 1.013 .354 & 0,581 & 0,275 & 0,16 & 934.058 & 0,528 & 0,277 & 0,146 & 980.359 & 0,55 & 0,268 & 0,148 & 946.446 & 0,526 & 0,287 & 0,151 \\
\hline
\end{tabular}


Tabla A6. $\mathrm{M}_{0}(\mathrm{k}), \mathrm{H}(\mathrm{k})$, A (k) y $\mathrm{n}^{\circ}$ de personas multidimensionalmente pobres. Clasificación subgrupos: regiones (continuación).

\begin{tabular}{|c|c|c|c|c|c|c|c|c|c|c|c|c|c|c|c|c|c|}
\hline \multirow[b]{2}{*}{$\mathrm{k}$} & \multirow[b]{2}{*}{ Subgrupo } & \multicolumn{4}{|c|}{2012} & \multicolumn{4}{|c|}{2013} & \multicolumn{4}{|c|}{2014} & \multicolumn{4}{|c|}{2015} \\
\hline & & $\begin{array}{c}\mathrm{N}^{\circ} \\
\text { personas }\end{array}$ & $\mathrm{H}$ & A & $\mathrm{M}_{0}$ & $\begin{array}{c}\mathrm{N}^{\circ} \\
\text { personas }\end{array}$ & $\mathrm{H}$ & A & $\mathrm{M}_{0}$ & $\begin{array}{c}\mathrm{N}^{\circ} \\
\text { personas }\end{array}$ & $\mathrm{H}$ & A & $\mathrm{M}_{0}$ & $\begin{array}{c}\mathrm{N}^{\circ} \\
\text { personas }\end{array}$ & $\mathrm{H}$ & A & $\mathrm{M}_{0}$ \\
\hline \multirow{17}{*}{$2 / 7$} & ES11 & 344.856 & 0,144 & 0,37 & 0,053 & 328.038 & 0,138 & 0,366 & 0,05 & 341.654 & 0,145 & 0,372 & 0,054 & 295.420 & 0,125 & 0,377 & 0,047 \\
\hline & ES12 & 116.599 & 0,125 & 0,356 & 0,045 & 91.129 & 0,098 & 0,388 & 0,038 & 100.896 & 0,11 & 0,372 & 0,041 & 99.089 & 0,108 & 0,382 & 0,041 \\
\hline & ES13 & 56.004 & 0,112 & 0,345 & 0,039 & 46.474 & 0,093 & 0,342 & 0,032 & 55.833 & 0,112 & 0,372 & 0,042 & 48.683 & 0,099 & 0,378 & 0,037 \\
\hline & ES21 & 197.281 & 0,107 & 0,358 & 0,038 & 186.823 & 0,101 & 0,381 & 0,039 & 136.833 & 0,075 & 0,38 & 0,029 & 124.212 & 0,068 & 0,369 & 0,025 \\
\hline & ES22 & 33.215 & 0,063 & 0,378 & 0,024 & 20.908 & 0,04 & 0,344 & 0,014 & 35.364 & 0,068 & 0,341 & 0,023 & 31.896 & 0,061 & 0,345 & 0,021 \\
\hline & ES23 & 27.062 & 0,099 & 0,368 & 0,036 & 26.865 & 0,101 & 0,4 & 0,04 & 25.081 & 0,097 & 0,412 & 0,04 & 30.603 & 0,119 & 0,338 & 0,04 \\
\hline & ES24 & 109.177 & 0,098 & 0,359 & 0,035 & 103.885 & 0,093 & 0,381 & 0,035 & 105.963 & 0,096 & 0,385 & 0,037 & 79.507 & 0,072 & 0,347 & 0,025 \\
\hline & ES30 & 593.364 & 0,111 & 0,362 & 0,04 & 738.014 & 0,14 & 0,389 & 0,054 & 594.504 & 0,113 & 0,38 & 0,043 & 571.697 & 0,108 & 0,376 & 0,041 \\
\hline & ES41 & 246.161 & 0,115 & 0,344 & 0,039 & 224.860 & 0,105 & 0,354 & 0,037 & 264.600 & 0,125 & 0,359 & 0,045 & 249.402 & 0,119 & 0,341 & 0,041 \\
\hline & ES42 & 306.044 & 0,176 & 0,349 & 0,062 & 384.830 & 0,222 & 0,37 & 0,082 & 297.712 & 0,175 & 0,382 & 0,067 & 340.702 & 0,202 & 0,373 & 0,076 \\
\hline & ES43 & 175.148 & 0,188 & 0,349 & 0,066 & 185.902 & 0,204 & 0,377 & 0,077 & 199.045 & 0,219 & 0,374 & 0,082 & 168.318 & 0,181 & 0,369 & 0,067 \\
\hline & ES51 & 888.597 & 0,144 & 0,387 & 0,056 & 772.762 & 0,126 & 0,39 & 0,049 & 793.881 & 0,13 & 0,374 & 0,049 & 645.307 & 0,105 & 0,374 & 0,039 \\
\hline & ES52 & 664.946 & 0,161 & 0,377 & 0,061 & 638.440 & 0,155 & 0,39 & 0,06 & 799.474 & 0,196 & 0,395 & 0,078 & 782.028 & 0,192 & 0,376 & 0,072 \\
\hline & ES53 & 112.581 & 0,125 & 0,371 & 0,046 & 143.189 & 0,156 & 0,38 & 0,059 & 112.572 & 0,122 & 0,392 & 0,048 & 122.702 & 0,132 & 0,396 & 0,052 \\
\hline & ES61 & 1.437 .843 & 0,21 & 0,395 & 0,083 & 1.634 .927 & 0,239 & 0,388 & 0,093 & 1.685 .369 & 0,246 & 0,396 & 0,098 & 1.592 .698 & 0,233 & 0,377 & 0,088 \\
\hline & ES62 & 232.031 & 0,197 & 0,393 & 0,077 & 226.426 & 0,192 & 0,414 & 0,079 & 294.778 & 0,249 & 0,403 & 0,101 & 232.030 & 0,198 & 0,382 & 0,075 \\
\hline & ES70 & 453.988 & 0,26 & 0,39 & 0,102 & 375.211 & 0,212 & 0,418 & 0,089 & 406.169 & 0,228 & 0,391 & 0,089 & 439.350 & 0,244 & 0,402 & 0,098 \\
\hline \multirow{12}{*}{$3 / 7$} & ES11 & 229.277 & 0,096 & 0,356 & 0,034 & 50.945 & 0,021 & 0,526 & 0,011 & 60.643 & 0,026 & 0,521 & 0,013 & 63.927 & 0,027 & 0,524 & 0,014 \\
\hline & ES12 & 52.301 & 0,056 & 0,367 & 0,021 & 19.750 & 0,021 & 0,571 & 0,012 & 22.392 & 0,024 & 0,561 & 0,014 & 28.425 & 0,031 & 0,503 & 0,016 \\
\hline & ES13 & 28.130 & 0,056 & 0,34 & 0,019 & 7.828 & 0,016 & 0,464 & 0,007 & 12.701 & 0,025 & 0,538 & 0,014 & 9.908 & 0,02 & 0,5 & 0,01 \\
\hline & ES21 & 124.051 & 0,067 & 0,339 & 0,023 & 51.264 & 0,028 & 0,525 & 0,015 & 34.350 & 0,019 & 0,536 & 0,01 & 26.216 & 0,014 & 0,498 & 0,007 \\
\hline & ES22 & 25.048 & 0,048 & 0,365 & 0,017 & 1.619 & 0,003 & 0,546 & 0,002 & 4.339 & 0,008 & 0,522 & 0,004 & 3.598 & 0,007 & 0,574 & 0,004 \\
\hline & ES23 & 19.742 & 0,072 & 0,343 & 0,025 & 8.530 & 0,032 & 0,56 & 0,018 & 10.075 & 0,039 & 0,53 & 0,021 & 3.654 & 0,014 & 0,486 & 0,007 \\
\hline & ES24 & 61.790 & 0,055 & 0,34 & 0,019 & 23.889 & 0,021 & 0,524 & 0,011 & 28.050 & 0,025 & 0,512 & 0,013 & 8.234 & 0,007 & 0,55 & 0,004 \\
\hline & ES30 & 432.987 & 0,081 & 0,362 & 0,029 & 210.116 & 0,04 & 0,516 & 0,021 & 152.041 & 0,029 & 0,51 & 0,015 & 114.807 & 0,022 & 0,513 & 0,011 \\
\hline & ES41 & 148.245 & 0,069 & 0,35 & 0,024 & 37.552 & 0,018 & 0,513 & 0,009 & 46.534 & 0,022 & 0,545 & 0,012 & 37.218 & 0,018 & 0,513 & 0,009 \\
\hline & ES42 & 184.887 & 0,107 & 0,35 & 0,037 & 88.692 & 0,051 & 0,5 & 0,026 & 71.228 & 0,042 & 0,53 & 0,022 & 88.333 & 0,052 & 0,514 & 0,027 \\
\hline & ES43 & 108.810 & 0,117 & 0,342 & 0,04 & 43.346 & 0,048 & 0,525 & 0,025 & 45.210 & 0,05 & 0,507 & 0,025 & 38.227 & 0,041 & 0,502 & 0,021 \\
\hline & ES51 & 712.163 & 0,115 & 0,373 & 0,043 & 211.512 & 0,034 & 0,537 & 0,019 & 174.613 & 0,029 & 0,527 & 0,015 & 158.079 & 0,026 & 0,51 & 0,013 \\
\hline
\end{tabular}




\begin{tabular}{lrlllrllllllllrrr} 
ES52 & 482.983 & 0,117 & 0,365 & 0,043 & 183.012 & 0,044 & 0,529 & 0,023 & 237.585 & 0,058 & 0,543 & 0,032 & 170.279 & 0,042 & 0,529 & 0,022 \\
ES53 & 87.444 & 0,097 & 0,361 & 0,035 & 29.209 & 0,032 & 0,567 & 0,018 & 32.558 & 0,035 & 0,561 & 0,02 & 35.799 & 0,038 & 0,544 & 0,021 \\
ES61 & 955.013 & 0,139 & 0,39 & 0,054 & 454.644 & 0,066 & 0,531 & 0,035 & 526.254 & 0,077 & 0,534 & 0,041 & 408.982 & 0,06 & 0,533 & 0,032 \\
ES62 & 178.759 & 0,152 & 0,374 & 0,057 & 71.627 & 0,061 & 0,576 & 0,035 & 91.654 & 0,078 & 0,538 & 0,042 & 61.044 & 0,052 & 0,531 & 0,028 \\
ES70 & 322.783 & 0,185 & 0,392 & 0,073 & 149.285 & 0,084 & 0,542 & 0,046 & 120.172 & 0,067 & 0,523 & 0,035 & 127.305 & 0,071 & 0,524 & 0,037 \\
\hline
\end{tabular}

Nota: ES11: Galicia, ES12: Principado de Asturias, ES13: Cantabria, ES21: País Vasco, ES22: Comunidad Foral de Navarra, ES23: La Rioja, ES24: Aragón, ES30: Comunidad de Madrid, ES41: Castilla y León, ES42: Castilla - La Mancha, ES43: Extremadura, ES51: Cataluña, ES52: Comunidad Valenciana, ES53: Illes Balears, ES61: Andalucía, ES62: Región de Murcia, ES70: Canarias. Excluidas: ES63: Ciudad Autónoma de Ceuta, ES64: Ciudad Autónoma de Melilla.

Fuente: Elaboración propia a partir de los microdatos de la ECV. 
Tabla A7. Tasas de privación censuradas (\%).

IDEI

PMS

Hacinamiento

\begin{tabular}{|c|c|c|c|c|c|c|c|c|c|c|c|c|c|c|c|c|c|c|c|c|c|c|c|c|}
\hline $\mathrm{k}$ & 2008 & 2009 & 2010 & 2011 & 2012 & 2013 & 2014 & 2015 & 2008 & 2009 & 2010 & 2011 & 2012 & 2013 & 2014 & 2015 & 2008 & 2009 & 2010 & 2011 & 2012 & 2013 & 2014 & 2015 \\
\hline $1 / 7$ & 15,12 & 15,36 & 15,94 & 16,09 & 17,3 & 17,18 & 18,06 & 17,84 & 3,2 & 4,09 & 4,5 & 4,37 & 5,52 & 5,71 & 6,59 & 5,89 & 1,4 & 1,13 & 0,79 & 1,27 & 0,99 & 0,91 & 0,75 & 0,67 \\
\hline $2 / 7$ & 8,57 & 8,93 & 9,46 & 9,89 & 10,78 & 10,77 & 11,52 & 10,92 & 2,59 & 3,25 & 3,56 & 3,6 & 4,51 & 4,73 & 5,44 & 5,08 & 0,81 & 0,79 & 0,56 & 0,75 & 0,73 & 0,77 & 0,54 & 0,48 \\
\hline $3 / 7$ & 2,27 & 2,34 & 2,72 & 2,69 & 3,05 & 3,73 & 3,79 & 3,24 & 1,32 & 1,5 & 1,63 & 1,74 & 2,23 & 2,68 & 2,93 & 2,39 & 0,42 & 0,37 & 0,27 & 0,29 & 0,39 & 0,45 & 0,33 & 0,22 \\
\hline
\end{tabular}

Humedades

Luz natural

Ducha

\begin{tabular}{|c|c|c|c|c|c|c|c|c|c|c|c|c|c|c|c|c|c|c|c|c|c|c|c|c|}
\hline $\mathrm{k}$ & 2008 & 2009 & 2010 & 2011 & 2012 & 2013 & 2014 & 2015 & 2008 & 2009 & 2010 & 2011 & 2012 & 2013 & 2014 & 2015 & 2008 & 2009 & 2010 & 2011 & 2012 & 2013 & 2014 & 2015 \\
\hline $1 / 7$ & 10,21 & 11,23 & 12,84 & 9,87 & 7,51 & 10,27 & 10,47 & 8,93 & 3,74 & 4,27 & 3,38 & 2,81 & 2,65 & 3,98 & 3,16 & 2,44 & 0,11 & 0,01 & 0,00 & 0,02 & 0,08 & 0,09 & 0,10 & 0,08 \\
\hline $2 / 7$ & 3,99 & 4,50 & 4,99 & 4,38 & 3,42 & 4,63 & 5,07 & 4,29 & 1,49 & 1,76 & 1,45 & 1,47 & 1,25 & 1,89 & 1,65 & 1,16 & 0,09 & 0,01 & - & 0,01 & 0,05 & 0,06 & 0,06 & 0,06 \\
\hline $3 / 7$ & 1,21 & 1,29 & 1,60 & 1,72 & 1,57 & 1,81 & 2,02 & 1,75 & 0,51 & 0,56 & 0,56 & 0,57 & 0,63 & 0,93 & 0,71 & 0,43 & 0,05 & 0,01 & - & - & 0,04 & 0,05 & 0,03 & 0,04 \\
\hline & \multicolumn{8}{|c|}{ Inodoro } & \multicolumn{8}{|c|}{ Ruidos } & \multicolumn{8}{|c|}{ Contaminación } \\
\hline $\mathrm{k}$ & 2008 & 2009 & 2010 & 2011 & 2012 & 2013 & 2014 & 2015 & 2008 & 2009 & 2010 & 2011 & 2012 & 2013 & 2014 & 2015 & 2008 & 2009 & 2010 & 2011 & 2012 & 2013 & 2014 & 2015 \\
\hline $1 / 7$ & 0,07 & 0,01 & - & 0,01 & 0,08 & 0,08 & 0,1 & 0,07 & 11,5 & 11,32 & 9,71 & 8,02 & 8,17 & 10,04 & 8,73 & 7,98 & 7,28 & 7,18 & 5,76 & 4,45 & 4,51 & 6,08 & 6,01 & 5,74 \\
\hline $2 / 7$ & 0,06 & 0,01 & - & 0,01 & 0,06 & 0,06 & 0,07 & 0,06 & 4,06 & 4,12 & 3,8 & 3,49 & 3,44 & 4,09 & 3,99 & 3,5 & 2,86 & 2,9 & 2,47 & 1,98 & 2,21 & 2,66 & 2,95 & 2,6 \\
\hline $3 / 7$ & 0,04 & 0,01 & - & - & 0,05 & 0,06 & 0,04 & 0,04 & 1,03 & 1,08 & 1,22 & 1,24 & 1,27 & 1,61 & 1,65 & 1,24 & 0,82 & 0,66 & 0,85 & 0,64 & 0,98 & 1,04 & 1,3 & 0,95 \\
\hline
\end{tabular}

Delincuencia

Estado salud

Problema crónico

\begin{tabular}{|c|c|c|c|c|c|c|c|c|c|c|c|c|c|c|c|c|c|c|c|c|c|c|c|c|}
\hline $\mathrm{k}$ & 2008 & 2009 & 2010 & 2011 & 2012 & 2013 & 2014 & 2015 & 2008 & 2009 & 2010 & 2011 & 2012 & 2013 & 2014 & 2015 & 2008 & 2009 & 2010 & 2011 & 2012 & 2013 & 2014 & 2015 \\
\hline $1 / 7$ & 8,57 & 9,09 & 7,51 & 5,88 & 6 & 8,5 & 6,97 & 5,59 & 6,8 & 7,2 & 6,69 & 6,21 & 6,66 & 6,98 & 6,8 & 5,84 & 20,33 & 19,98 & 19,06 & 15,75 & 17,8 & 20,38 & 18,87 & 20,54 \\
\hline $2 / 7$ & 3,12 & 3,46 & 3,07 & 2,53 & 2,85 & 3,81 & 3,28 & 2,34 & 2,76 & 2,73 & 2,58 & 2,5 & 2,36 & 2,71 & 2,66 & 2,11 & 6,55 & 6,42 & 6,07 & 5,19 & 5,59 & 6,66 & 6,56 & 6,55 \\
\hline $3 / 7$ & 0,94 & 0,99 & 0,93 & 0,88 & 1,11 & 1,46 & 1,28 & 0,93 & 0,75 & 0,72 & 0,74 & 0,7 & 0,66 & 0,86 & 0,93 & 0,62 & 1,53 & 1,45 & 1,54 & 1,39 & 1,62 & 2,07 & 2,34 & 1,85 \\
\hline & \multicolumn{8}{|c|}{ Limitación grave } & \multicolumn{8}{|c|}{ Acceso médico } & \multicolumn{8}{|c|}{ Acceso dentista } \\
\hline $\mathrm{k}$ & 2008 & 2009 & 2010 & 2011 & 2012 & 2013 & 2014 & 2015 & 2008 & 2009 & 2010 & 2011 & 2012 & 2013 & 2014 & 2015 & 2008 & 2009 & 2010 & 2011 & 2012 & 2013 & 2014 & 2015 \\
\hline $1 / 7$ & 4,43 & 4,59 & 4,39 & 3,95 & 4,27 & 4,48 & 4,33 & 4,09 & 1,48 & 1,32 & 1,04 & 0,89 & 1,30 & 1,36 & 1,17 & 0,42 & 3,63 & 3,85 & 3,99 & 3,01 & 4,96 & 5,86 & 6,03 & 3,97 \\
\hline $2 / 7$ & 1,82 & 1,89 & 1,72 & 1,67 & 1,54 & 1,78 & 1,75 & 1,50 & 0,51 & 0,43 & 0,36 & 0,31 & 0,60 & 0,61 & 0,55 & 0,19 & 1,69 & 1,75 & 1,94 & 1,51 & 2,55 & 3,26 & 3,79 & 2,22 \\
\hline $3 / 7$ & 0,45 & 0,47 & 0,53 & 0,48 & 0,47 & 0,55 & 0,55 & 0,43 & 0,12 & 0,10 & 0,07 & 0,14 & 0,20 & 0,24 & 0,27 & 0,09 & 0,49 & 0,62 & 0,77 & 0,61 & 1,11 & 1,43 & 1,80 & 0,94 \\
\hline
\end{tabular}




\begin{tabular}{ccccccccccccccccc} 
& \cline { 2 - 3 } & \multicolumn{10}{c}{ BIT } & \multicolumn{11}{c}{ Estudios } \\
\hline $\mathrm{k}$ & 2008 & 2009 & 2010 & 2011 & 2012 & 2013 & 2014 & 2015 & 2008 & 2009 & 2010 & 2011 & 2012 & 2013 & 2014 & 2015 \\
\hline $1 / 7$ & 7,2 & 8,06 & 10,66 & 13,09 & 13,68 & 14,38 & 15,12 & 14,04 & 32,35 & 30,94 & 30,08 & 30,87 & 28,65 & 27,15 & 25,62 & 25,26 \\
$2 / 7$ & 4,68 & 5,28 & 6,89 & 8,74 & 9,37 & 9,81 & 10,34 & 9,17 & 10,55 & 10,65 & 10,39 & 10,63 & 9,81 & 9,8 & 8,9 & 8,52 \\
$3 / 7$ & 1,54 & 1,99 & 2,42 & 2,51 & 2,72 & 3,4 & 3,62 & 2,86 & 2,12 & 2,37 & 2,47 & 2,58 & 2,52 & 3,08 & 2,76 & 2,45 \\
\hline
\end{tabular}

Fuente: Elaboración propia a partir de los microdatos de la ECV. 


\section{Tabla A8. Contribución de los indicadores al índice M0 (k) (\%).}

IDEI

PMS

Hacinamiento

\begin{tabular}{|c|c|c|c|c|c|c|c|c|c|c|c|c|c|c|c|c|c|c|c|c|c|c|c|c|}
\hline $\mathrm{k}$ & 2008 & 2009 & 2010 & 2011 & 2012 & 2013 & 2014 & 2015 & 2008 & 2009 & 2010 & 2011 & 2012 & 2013 & 2014 & 2015 & 2008 & 2009 & 2010 & 2011 & 2012 & 2013 & 2014 & 2015 \\
\hline $1 / 7$ & 19,53 & 19,61 & 20,1 & 20,29 & 21,45 & 20,58 & 21,77 & 22,62 & 4,13 & 5,22 & 5,68 & 5,51 & 6,84 & 6,83 & 7,94 & 7,47 & 0,36 & 0,29 & 0,2 & 0,32 & 0,25 & 0,22 & 0,18 & 0,17 \\
\hline $2 / 7$ & 25,43 & 25,04 & 25,34 & 25,31 & 26,33 & 24,98 & 26,1 & 27,15 & 7,69 & 9,11 & 9,52 & 9,2 & 11,02 & 10,97 & 12,33 & 12,62 & 0,48 & 0,44 & 0,3 & 0,39 & 0,36 & 0,36 & 0,25 & 0,24 \\
\hline $3 / 7$ & 24,43 & 22,86 & 23,72 & 23,12 & 23,48 & 23,41 & 23,22 & 24,44 & 14,21 & 14,7 & 14,24 & 15 & 17,18 & 16,82 & 17,97 & 18,04 & 0,9 & 0,73 & 0,47 & 0,5 & 0,61 & 0,56 & 0,4 & 0,33 \\
\hline & \multicolumn{8}{|c|}{ Humedades } & \multicolumn{8}{|c|}{ Luz natural } & \multicolumn{8}{|c|}{ Ducha } \\
\hline $\mathrm{k}$ & 2008 & 2009 & 2010 & 2011 & 2012 & 2013 & 2014 & 2015 & 2008 & 2009 & 2010 & 2011 & 2012 & 2013 & 2014 & 2015 & 2008 & 2009 & 2010 & 2011 & 2012 & 2013 & 2014 & 2015 \\
\hline $1 / 7$ & 2,64 & 2,87 & 3,24 & 2,49 & 1,86 & 2,46 & 2,52 & 2,27 & 0,97 & 1,09 & 0,85 & 0,71 & 0,66 & 0,95 & 0,76 & 0,62 & 0,03 & 0 & 0 & 0 & 0,02 & 0,02 & 0,02 & 0,02 \\
\hline $2 / 7$ & 2,37 & 2,53 & 2,67 & 2,24 & 1,67 & 2,15 & 2,3 & 2,13 & 0,88 & 0,99 & 0,78 & 0,75 & 0,61 & 0,88 & 0,75 & 0,58 & 0,05 & 0 & . & 0,01 & 0,03 & 0,03 & 0,03 & 0,03 \\
\hline $3 / 7$ & 2,61 & 2,52 & 2,8 & 2,96 & 2,41 & 2,27 & 2,47 & 2,64 & 1,09 & 1,1 & 0,98 & 0,99 & 0,97 & 1,16 & 0,87 & 0,64 & 0,11 & 0,01 & . & . & 0,06 & 0,07 & 0,03 & 0,06 \\
\hline & \multicolumn{8}{|c|}{ Inodoro } & \multicolumn{8}{|c|}{ Ruidos } & \multicolumn{8}{|c|}{ Contaminación } \\
\hline $\mathrm{k}$ & 2008 & 2009 & 2010 & 2011 & 2012 & 2013 & 2014 & 2015 & 2008 & 2009 & 2010 & 2011 & 2012 & 2013 & 2014 & 2015 & 2008 & 2009 & 2010 & 2011 & 2012 & 2013 & 2014 & 2015 \\
\hline $1 / 7$ & 0,02 & 0 & . & 0 & 0,02 & 0,02 & 0,02 & 0,02 & 4,95 & 4,81 & 4,08 & 3,37 & 3,38 & 4,01 & 3,51 & 3,37 & 3,13 & 3,05 & 2,42 & 1,87 & 1,87 & 2,43 & 2,42 & 2,43 \\
\hline $2 / 7$ & 0,03 & 0,01 & . & 0 & 0,03 & 0,03 & 0,03 & 0,03 & 4,01 & 3,85 & 3,39 & 2,97 & 2,8 & 3,16 & 3,01 & 2,9 & 2,83 & 2,71 & 2,2 & 1,69 & 1,8 & 2,06 & 2,23 & 2,15 \\
\hline $3 / 7$ & 0,09 & 0,02 & & . & 0,08 & 0,07 & 0,05 & 0,06 & 3,69 & 3,53 & 3,55 & 3,55 & 3,25 & 3,36 & 3,36 & 3,13 & 2,95 & 2,16 & 2,47 & 1,85 & 2,51 & 2,18 & 2,65 & 2,39 \\
\hline & \multicolumn{8}{|c|}{ Delincuencia } & \multicolumn{8}{|c|}{ Estado salud } & \multicolumn{8}{|c|}{ Problema crónico } \\
\hline $\mathrm{k}$ & 2008 & 2009 & 2010 & 2011 & 2012 & 2013 & 2014 & 2015 & 2008 & 2009 & 2010 & 2011 & 2012 & 2013 & 2014 & 2015 & 2008 & 2009 & 2010 & 2011 & 2012 & 2013 & 2014 & 2015 \\
\hline $1 / 7$ & 3,69 & 3,87 & 3,16 & 2,47 & 2,48 & 3,39 & 2,8 & 2,36 & 1,76 & 1,84 & 1,69 & 1,57 & 1,65 & 1,67 & 1,64 & 1,48 & 5,25 & 5,1 & 4,81 & 3,97 & 4,42 & 4,88 & 4,55 & 5,21 \\
\hline $2 / 7$ & 3,08 & 3,24 & 2,74 & 2,16 & 2,32 & 2,94 & 2,48 & 1,94 & 1,64 & 1,53 & 1,38 & 1,28 & 1,15 & 1,26 & 1,21 & 1,05 & 3,89 & 3,6 & 3,25 & 2,66 & 2,73 & 3,09 & 2,97 & 3,26 \\
\hline $3 / 7$ & 3,36 & 3,21 & 2,71 & 2,52 & 2,85 & 3,05 & 2,61 & 2,33 & 1,61 & 1,41 & 1,29 & 1,2 & 1,02 & 1,07 & 1,14 & 0,93 & 3,28 & 2,83 & 2,69 & 2,4 & 2,5 & 2,6 & 2,86 & 2,79 \\
\hline & \multicolumn{8}{|c|}{ Limitación grave } & \multicolumn{8}{|c|}{ Acceso médico } & \multicolumn{8}{|c|}{ Acceso dentista } \\
\hline $\mathrm{k}$ & 2008 & 2009 & 2010 & 2011 & 2012 & 2013 & 2014 & 2015 & 2008 & 2009 & 2010 & 2011 & 2012 & 2013 & 2014 & 2015 & 2008 & 2009 & 2010 & 2011 & 2012 & 2013 & 2014 & 2015 \\
\hline $1 / 7$ & 1,14 & 1,17 & 1,11 & 1 & 1,06 & 1,07 & 1,04 & 1,04 & 0,38 & 0,34 & 0,26 & 0,22 & 0,32 & 0,33 & 0,28 & 0,11 & 0,94 & 0,98 & 1,01 & 0,76 & 1,23 & 1,4 & 1,45 & 1,01 \\
\hline $2 / 7$ & 1,08 & 1,06 & 0,92 & 0,85 & 0,75 & 0,83 & 0,79 & 0,74 & 0,3 & 0,24 & 0,19 & 0,16 & 0,29 & 0,28 & 0,25 & 0,09 & 1 & 0,98 & 1,04 & 0,77 & 1,25 & 1,51 & 1,72 & 1,1 \\
\hline $3 / 7$ & 0,96 & 0,91 & 0,93 & 0,82 & 0,72 & 0,69 & 0,67 & 0,64 & 0,26 & 0,2 & 0,12 & 0,25 & 0,31 & 0,3 & 0,33 & 0,14 & 1,06 & 1,21 & 1,34 & 1,05 & 1,7 & 1,79 & 2,21 & 1,42 \\
\hline
\end{tabular}




\begin{tabular}{cccccccccccccccccc} 
& \cline { 2 - 3 } & \multicolumn{11}{c}{ BIT } & \multicolumn{11}{c}{ Estudios } \\
\hline $\mathrm{k}$ & 2008 & 2009 & 2010 & 2011 & 2012 & 2013 & 2014 & 2015 & 2008 & 2009 & 2010 & 2011 & 2012 & 2013 & 2014 & 2015 \\
\hline $1 / 7$ & 9,29 & 10,29 & 13,45 & 16,5 & 16,97 & 17,22 & 18,22 & 17,8 & 41,78 & 39,48 & 37,94 & 38,93 & 35,53 & 32,52 & 30,87 & 32,03 \\
$2 / 7$ & 13,89 & 14,81 & 18,46 & 22,37 & 22,89 & 22,75 & 23,43 & 22,8 & 31,33 & 29,87 & 27,82 & 27,19 & 23,97 & 22,74 & 20,16 & 21,18 \\
$3 / 7$ & 16,57 & 19,42 & 21,1 & 21,63 & 20,95 & 21,3 & 22,21 & 21,57 & 22,81 & 23,19 & 21,58 & 22,17 & 19,42 & 19,3 & 16,92 & 18,44 \\
\hline
\end{tabular}

Fuente: Elaboración propia a partir de los microdatos de la ECV. 
Tabla A9. Tasas de privación censuradas por grupos de edad para $\mathrm{k}=2 / 7(\%)$.

\begin{tabular}{cccccc}
\hline Año & 2008 & 2009 & 2010 & 2011 \\
\hline
\end{tabular}

\begin{tabular}{lllllllllllllllllllllllll}
\multirow{2}{*}{ Grupo de edad } & $<24$ & $25-34$ & $35-49$ & $50-64$ & $>65$ & $<24$ & $25-34$ & $35-49$ & $50-64$ & $>65$ & $<24$ & $25-34$ & $35-49$ & $50-64$ & $>65$ & $<24$ & $25-34$ & $35-49$ & $50-64$ & $>65$
\end{tabular}

Grupo de edad años años años años años años años años años años años años años años años años años años años años

\begin{tabular}{|c|c|c|c|c|c|c|c|c|c|c|c|c|c|c|c|c|c|c|c|c|c|}
\hline Dimensión & Indicador & & & & & & & & & & & & & & & & & & & & \\
\hline Económica & IDEI & 10,24 & 6,38 & 8,86 & 7,65 & 10,35 & 9,49 & 7,45 & 8,70 & 8,94 & 10,42 & 12,17 & 8,50 & 9,95 & 8,43 & 9,17 & 11,44 & 10,33 & 10,42 & 9,48 & 8,27 \\
\hline Material & PMS & 3,91 & 3,04 & 2,76 & 1,78 & 1,88 & 4,54 & 3,59 & 3,56 & 2,76 & 2,15 & 5,88 & 3,34 & 4,09 & 3,03 & 2,15 & 4,96 & 3,19 & 4,33 & 3,23 & 2,52 \\
\hline \multirow[t]{5}{*}{ Vivienda } & Hacinamiento & 1,57 & 1,15 & 0,70 & 0,65 & 0,30 & 1,48 & 1,06 & 0,74 & 0,61 & 0,34 & 0,98 & 0,63 & 0,85 & 0,19 & 0,19 & 1,44 & 0,88 & 0,84 & 0,64 & 0,24 \\
\hline & Humedades & 3,80 & 2,53 & 3,36 & 5,00 & 5,55 & 3,88 & 3,03 & 3,66 & 5,79 & 6,30 & 5,23 & 3,59 & 5,01 & 5,65 & 5,48 & 4,50 & 3,77 & 4,30 & 5,01 & 4,32 \\
\hline & Luz Natural & 1,54 & 0,66 & 1,26 & 1,84 & 2,30 & 1,58 & 1,25 & 1,59 & 2,21 & 2,17 & 1,41 & 1,28 & 1,29 & 1,43 & 1,91 & 1,47 & 1,29 & 1,47 & 1,78 & 1,32 \\
\hline & Ducha & 0,07 & 0,00 & 0,06 & 0,14 & 0,20 & 0,00 & 0,00 & 0,00 & 0,00 & 0,03 & 0,00 & 0,00 & 0,00 & 0,00 & 0,00 & 0,00 & 0,00 & 0,03 & 0,00 & 0,02 \\
\hline & Inodoro & 0,07 & 0,00 & 0,06 & 0,10 & 0,06 & 0,00 & 0,00 & 0,03 & 0,00 & 0,00 & 0,00 & 0,00 & 0,00 & 0,00 & 0,00 & 0,00 & 0,00 & 0,03 & 0,00 & 0,00 \\
\hline \multirow[t]{3}{*}{ Entorno } & Ruidos & 4,10 & 1,99 & 3,39 & 5,45 & 5,74 & 3,83 & 2,43 & 3,36 & 5,77 & 5,41 & 3,08 & 2,80 & 3,14 & 5,04 & 4,85 & 3,02 & 3,05 & 3,10 & 4,25 & 3,91 \\
\hline & Contan & 2,46 & 1,50 & 2,38 & 3,99 & 4,06 & 2,62 & 1,62 & 2,22 & 4,39 & 3,81 & 1,95 & 1,85 & 2,33 & 3,11 & 2,91 & 1,62 & 1,92 & 1,76 & 2,38 & 2,14 \\
\hline & Delince & 2,69 & 1,58 & 2,49 & 4,28 & 4,73 & 3,31 & 1,55 & 2,57 & 5,30 & 4,90 & 2,52 & 1,99 & 2,58 & 4,15 & 4,01 & 1,74 & 1,97 & 2,13 & 3,44 & 3,10 \\
\hline \multirow[t]{5}{*}{ Salud } & Estado salud & 0,18 & 0,39 & 1,39 & 4,89 & 6,70 & 0,20 & 0,69 & 0,97 & 4,46 & 7,16 & 0,26 & 0,67 & 1,47 & 4,24 & 5,72 & 0,44 & 0,88 & 1,49 & 3,92 & 5,12 \\
\hline & Problema crónico & 2,22 & 1,60 & 4,02 & 12,24 & 12,32 & 2,26 & 1,97 & 3,53 & 11,69 & 12,29 & 2,32 & 2,09 & 3,87 & 10,84 & 10,37 & 1,56 & 1,75 & 3,35 & 9,70 & 8,33 \\
\hline & Limitación grave & 0,25 & 0,33 & 1,03 & 2,86 & 4,45 & 0,52 & 0,77 & 0,91 & 2,53 & 4,66 & 0,60 & 0,40 & 1,02 & 2,60 & 3,80 & 0,34 & 0,68 & 1,16 & 2,26 & 3,47 \\
\hline & Acceso 1 & 0,57 & 0,28 & 0,75 & 0,71 & 0,15 & 0,38 & 0,50 & 0,51 & 0,39 & 0,31 & 0,15 & 0,53 & 0,38 & 0,37 & 0,29 & 0,14 & 0,21 & 0,45 & 0,26 & 0,36 \\
\hline & Acceso dentista & 1,77 & 0,76 & 1,91 & 2,17 & 1,78 & 1,94 & 1,22 & 2,04 & 2,38 & 1,08 & 2,15 & 1,55 & 2,20 & 2,38 & 1,33 & 0,95 & 1,14 & 1,67 & 2,11 & 1,31 \\
\hline Trabajo & BIT & 3,96 & 2,29 & 3,71 & 13,31 & 0,00 & 4,81 & 3,77 & 4,12 & 13,62 & 0,00 & 7,09 & 5,21 & 6,85 & 14,86 & 0,00 & 9,21 & 8,86 & 8,26 & 17,26 & 0,00 \\
\hline \multirow{2}{*}{ Educación } & Estudios & 7,35 & 4,59 & 7,87 & 16,81 & 16,30 & 5,95 & 5,06 & 7,75 & 17,53 & 16,30 & 7,82 & 4,74 & 7,58 & 17,54 & 13,97 & 6,05 & 5,56 & 8,61 & 18,42 & 12,55 \\
\hline & & \multicolumn{5}{|c|}{2012} & \multicolumn{5}{|c|}{2013} & \multicolumn{5}{|c|}{2014} & \multicolumn{5}{|c|}{2015} \\
\hline Económica & IDEI & 15,68 & 11,36 & 11,61 & 10,79 & 6,38 & 15,60 & 11,19 & 13,07 & 10,21 & 5,18 & 16,37 & 13,55 & 13,67 & 11,32 & 4,77 & 17,00 & 10,90 & 12,54 & 11,34 & 5,30 \\
\hline Material & PMS & 6,31 & 5,46 & 5,01 & 3,88 & 2,64 & 6,16 & 5,61 & 5,96 & 3,78 & 2,51 & 7,58 & 6,57 & 6,23 & 5,62 & 2,23 & 7,35 & 6,02 & 5,82 & 5,28 & 2,06 \\
\hline \multirow[t]{5}{*}{ Vivienda } & Hacinamiento & 1,52 & 0,84 & 0,94 & 0,46 & 0,20 & 1,90 & 0,71 & 1,18 & 0,19 & 0,25 & 1,25 & 0,63 & 0,57 & 0,50 & 0,14 & 1,07 & 0,45 & 0,56 & 0,36 & 0,22 \\
\hline & Humedades & 3,57 & 3,78 & 3,28 & 3,73 & 2,92 & 4,98 & 4,20 & 5,10 & 4,75 & 3,96 & 5,79 & 5,16 & 5,20 & 5,74 & 3,77 & 5,29 & 4,18 & 4,44 & 4,95 & 2,96 \\
\hline & Luz Natural & 0,85 & 1,49 & 1,29 & 1,45 & 0,97 & 2,45 & 1,20 & 2,18 & 2,05 & 1,58 & 1,43 & 2,23 & 1,61 & 1,48 & 1,57 & 1,36 & 0,84 & 1,30 & 1,39 & 0,84 \\
\hline & Ducha & 0,00 & 0,02 & 0,10 & 0,02 & 0,08 & 0,00 & 0,02 & 0,15 & 0,02 & 0,01 & 0,05 & 0,05 & 0,02 & 0,09 & 0,09 & 0,00 & 0,05 & 0,03 & 0,09 & 0,08 \\
\hline & Inodoro & 0,00 & 0,04 & 0,11 & 0,05 & 0,06 & 0,00 & 0,03 & 0,14 & 0,05 & 0,00 & 0,00 & 0,15 & 0,03 & 0,09 & 0,05 & 0,00 & 0,05 & 0,03 & 0,09 & 0,10 \\
\hline \multirow[t]{3}{*}{ Entorno } & Ruidos & 3,97 & 2,74 & 3,24 & 4,30 & 3,12 & 2,83 & 3,55 & 3,85 & 4,76 & 4,80 & 4,06 & 3,80 & 3,45 & 4,74 & 4,06 & 3,34 & 3,31 & 3,20 & 4,46 & 3,09 \\
\hline & Contaminación & 2,05 & 2,09 & 2,13 & 2,71 & 2,00 & 2,03 & 2,22 & 2,51 & 3,08 & 3,12 & 2,42 & 3,09 & 2,80 & 3,19 & 3,08 & 2,78 & 1,97 & 2,69 & 3,05 & 2,35 \\
\hline & Delincuencia & 2,68 & 2,74 & 2,39 & 3,51 & 3,00 & 3,13 & 2,74 & 3,16 & 4,56 & 5,15 & 2,74 & 3,57 & 2,67 & 3,73 & 3,71 & 2,99 & 1,52 & 2,26 & 2,77 & 2,25 \\
\hline \multirow[t]{5}{*}{ Salud } & Estado salud & 0,20 & 0,55 & 1,29 & 4,20 & 4,71 & 0,22 & 0,54 & 1,43 & 4,17 & 6,03 & 0,24 & 0,63 & 1,46 & 4,81 & 4,81 & 0,39 & 0,30 & 1,15 & 3,68 & 3,88 \\
\hline & Problema crónico & 1,98 & 2,37 & 3,92 & 10,55 & 7,47 & 2,53 & 2,50 & 5,18 & 11,20 & 9,46 & 2,64 & 3,33 & 4,78 & 11,67 & 7,99 & 2,28 & 2,54 & 5,33 & 11,56 & 7,77 \\
\hline & Limitación grave & 0,27 & 0,39 & 1,03 & 2,38 & 3,09 & 0,28 & 0,55 & 1,12 & 2,24 & 4,03 & 0,56 & 0,59 & 0,86 & 2,56 & 3,59 & 0,39 & 0,16 & 0,85 & 2,62 & 2,66 \\
\hline & Acceso médico & 0,06 & 0,92 & 0,52 & 0,77 & 0,53 & 0,19 & 0,66 & 0,81 & 0,60 & 0,50 & 0,54 & 0,46 & 0,72 & 0,74 & 0,16 & 0,16 & 0,21 & 0,14 & 0,23 & 0,21 \\
\hline & Acceso dentista & 2,06 & 2,48 & 2,83 & 3,40 & 1,56 & 2,41 & 3,34 & 3,94 & 4,06 & 1,81 & 3,05 & 4,26 & 4,16 & 5,31 & 1,65 & 2,05 & 1,76 & 2,52 & 3,34 & 1,02 \\
\hline
\end{tabular}




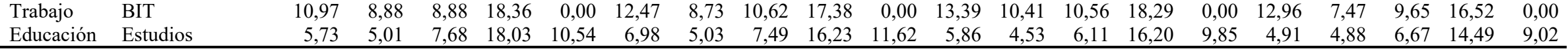

Fuente: Elaboración propia a partir de los microdatos de la ECV. 